\title{
Republic of Madagascar: Poverty Reduction Strategy Paper
}

Poverty Reduction Strategy Papers (PRSPs) are prepared by member countries in broad consultation with stakeholders and development partners, including the staffs of the World Bank and the IMF. Updated every three years with annual progress reports, they describe the country's macroeconomic, structural, and social policies in support of growth and poverty reduction, as well as associated external financing needs and major sources of financing. This country document for the Republic of Madagascar is being made available on the IMF website by agreement with the member country as a service to users of the IMF website.

To assist the IMF in evaluating the publication policy, reader comments are invited and may be sent by e-mail to publicationpolicy@imf.org.

Copies of this report are available to the public from

International Monetary Fund • Publication Services

$70019^{\text {th }}$ Street, N.W. $\bullet$ Washington, D.C. 20431

Telephone: (202) 623-7430 • Telefax: (202) 623-7201

E-mail: publications@imf.org •Internet: http://www.imf.org

Price: $\$ 18.00$ a copy

\section{International Monetary Fund \\ Washington, D.C.}




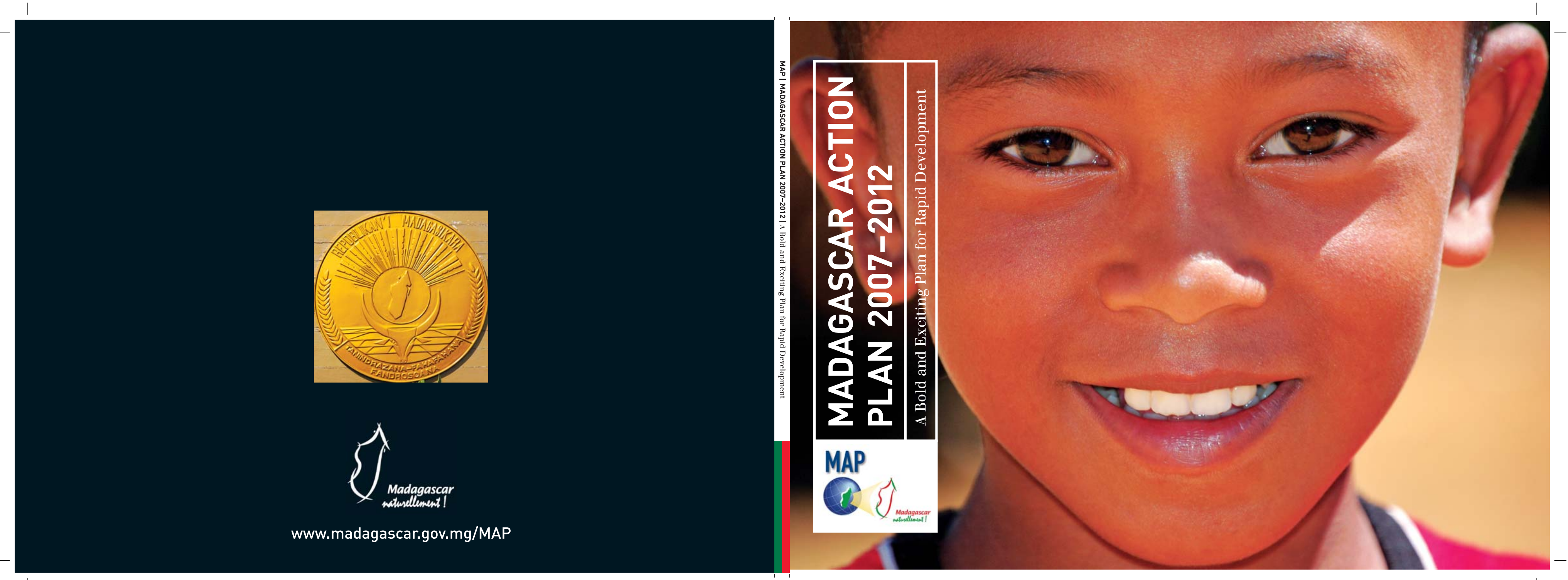



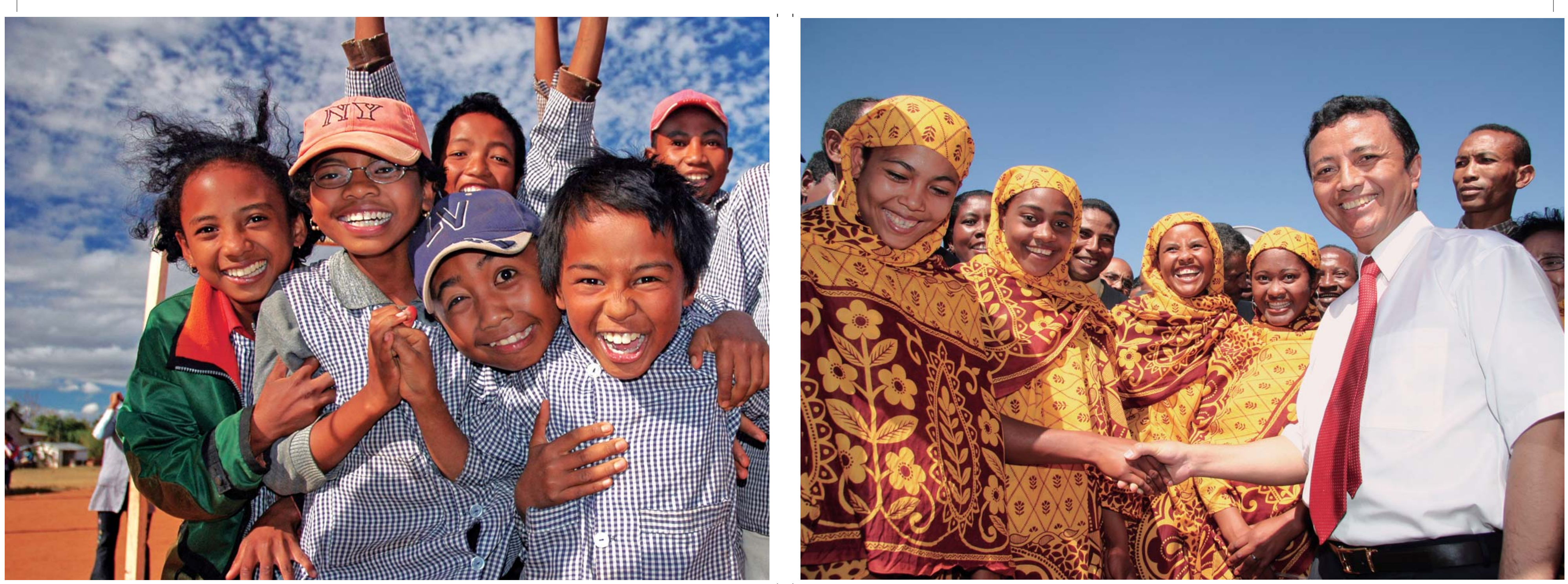


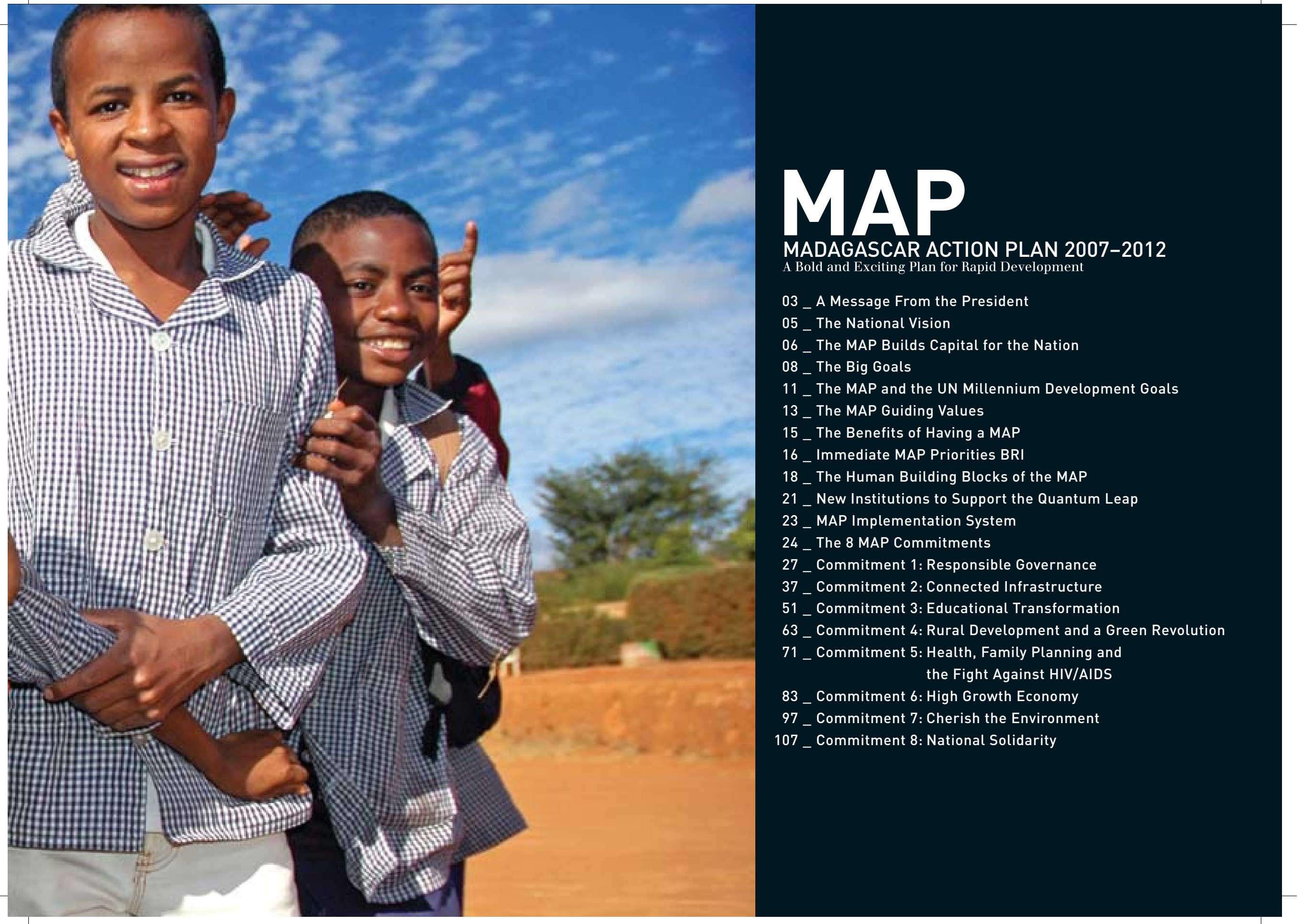




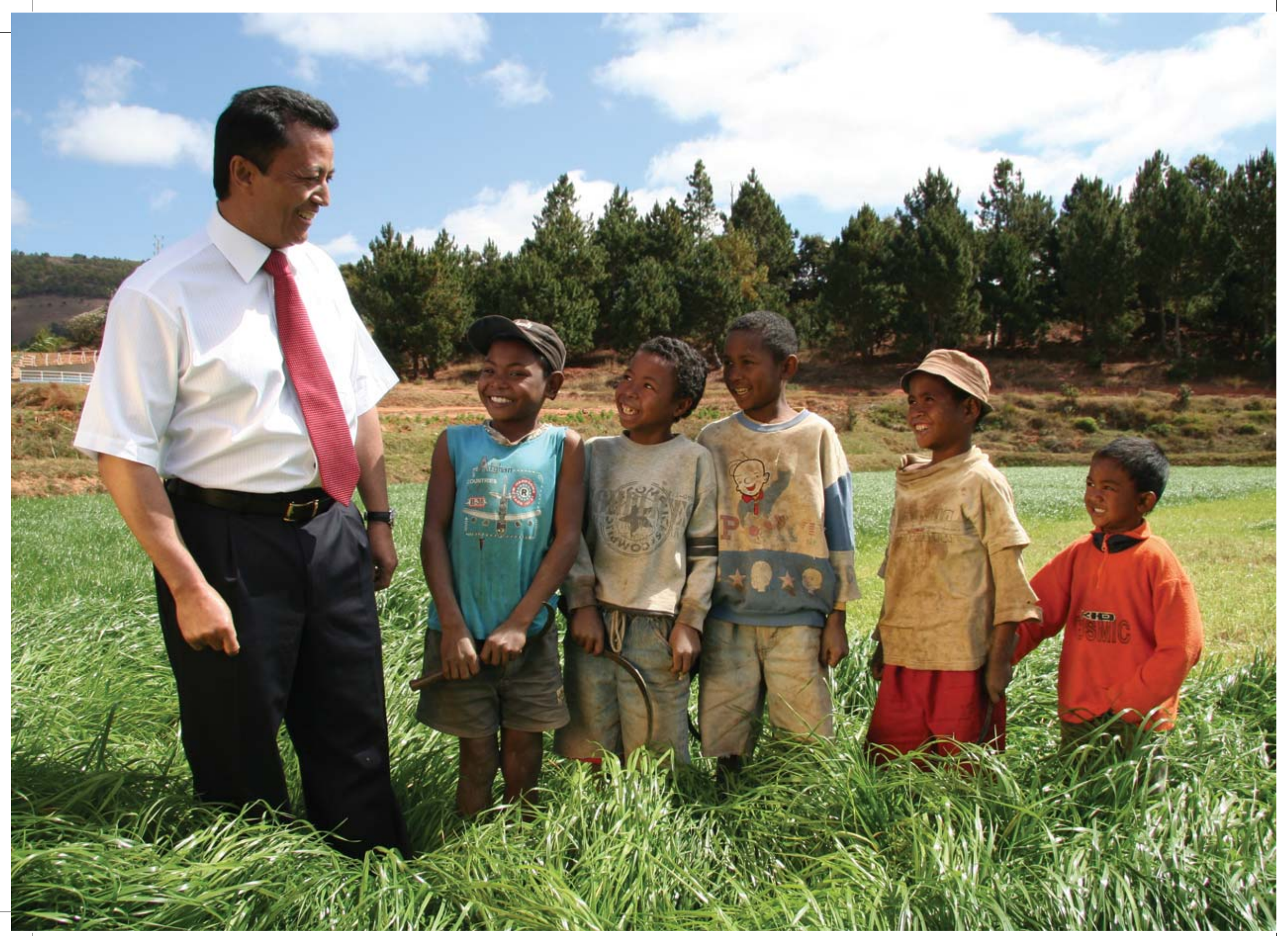




\section{A MESSAGE FROM THE PRESIDENT Marc RAVALOMANANA}

Dear fellow citizens of Madagascar

Dear members of the international community

Madagascar has embarked on the path of transformation. Since 2002 we have laid the foundation that will allow our country to move forward rapidly. In November 2004 we created our Vision "Madagascar, Naturally" and we have designed and implemented many programs to support our development.

To accelerate and better coordinate the development process and to make a quantum leap, we have created the Madagascar Action Plan, the MAP. The MAP is a bold, five year plan which establishes direction and priorities for the nation from 2007 to 2012 . It states the commitments, strategies and actions that will ignite rapid orowth, lead to the reduction of poverts, and ensure that the country develops in response to the challen oes of olobalization and in accordance with the national vision - Madagascar Naturally and the UN Millennium Development Goals.

To the people of Madagascar, I invite you to become active participants in the implementation of the MAP. Everyone has a role to play in the work ahead. Rapid development will bring tremendous benefits to all the villages and town of Madagascar.

To my colleagues in the civil service, we now must face the challenge of strengthening the efficiency of the public administration to respond to the expectations of the population through provision of quality services. We also should improve our capacity to absorb and use efficiently all resources that are available to us from the international community and the donors. And we will benefit from our efforts. The time has come to reconsider the status of public servants in the Public Administration. I promise to do so. The Public Administration is the lead employer nationwide. We, its emplovees, are "public servants" and we must be the examples of true service and professionalism. We should show devotion, courage, integrity, and merit.

To the private sector, you are central to the achievement of the MAP goals. We are committed to becoming a highgrowth economy and making a quantum leap in our development. We must promote participation of loc enterprises in all sectors of the economy to create rapid employment growth. We must attract more foreign investors to support our economy. The time has come to provide strong support to the rapid and broad developmen of the private sector to increase production of quality and competitive goods suitable for export to regional and international markets. Our policy is based on the spreading of investments that will contribute to employment creation, to the strengthening of professional education, and to the improvement of the living conditions of the Malagasy people.

To our development partners, the international community and the donors, you have played a vital role in the developmen of Madagascar. I thank you on behalf of all the Malagasy people. And I would like to gratefully thank you in advance for the substantial support that you will provide us for the implementation of the MAP. We need your assistance and strong cooperation to improve the infrastructure, develop the educational system, promote rural development, and create a comprehensive health sector that aggressively addresses family planning and the fight against HIV/AIDS. Mutual tru is crucial to success. We will continue to strengthen this partnership.

As President of the Republic of Madagascar, I publicly declare my commitment to providing the necessary leadershi

God bless our country,

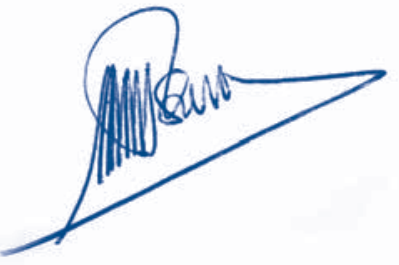

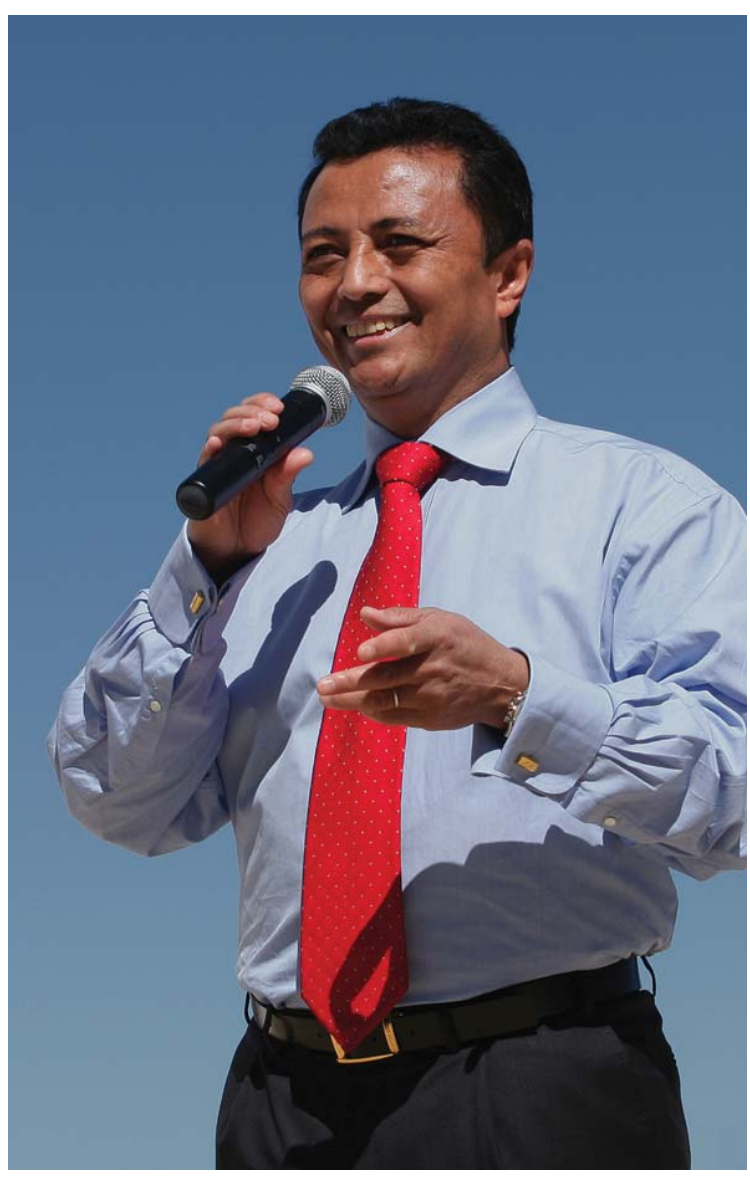




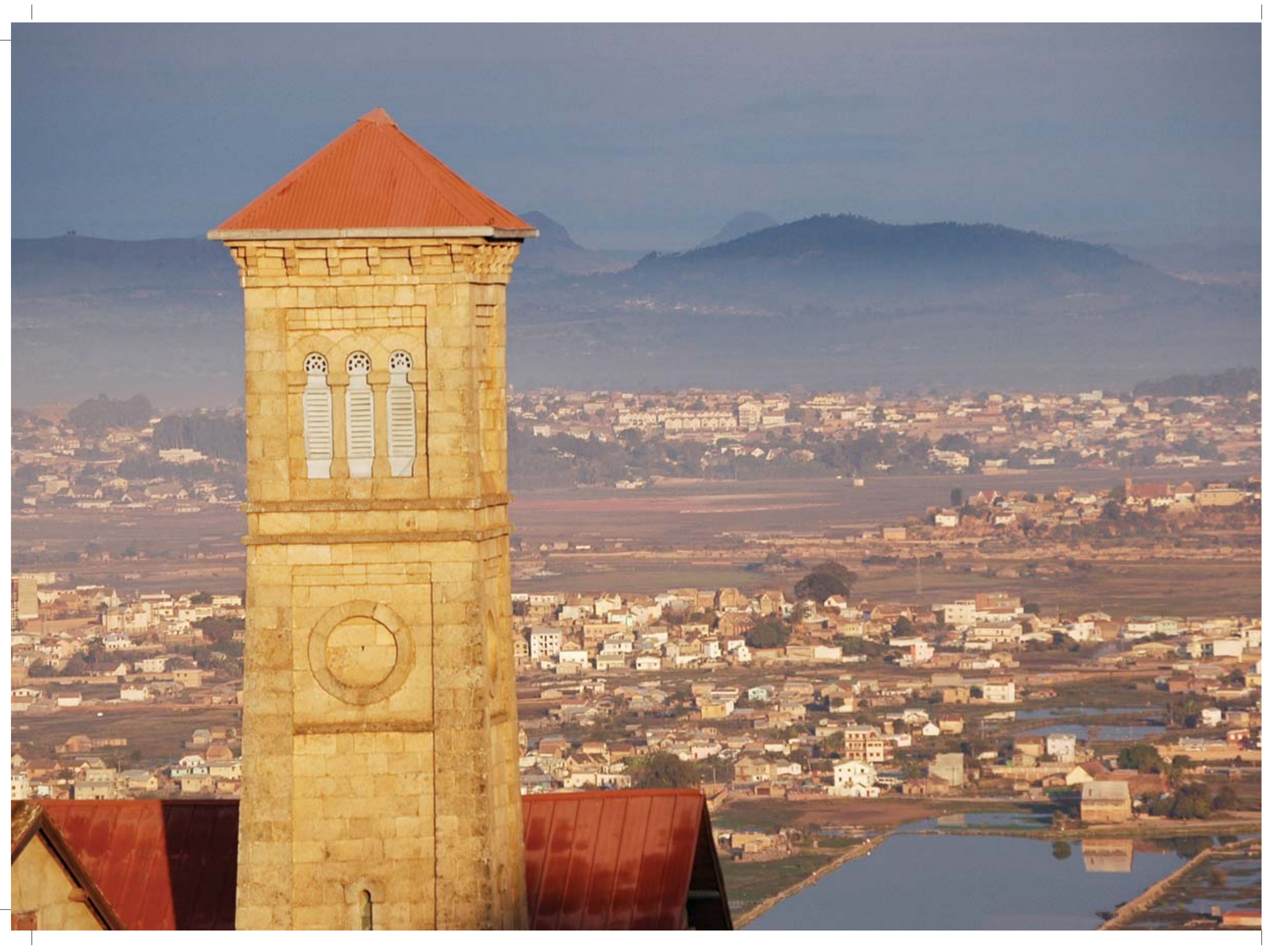




\section{THE NATIONAL VISION : MADAGASCAR NATURALLY}

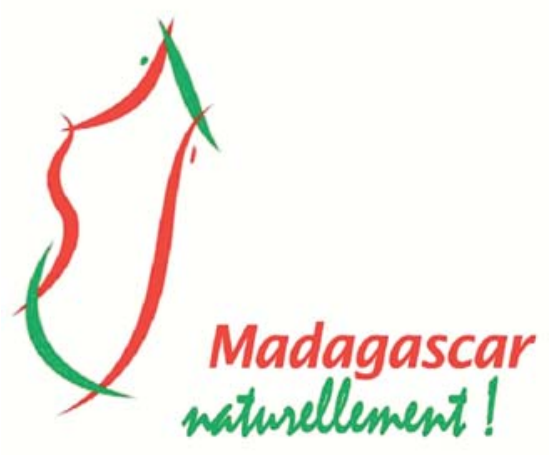

The Malagasy people, equally in rural and urban areas, will be healthy and well-educated. They will be active participants in the development process and be gainfully employed in agriculture, industry and the provision of services.

As a nation, we will honor the multitude of cultures and traditions of all the people of Madagascar. We will be proud of our country, united in national solidarity, and work together to achieve our dreams.

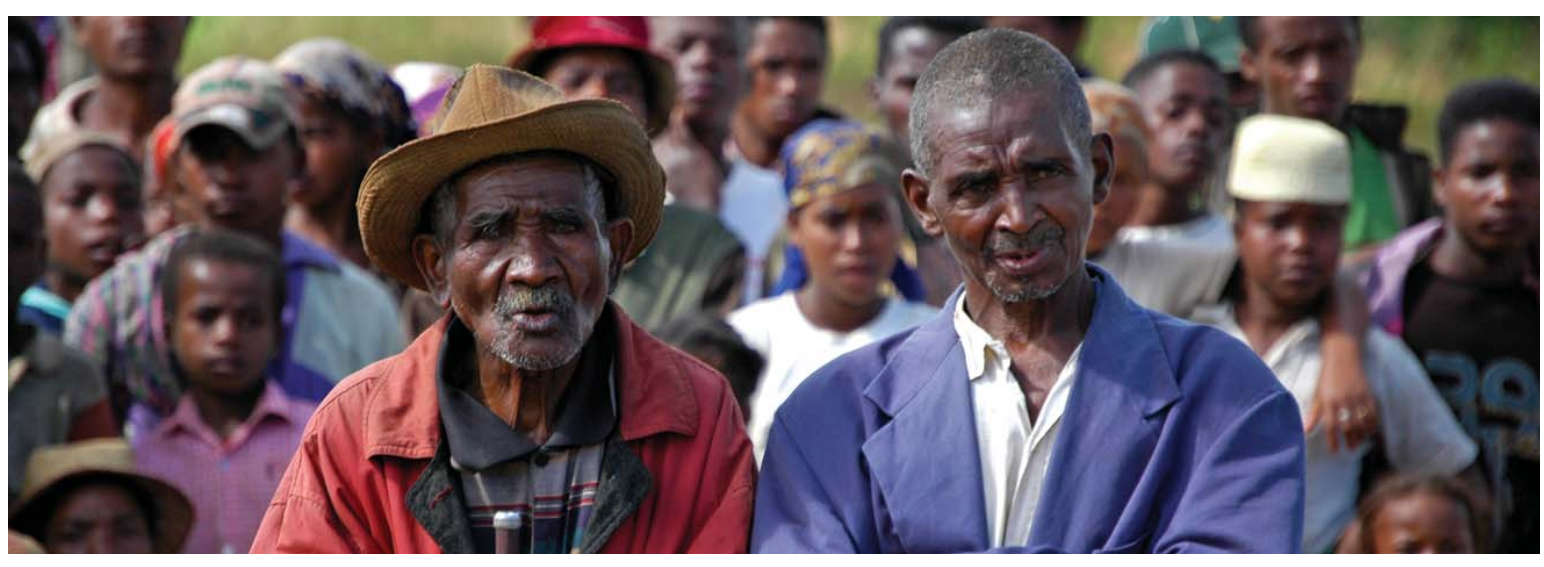




\section{THE MAP BUILDS CAPITAL FOR THE NATION}

\section{Human Capital}

Human capital includes the health services, nutrition support, education and skill buildin that allows each person to be economically and socially productive.

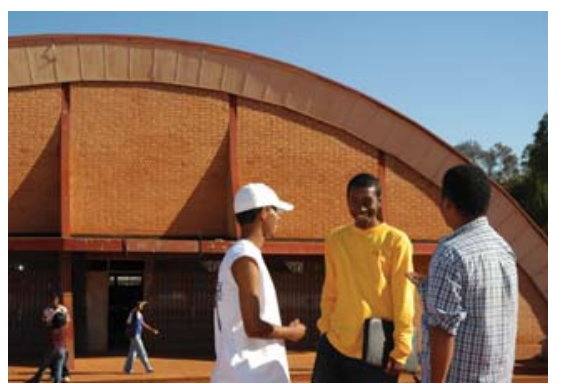

\section{Infrastructure Capita}

Infrastructure capital is the roads, power, water and sanitation, airports and seaports, and telecommunications systems that are critical to support business, government and the general populatio

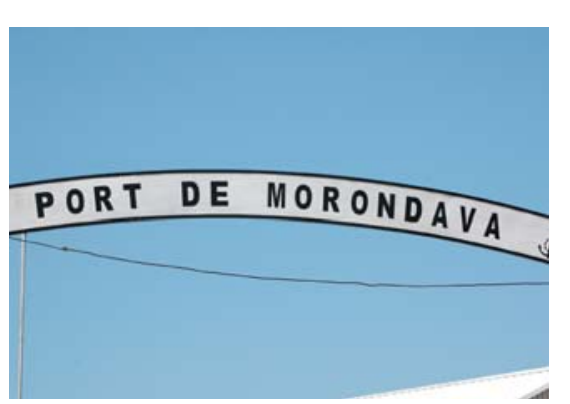

\section{Private Sector Capital}

Private sector capital is the machinery, facilities, transportation, processes, strategies, and legal frameworks needed for busines to global economy.

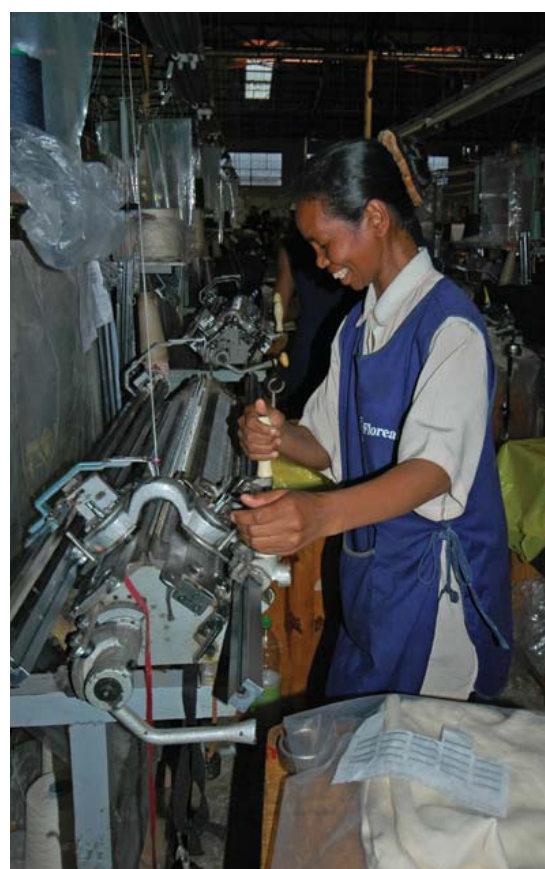

\section{Natural Capital}

Natural capital is the arable land, healthy soils, biodiversity, and well-functioning ecosystems that provide the environmenta inputs needed for the country to flourish.

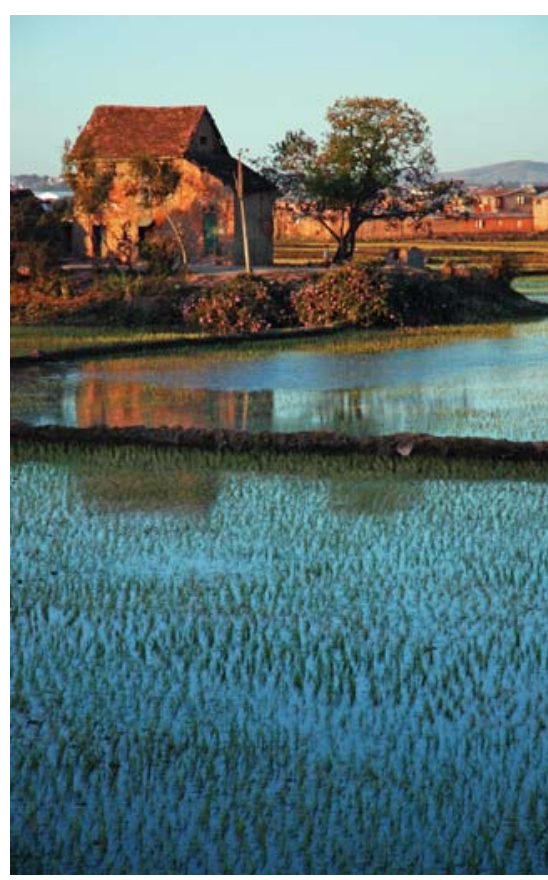




\section{Leadership Capital}

Leadership capital is the leadership and managerial ability that exists throughou the nation to promote change, guide and maintenance of all the other forms of national capital.

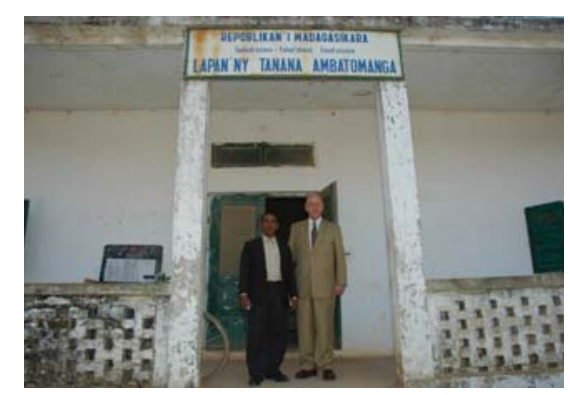

\section{Knowledge Capital}

Knowledge capital is the scientific and

echnological know-how that raises

productivity in business and government and

promotes creative and competitive practices.

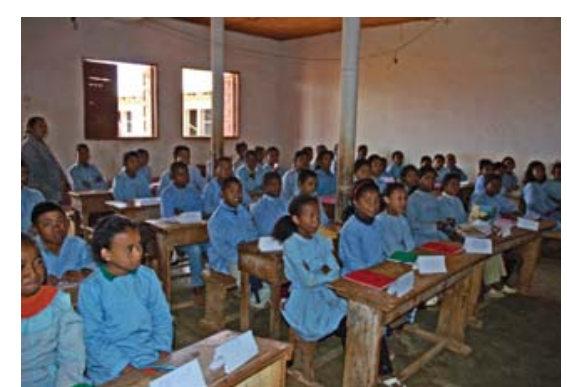

\section{Public Institutional Capital}

Public institutional capital is the responsible governance and civil service support to the nation needed to implement government policy and provide quality services to the people in timely, efficient, and effective manner.

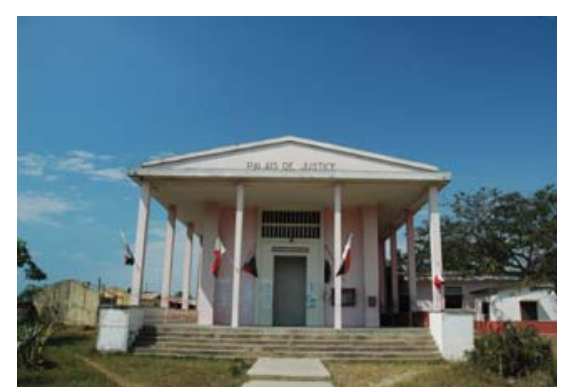


THE BIG GOALS

\begin{tabular}{|lcc|}
\hline INDICATOR & 2005 & 2012 \\
\hline UN Human Development Index (Ranking) & 146 out of 177 & 100 \\
\hline $\begin{array}{l}\text { Poverty Rate } \\
\text { (\% of population living below \$2 a day) }\end{array}$ & $\begin{array}{c}\text { (in 2003) } \\
\text { Family Size (Fertility Rate) }\end{array}$ & $50 \%$ \\
\hline Life Expectancy & 5.4 & 3 to 4 \\
\hline Literacy & 55.5 & 58 to 61 \\
\hline $\begin{array}{l}\text { Percentage of Children Completing } \\
\text { Secondary School }\end{array}$ & $63 \%$ & $80 \%$ \\
\hline Economic Growth & Lower Sec. $19 \%$ & Lower Sec. $56 \%$ \\
\hline GDP (USD) & Upper Sec. $7 \%$ & Upper Sec. $40 \%$ \\
\hline GDP Per Capita (USD) & $4.6 \%$ & $8 \%$ to $10 \%$ \\
\hline Foreign Direct Investment & $\$ 5$ Billion & $\$ 12$ Billion \\
\hline World Bank Business Climate Ranking & $\$ 309$ & $\$ 476$ \\
\hline Corruption Perception Index & $\$ 84$ Million & $\$ 500$ Million \\
\hline Households Having Land Title & 131 & 80 \\
\hline
\end{tabular}

The MAP goals and strategies are directed to achieving poverty reduction and the enhancement of the quality of life for all Malagasy. 

19.

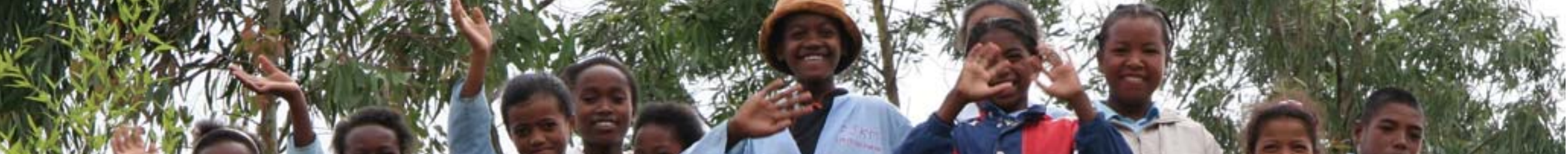
M.

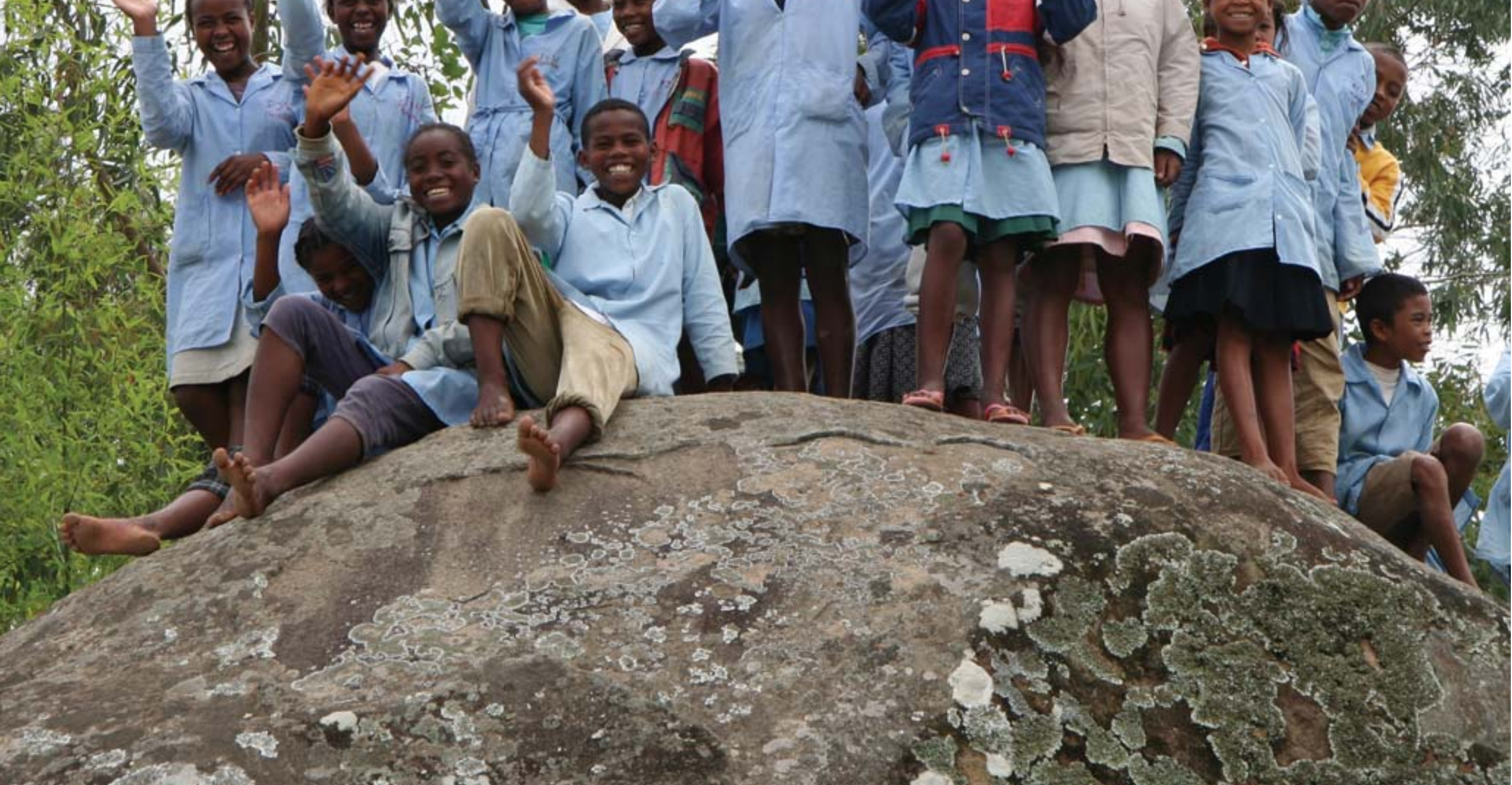

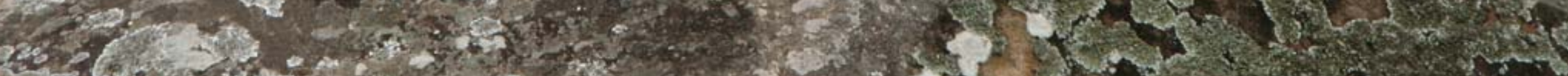

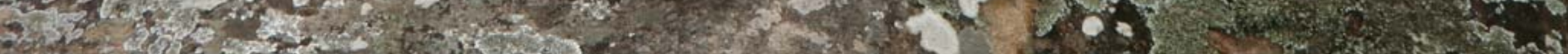




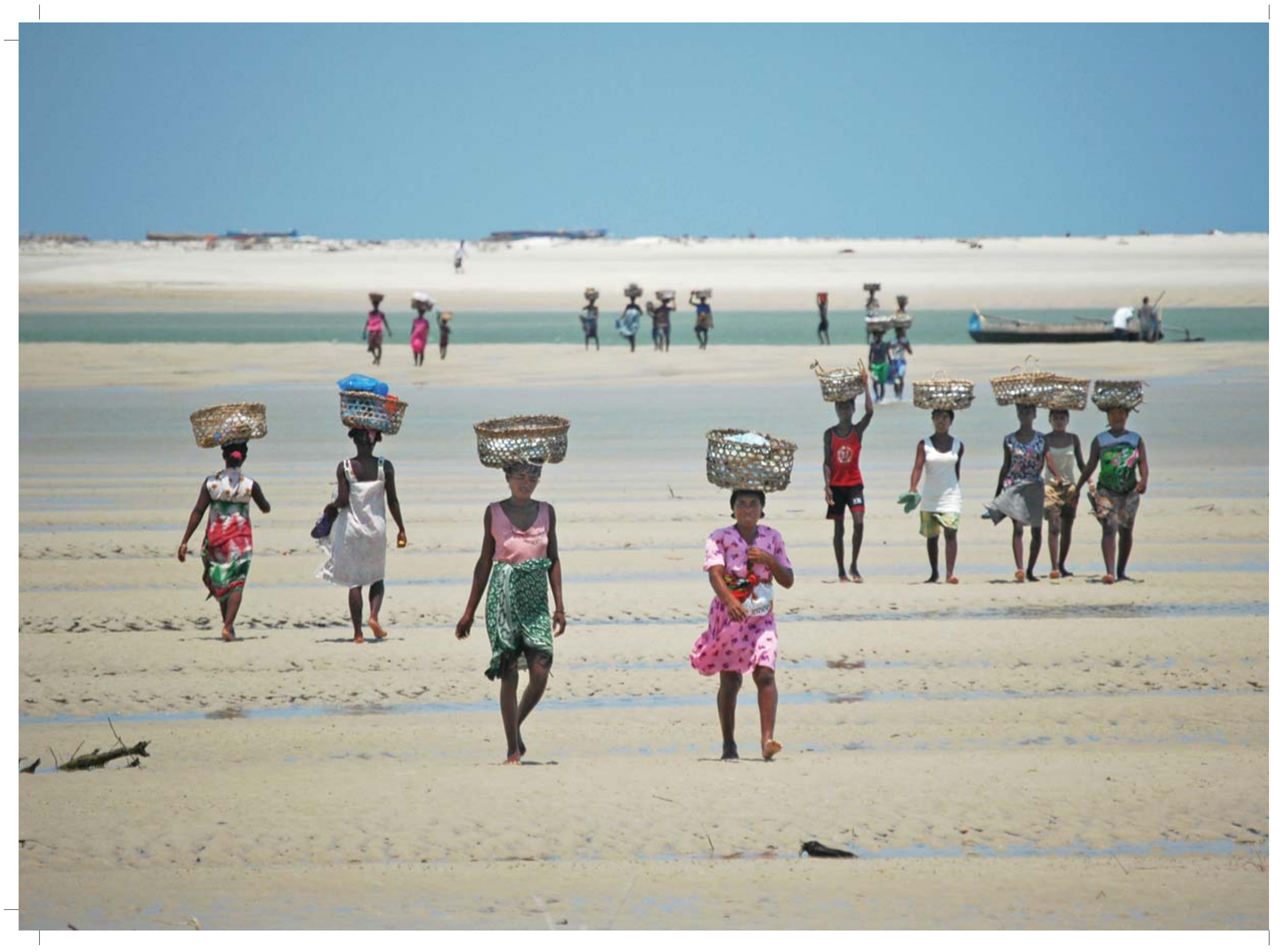




\section{THE MAP AND THE UN MILLENNIUM DEVELOPMENT GOALS}

\section{The MDG's are:}

1. Eradicate extreme poverty and hunger. Reduce by $1 / 2$ the portion of world population that lives with less than $1 \$$ per day until 2015 ; reduce by $1 / 2$ world population that hungers.

\section{Achieve universal primary education.}

All children will complete primary school by 2015 .

\section{Promote gender equality and} empower women.

Elimination of inequality of boys and girls at all levels of education by 2015 .

\section{Reduce child mortality.}

Child mortality will be reduced by $2 / 3$ by 2015 .
5. Improve maternal health.

Reduce mortality of mothers by $1 / 2$ by 2015 .

\section{Combat HIV/AIDS, malaria and}

other diseases.

Containment and change of trend until 2015.

7. Ensure environmental sustainability.

a) Strategies for sustainable development, protection of natural resources.

b) Halve the population without access to drinking water and sanitation by 2015 .

\section{Develop a global partnership} for development.

Open trade and finance systems, access to markets, Debt Relief, jobs for young people, access to medicine at a fair price, and access to new technologies.

\section{We declare our}

commitment to achieve the UN Millennium

Development Goals.

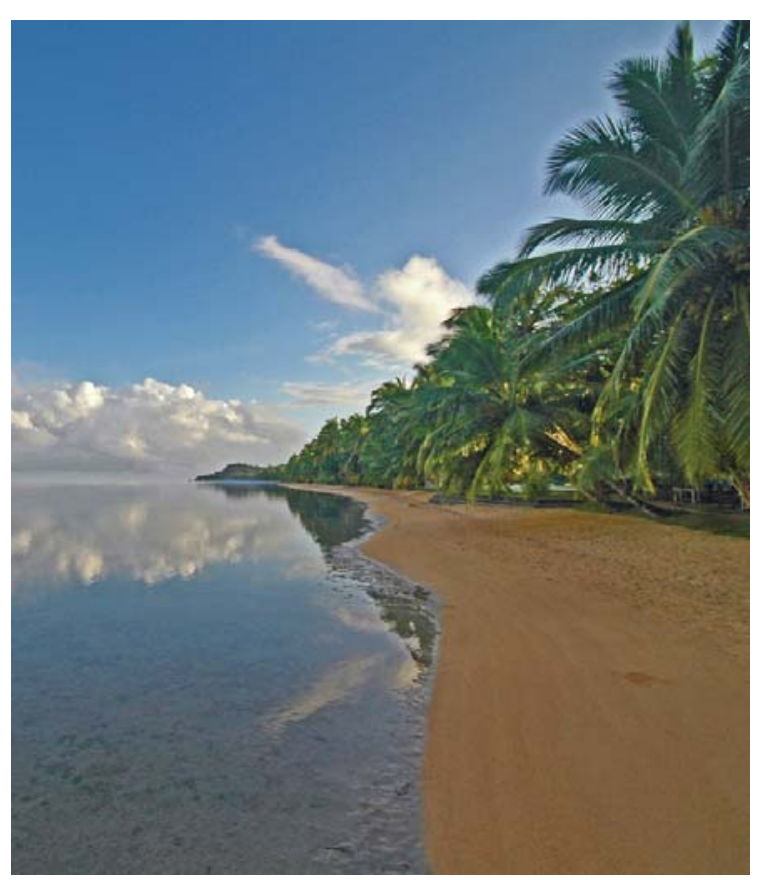




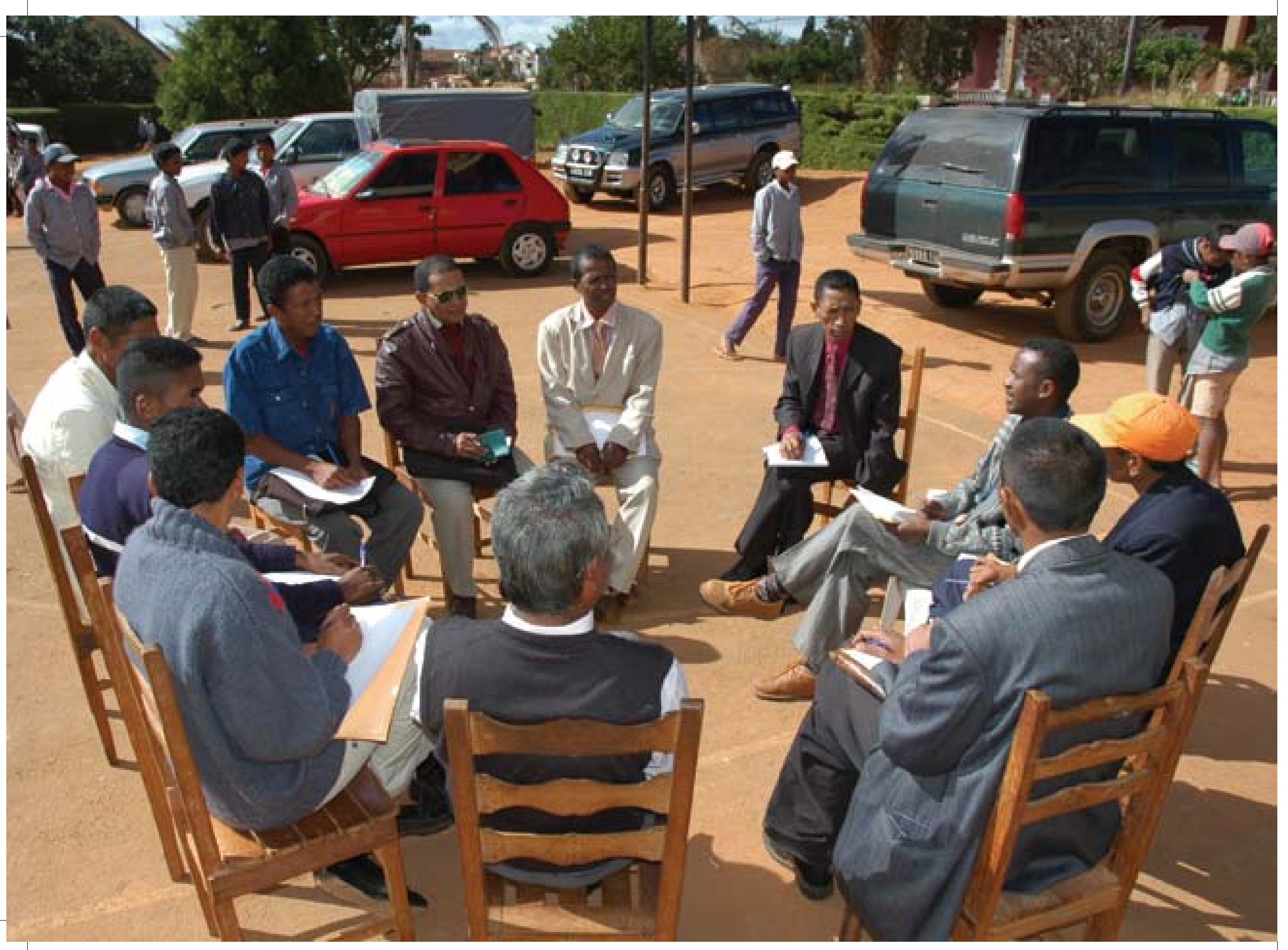




\section{THE MAP GUIDING VALUES}

We recognize that in order to successfully implement the MAP, we need to operate according to a new set of shared values.

These values will be emphasized in all aspects of governance and administration.

\section{Professionalism in All That We Do}

Everybody must work to achieve the best

professional standard.

\section{Shared Leadership}

Leadership must be displayed at all levels of government and in all sectors of society.

Leaders must show initiative and focus, and mobilize people and resources to make the vision and MAP goals a reality.

\section{Continuous Capacity Building}

We must be continuous learners and constantly work to strengthen our skills and abilities and our institutional capabilities so that we can succeed.

\section{Participation and Cooperation}

We will promote teamwork, participation and cooperation with all the people, regions, communes, civil society and donors.

\section{Leverage Resources}

We must minimize waste and maximize gains to ensure the smart and productive use of the nation's resources.

\section{Competitiveness}

In order to succeed in the global market place and the regional and international arena, our educational system, civil service, and the private sector must be highly competitive.

\section{Integrity}

Integrity, honesty, and trust are essential for a government to produce results. We must be committed to operating with uncompromising integrity.

The Will to Succeed

We must be persistent, display initiative, and do what we commit ourselves to do and we must get results!

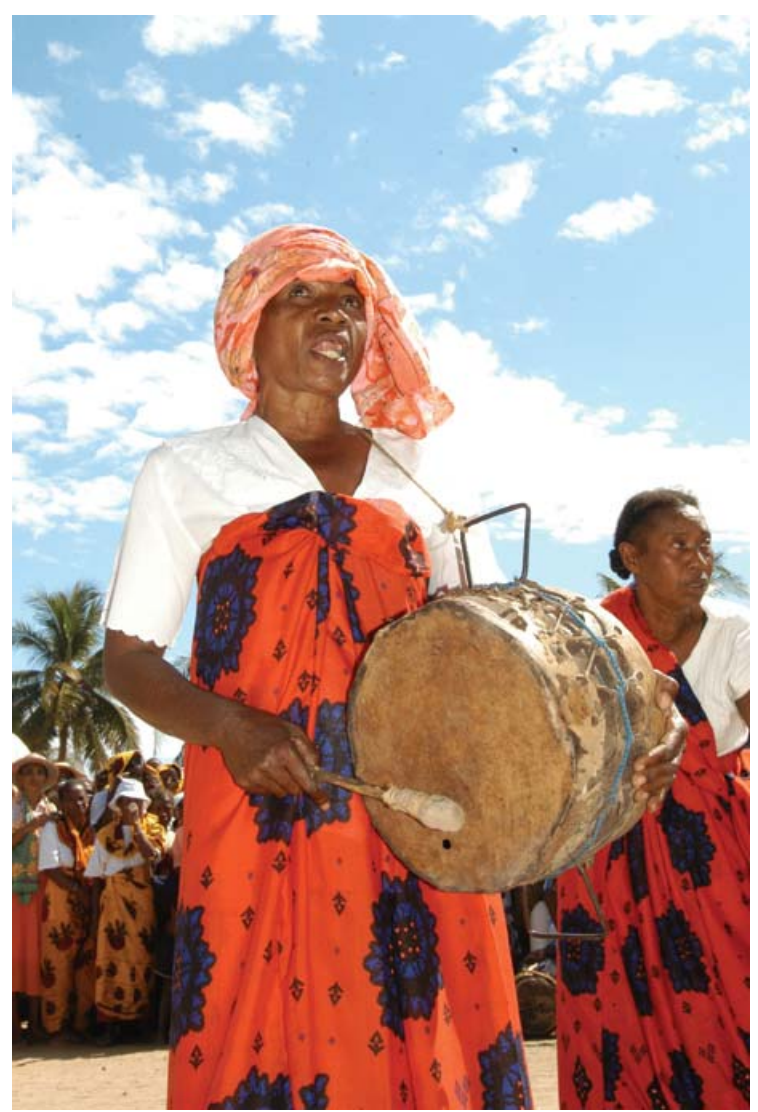




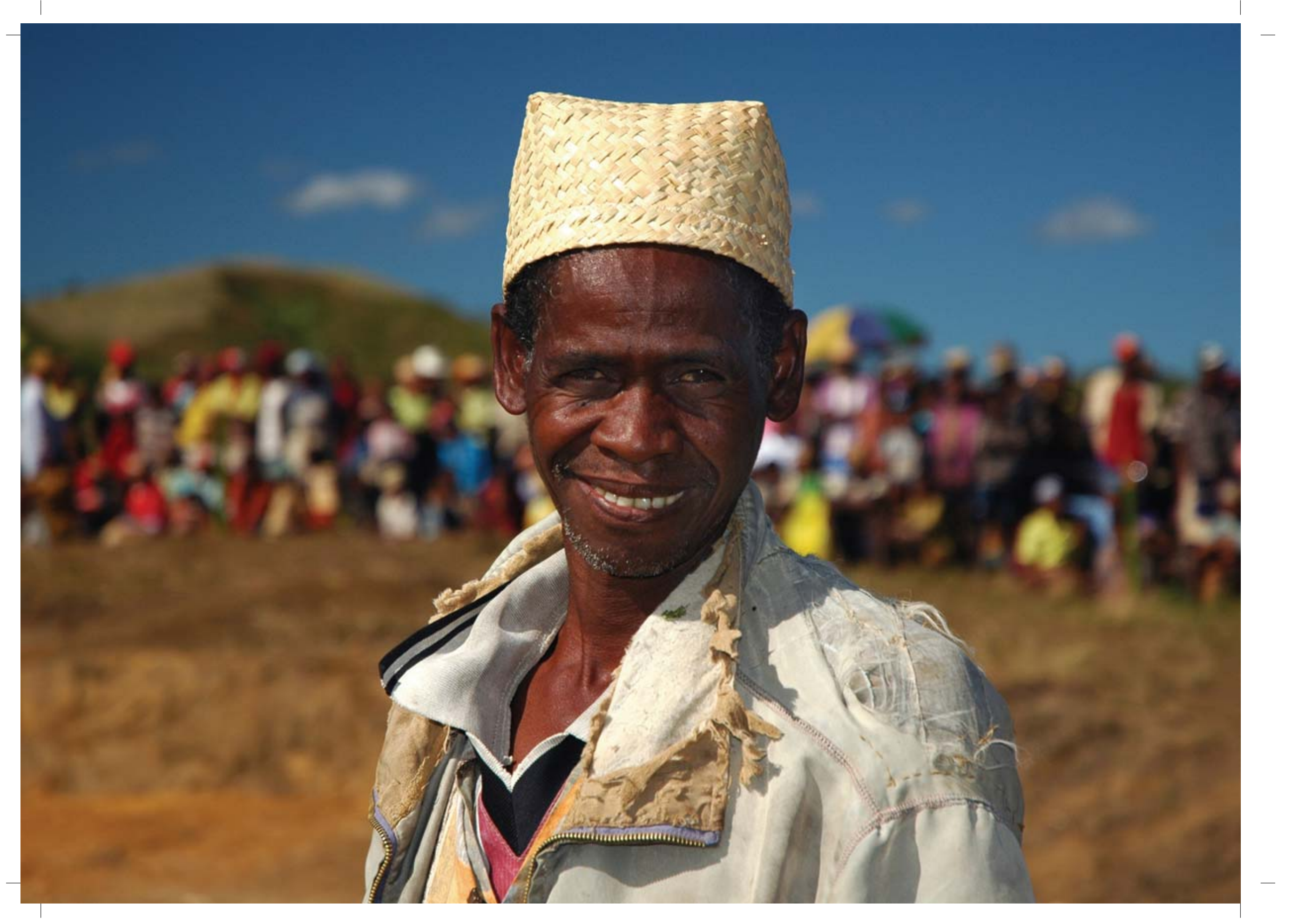




\section{THE BENEFITS OF HAVING THE MAP}

\section{For the People of Madagascar}

The MAP will create optimism and confidence in the future.

For the Malagasy Public Administration

The MAP is there to empower and guide the civil service.

For National Investors and Local Companies The business community should feel confident that real and sustainable change is happening.

For International Investors

International investors should feel confident and excited about investing in Madagascar.

For the Development Partners

The donors should see Madagascar as a country committed to using resources wisely, responsibly and efficiently to orchestrate a real quantum leap.

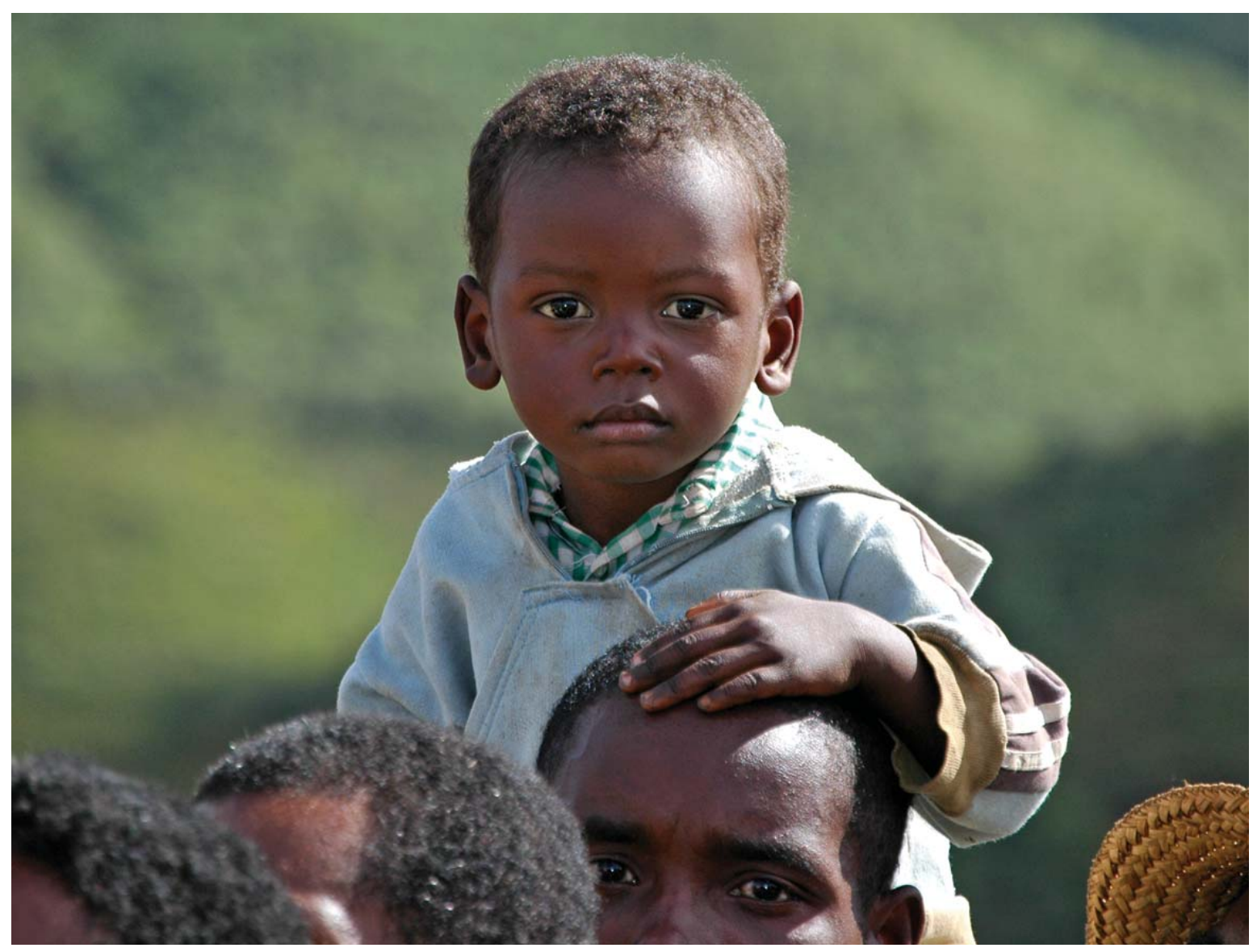




\section{IMMEDIATE MAP PRIORITIES: THE BREAKTHROUGH REFORM INITIATIVES (BRI)}

We are serious in our intention to make the MAP commitments become a reality for Madagascar. This is a pioneering effort as we are out to achieve what so many other developing countries have only dreamt about. We will turn our dream into reality. To do that we must conduct a series of major reforms that we are calling "Breakthrough Reform Initiatives.” These breakthrough reform initiatives, BRI, are urgent projects that require immediate attention, superior leadership, collaboration across ministries, and dedicated resources.

BRI 1:

Public Finance Reform

We have to collect more revenues in order to fund the projects and initiatives in the MAP. This is important in order to reduce our dependency on donors. As of 2006 , this is one of the Government's weakest areas. Madagascar currently collects approximately $10 \%$ of its GDP from taxe and customs duties. We will increase this figure to $15 \%$ by the year 2012. This will necessitate making dramatic changes in the tax code (making it simple) and the tax administrative process (making it more efficient, effective, and fair). With the support of the IMF and the World Bank, in the early part or 2007 we will conduct a thorough analysis of the tax code. This will be donerwilh active of the private sector and the civil society.

Within the Government, tight budget control and fiscal responsibility will also be promoted. This will necessitate establishing funding priorities for the government that promote high growth and the facilitation of important social programs.

\section{BRI 2:}

Significant Increase In Investment To Promote High Growth

Through the ECONOMIC DEVELOPMENT BOARD OF MADAGASCAR we will create strong sector plans to ensure the following export-oriented industries can develop rapidly Manufacturing, agri-business, mining, and tourism.

- We will begin an international campaign to promote

- We will prioritize infrastructure projects to support key industries.

- We will provide appropriate incentives, regulations and policies to facilitate the attraction, growth and expansion of key sectors.

- We will provide access to land, establish a bold investment law, and create an effective arbitration system to enforce contracts, mediate disputes and ensure security of investments.

- We will address the impediments and establish a business climate that investors value. Madagascar as a place to invest.

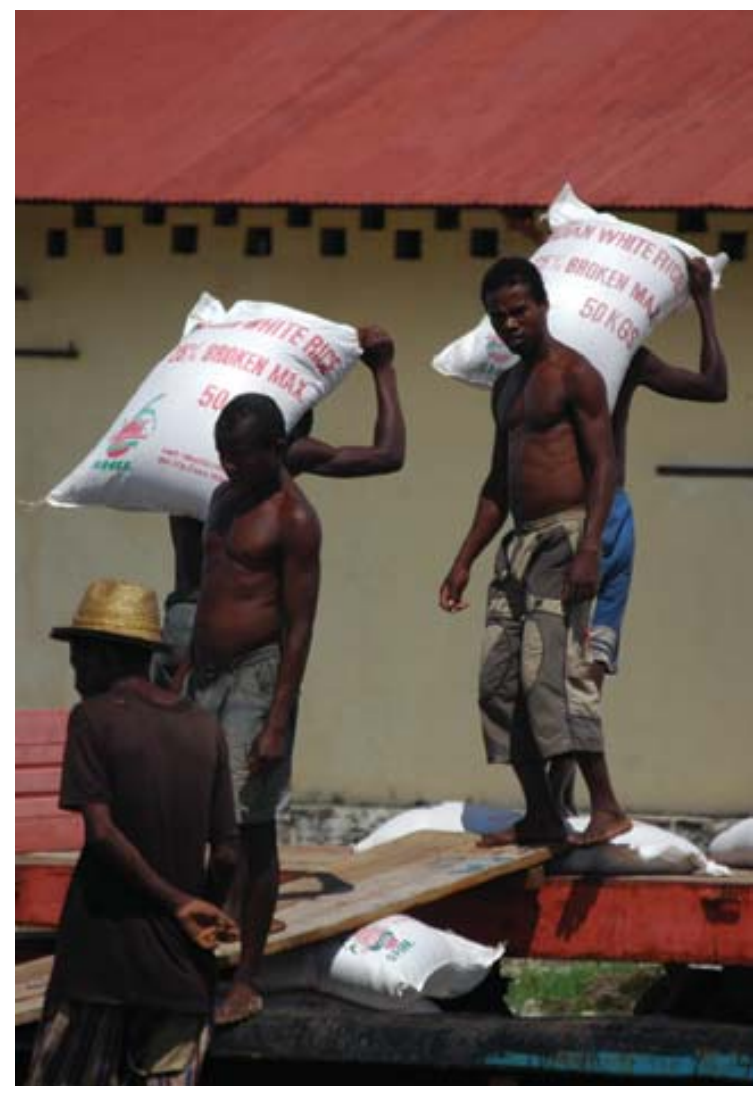




\section{BRI 3:}

\section{Sow The Seeds of A Green Revolution}

We will begin the process for creating a green revolution in Madagascar. A green revolution is the flourishing of the fields and crops of the farmers to ensure there is no hunger but an abundance of food that can meet domestic needs and also be used for export purposes. As of 2006, Madagascar was an importer of rice. Over the next few years Madagascar will become an exporter of rice and other crops. To facilitate the green revolution, the government will ensure that the needed seeds, fertilizers, and training are provided to the farmers, and new cooperative processes are established to help in the collection and distribution of harvests.

\section{BRI 4:}

\section{Transform Public Security}

In regards to security, the dahalo (cattle rustlers) of the rural areas are a real annoyance and a serious impediment to

progress. Also, we have a serious problem with smuggling of precious stones and timber, and illegal fishing. We will not simply reform security but transform our security system to ensure that Madagascar is a safe and secure place to live, farm, travel, invest, and conduct business.

\section{BRI 5:}

Implement Bold New Measures For Health And Family Planning

Our population rate is increasing too rapidly. Family size needs to be reduced. In some rural areas there are 7 to 10 children per household. Contraceptives and birth control advice will be made available to reduce the size of the average family.

Malaria is rampant in Madagascar. As of 2006 only half of the population is protected when they sleep by bed nets. We have launched the Malaria Project to ensure that within 2 years every person has a bed net.

Also, we are committed to ensuring that HIV/AIDS never advances like it has throughout many African countries. A of 2006 , only $1 \%$ of the population was infected with the AIDS virus, as compared with $30 \%$ in South Africa. We have begu to put in place a "best practice" strategy on HIV/AIDS policy.

\section{BRI 6:}

Transform The Judiciary

We will undertake a series of major reforms of the judicial system - commercial courts, sentencing guidelines and prison system - to ensure that the people and investors have complete confidence and trust in the system. The judiciary must be efficient, effective and operate with utmost integrity.

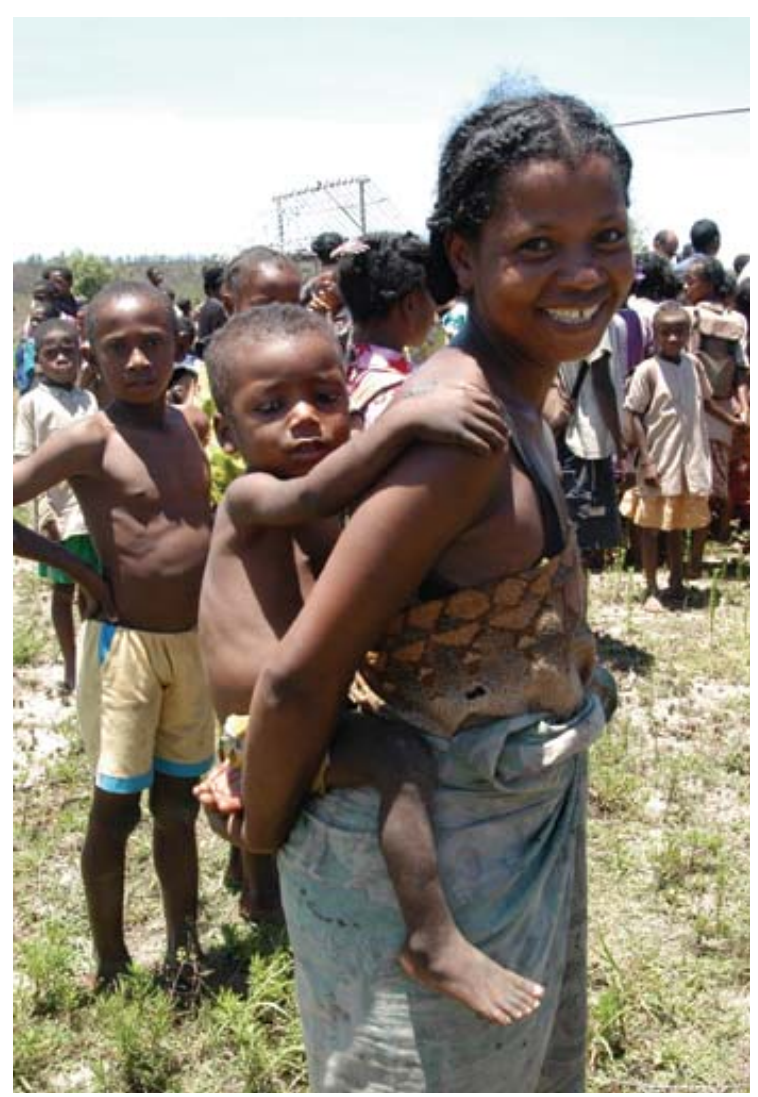




\section{THE HUMAN BUILDING BLOCKS OF THE MAP People make it happen}

\section{Develop Leadership Capacity}

Fundamentally, leadership is about mobilizing others to face reality, solve problems, produce resources, and achieve goals. We need strong leaders in all our institutions - the government, businesses, churches, schools, and civil society to do this work. By virtue of being at one time a colonized country, a socialist country, and a donor-dependent country, too many people have developed the habit of waiting for someone els to provide leadership. That now has to change.

To provide the needed leadership to make the MAP a reality, we will actively seek out and reward "top performers" and put them in important positions of responsibility so that they can drive the reforms.

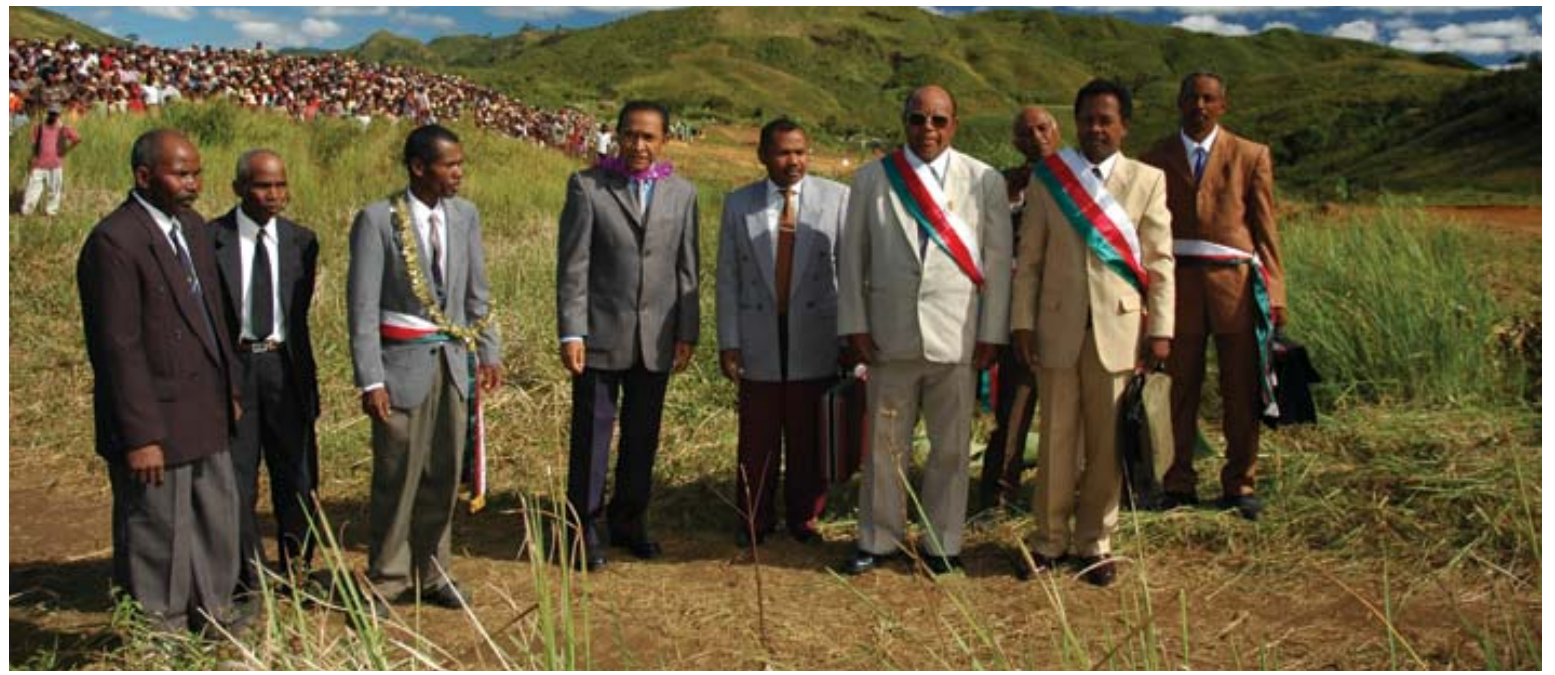
at the Presidential palace of Iavoloha. This institute will
Also, to support the development of leadership capacity we (have created the National Leadership Institute of Madagascar provide training and coaching for ministers, secretary generals, director generals, chef de region, chef de district, youth leaders, civil society leaders and business leaders. We will also be strengthening other educational and training institutions in the country, such as ENAM and the universities.

The MAP is about people - the Malagasy people. To achieve our goals, some of our values, habits, practices and priorities will need to change. Butt hand in hand, should er to shoulder and heart to heart - we can do it.

To succeed, we will need to attend to the humain build ding blocks that provide the foundation for a transformation. 


\section{Change Mindsets And Habits}

We must change the mindsets, habits, practices and processe that get in the way of progress. As a people we must be able to deal with the threats and dangers that confront us in the age of globalization, and also be able to take advantage of abundant in the world.

Progress necessitates change. Of course, in our culture there is much that is precious and needs to be protected. But some is much that is precious and needs to be protected. But some diseard The le help facilitate this process of change, even loss, throug, listening, diatogue, encouragent and lears,

\section{Fight Corruption}

We are all tired of corruption. Corruption increases the cost of doing business and increases the cost of the provision of government services. The leadership work is to be tough on corruption in any form - zero tolerance. While being tough, we must also promote a value shift in government and society. Those who engage in corruption, be they local civil serva or international businessmen, clearly hold a value that emphasizes self-interest over community or national interest. Leaders must aggressively promote, in their words and deeds, the values and practices that build national solidarity, integrity, and a clean and efficient way of operating.

\section{Increase Know-how}

Skills, skills, skills! Madagascar needs rapidly to develop the skills, know-how, and technology to thrive in a competitive and global environment. This will take time but we mus accelerate this learning process. Our policy is to use

international experts to coach and train locals, attract more overseas Malagasy back home, and send more Malagasies to training programs and courses - in the country and abroad.

\section{Mobilize People And Resources}

To make the MAP a reality we need to mobilize an extraordinary level of resources - financial, technical, material, and human. This will require creativity, initiative and leadership. We know we must do at least three things:

1) We must actively seek donor support and assistance - not just from the main donors, but increasingly more from bilateral donors and international foundations.

2) We eventually want to become self-sufficient and reduce our dependency on donors, therefore we must ensure
that our national assets and resources are managed in a way to ensure maximum financial benefits for the country.

3) We will make genuine reforms in the tax regime and customs to allow us to significantly increase government revenues that can then fund our social programs in health, education, security, and rural development.

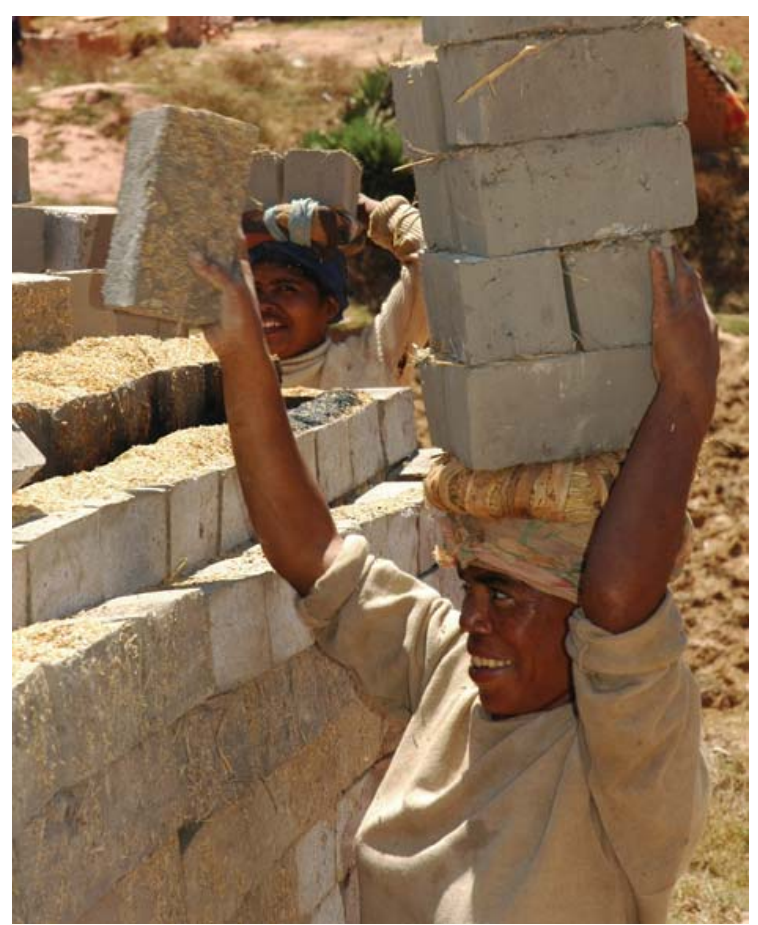




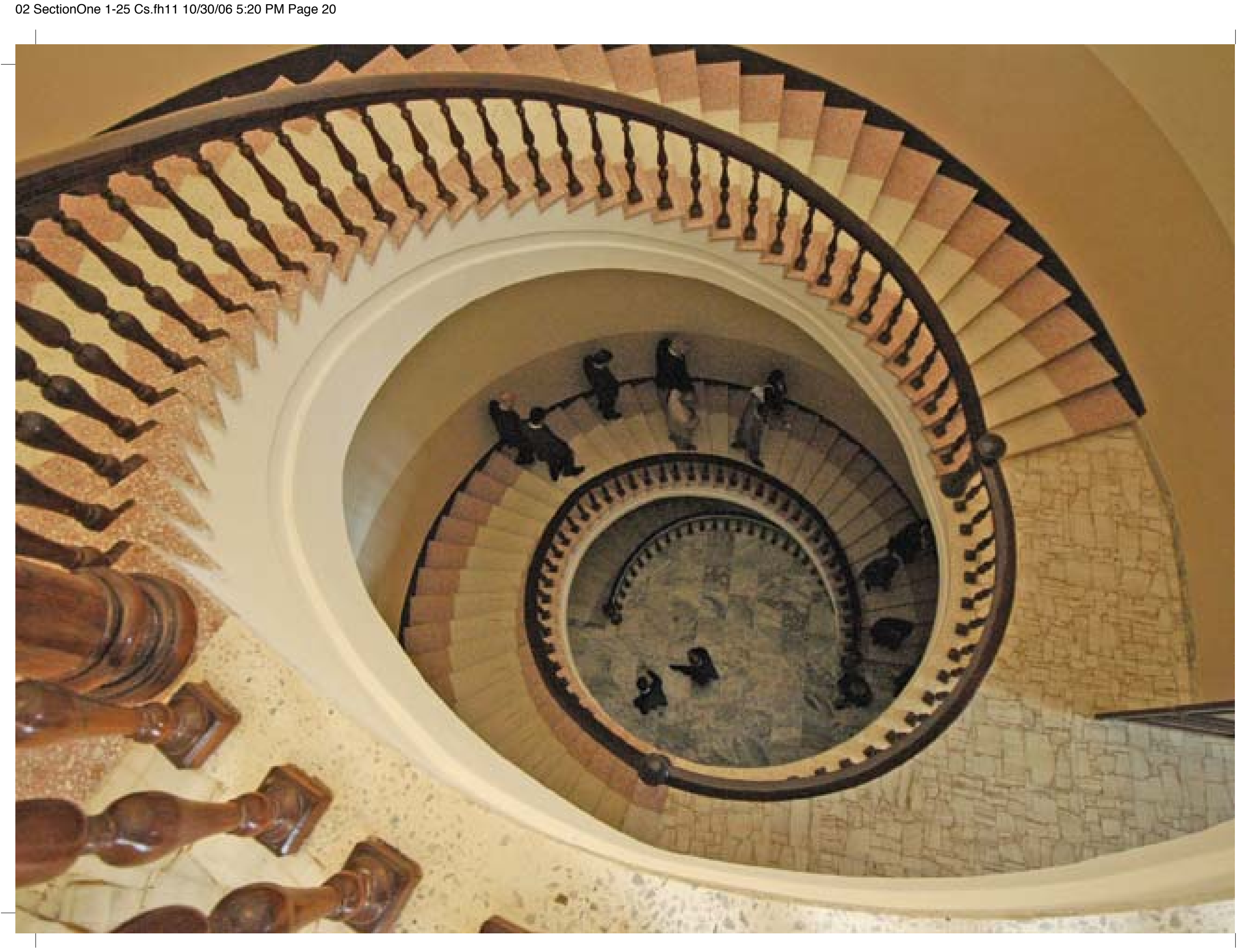




\section{NEW INSTITUTIONS TO SUPPORT THE QUANTUM LEAP}

The National Leadership Institute of Madagascar:

Developing Leadership Capacity for MAP Rapid Development

The National Leadership Institute of Madagascar (NLIM) was created in 2006 to provide cutting-edge training to build leadership capacity at all levels of government and for all sectors of society.

The NLIM is committed to training leaders to be professional, operate with integrity, be effective problem solvers and to achieve results.

It will operate hand in hand with ENAM (the National School for Public Administration) to develop government leadership capacity.

\section{The Economic Development} Board Of Madagascar:

Developing the Business Conditions for MAP Rapid Development

The EDBM was set up in 2006 to facilitate and promote private domestic and foreign investment. The EDBM is charged with ensuring that the business climate of Madagascar is attractive for companies and conducive for the success of private enterprises.

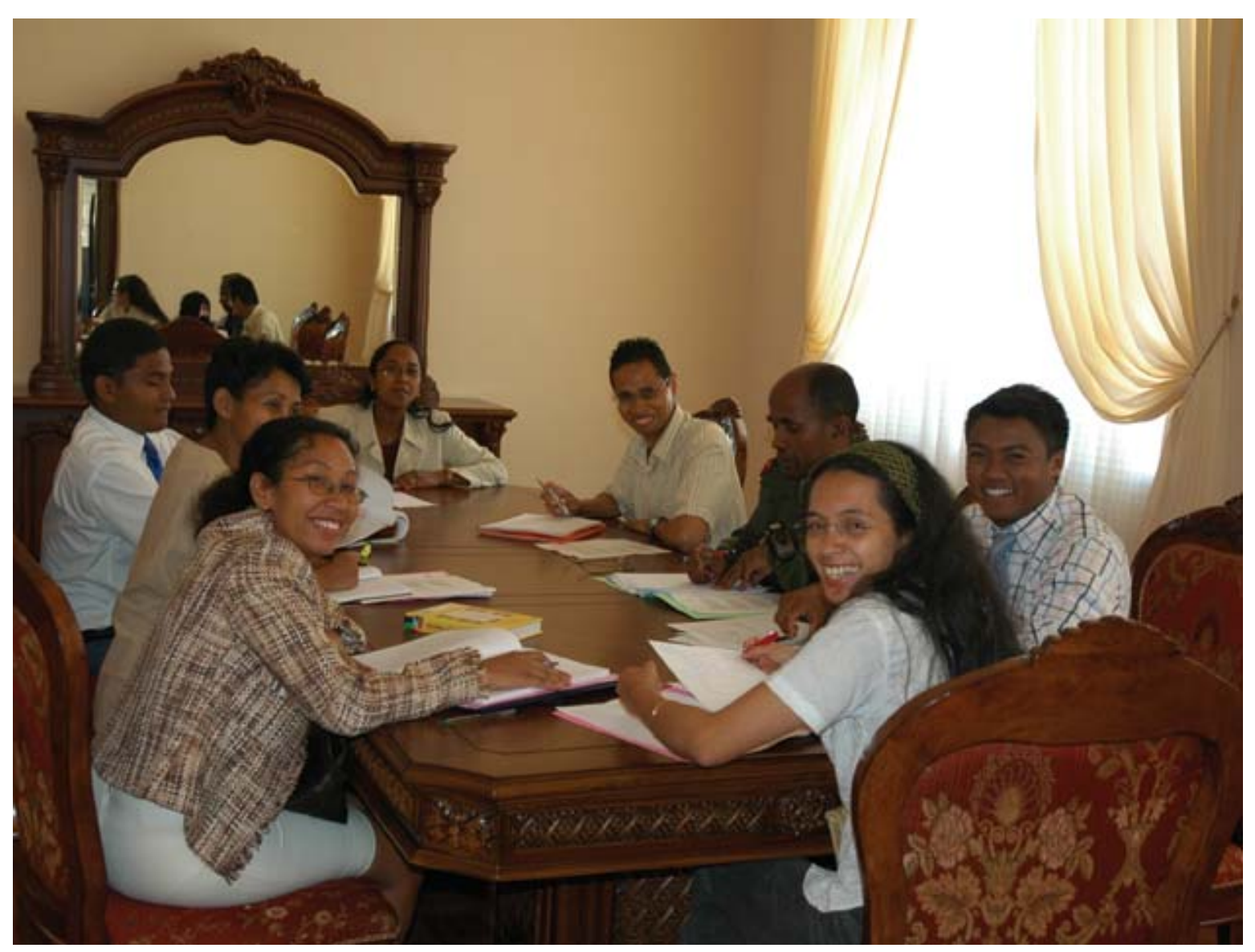



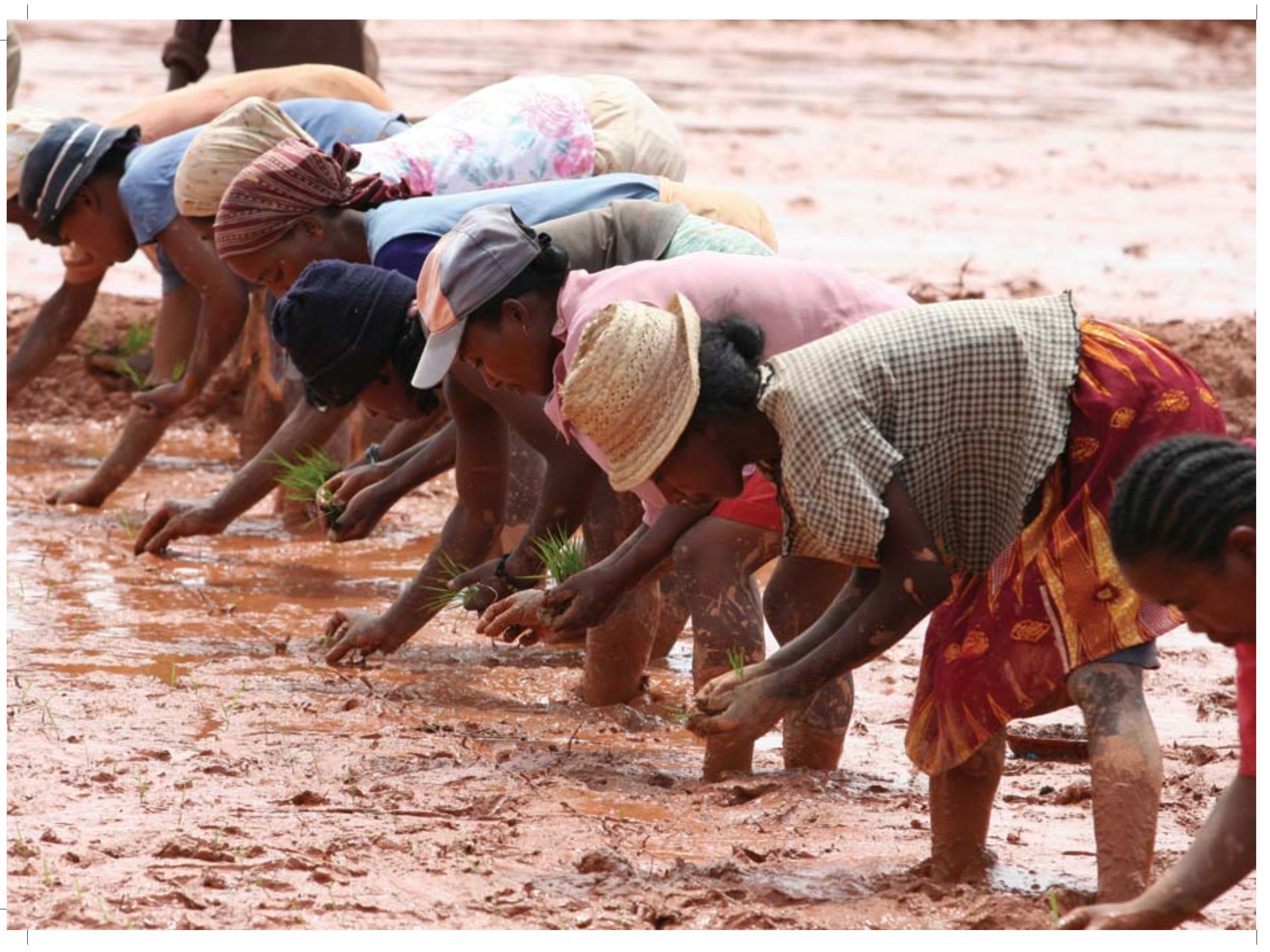


\section{MAP IMPLEMENTATION SYSTEM}

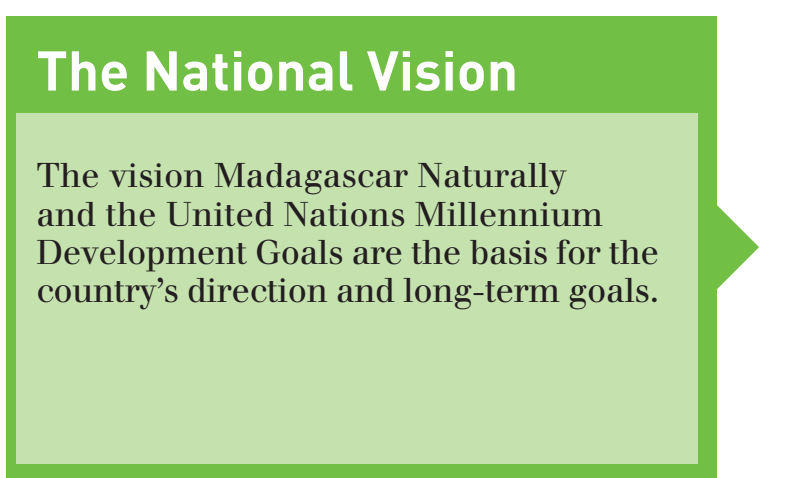

\section{Monitoring \& Feedback}

Monitoring and feedback mechanisms will be established so that the

Government can evaluate progress

and make adjustments and mid-course corrections as needed.

\section{The MAP}

The MAP five year plan reflects the eight bold commitments required to extricate the country from poverty and launch a quantum leap in medium and long-term development.

\section{Donor Coordination}

Donor Coordination will take place through an annual Donor's Conference and sector meetings to ensure the efficient harmonization and allocation of funds, and to ensure results are achieved, and there is a sustainable impact on poverty reduction.

\section{National Programs}

The MAP commitments and goals are specified in greater detail in sectoral National Programs - health, education, security, transport, etc.

\section{Annual Planning}

The MAP commitments are operationalized and implemented through the annual planning process of The Politique Generale de lètat and the national budget. 


\section{THE 8 MAP COMMITMENTS}

\section{Responsible \\ Governance

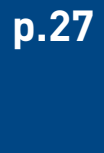

We will have a government that every citizen and the international community can trust and have confidence in. This government and the civil service will have integrity, be efficient, and act professional in all pursuits, activities, and the provision of services.

\section{Connected \\ Infrastructure}

\section{Educational \\ Transformation}

p.51

We will be a connected nation. We will build quality roads, railroads, ports, airports, and information technology systems all across the country to enable the process of rapid development, the facilitation of business and trade, communication amongst our citizens and visitors, and to ensure that the standard of living and the access to resources and global knowledge will improve for all.
We will create an education system with world class standards in quality and in effectiveness, which stimulates creativity and helps our students to actually transform their dreams into reality, and which provides Madagascar with the necessary human nation and a successful player in the world economy. resources to become a competitive

\section{Rural Development p.63 and a Green Revolution}

Dynamic rural development and real poverty alleviation is at the core of the government's endeavors. Our rural areas will flourish and prosper through a green revolution production. Agri-business centers will be established in every region to assist in training and the provision of needs such as irrigation, seeds, fertilizer and storage facilities.

To further support rapid rural development, better roads and communication networks will be established and the Government will provide favorable conditions for the flourishing of entrepreneurship and private sector initiatives. 


\section{Health, Family \\ Planning and the \\ Fight Against HIV/AIDS}

We will work to ensure that all of our people are healthy and can contribute productively to the development of the nation and lead long and fruitful lives. The problems of malnutrition and malaria will be brought to a halt. HIV and AIDS will not advance any further; safe drinking water will become accessible; and, through education and the provision of

health services the average size of the Malagasy family will be reduced.

High Growth
Economy

Madagascar will have a high growth economy with growth rates reaching between $7 \%$ and $10 \%$ by 2012 . We will ensure that we have a diversified and strong private sector driven by local and international investment and trade.

The Government will generate the fundamental conditions that will support the facilitation of business. We will encourage the pursuit of the best ideas and cutting edge techniques, technologies, and strategies to ensure that we as ation are responsive to the challenges of globalization productive in the workplace, and gain a competitive advantage.

\section{Cherish the \\ Environment \\ p.97}

Madagascar will be a world

leader in the development and implementation of environmental best-practice. After many decades of exploitation and neglect, we have begun to turn the tide. We will become a "green island" again.

Our commitment is to care for. cherish and protect our extraordinary environment.

\section{National}

Solidarity

We will continue to forge a strong, unified national identity that honors the multitude of cultures and traditions of all the people of Madagascar and promotes participation and partnership. Our people must be proud of who they are, stand with their heads held high, display confidence in the face of the many challenges facing us, and take full and shared responsibility for guiding the nation into the future. 


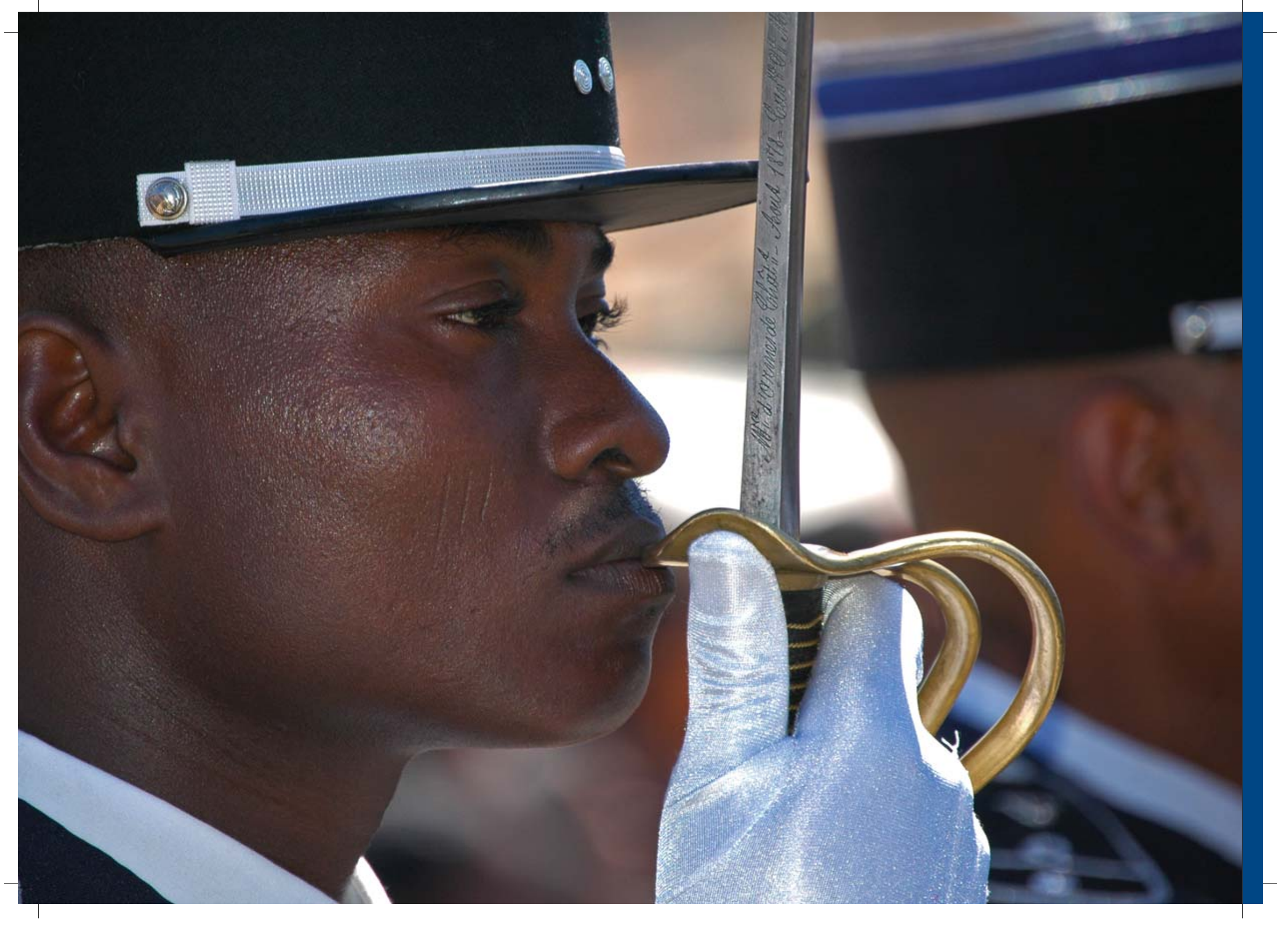




\section{COMMITMENT ONE RESPONSIBLE GOVERNANCE}

We will have a government that every citizen and the international community can trust and have confidence in. This government and the civil service will have integrity, be efficient, and act totally professional in all pursuits, activities, and the provision of services. 


\section{CHALLENGE 1 >}

\section{PROVIDE SUFFICIENT SECURITY TO PROTECT PEOPLE} AND PROPERTY

Current Reality

Madagascar is a safe country, however in some parts of the country, criminal activities persist. In 2003, a National Plan for Security was created, but due to lack of resources it has not been fully implemented. Zebu and crop theft still exist in many areas. Illegal trafficking in fish, gemstones, gold and timber is of serious concern given its magnitude. Drug crops thrive in limited areas, feeding smuggling and urban crime. In 2005, about 5,700 Dahalo (cattle thieves) were anteste

an

Goals

1. Madagascar will be a safe country to live in, to travel in and to invest in.

2. All red zones will be clean areas and zebu theft will be significantly diminished.

3. Urban crime will be under control and brought back to an acceptable level.

Strategies

1. Review current system, adopt best practices, train and develop security forces in improved methodologies.

2. Align the mission of the security forces to national and regional needs and mobilize resources to support the mission.

3. Rationalize institutions, improve and reinforce the coordination between security institutions and civil institutions.

4. Increase the surveillance of national coasts and strengthen
customs offices and security forces to secure our borders.

Increase the surveillance of national coasts and strengthen
customs offices and security forces to secure our borders.

\section{PRIORITY PROJECTS AND ACTIVITIES}

\section{PROJECT LEADER}

1. Review the laws, rules and processes to achieve effective and efficient coordination of security forces and justice for crime prevention and pursuit of criminals

Minister responsible for Interior

2. Train and develop local "dina" to ensure effectiveness and consistency in the application of the law

3. Identify, obtain, use and maintain new resources, transport and communication equipment, and weapons to prevent and pursue criminal activity, and protect economic zones

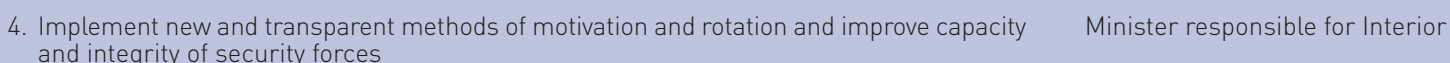

4. Implement new and transparent methods of motivation and rotation and improve capacity_ Minister responsible for Interior and integrity of security forces

5. Restructure the Zebu industry (ranching and trading) to minimize corruption and theft Minister responsible for Interior

INDICATORS

Crime rate: number of crimes (per 1,000 citizens)

4.2

Number of red districts (high Zebu theft and crime): out of 111 Districts

Surveillance of territorial waters and exclusive economic zones

$17 \%$

61

$17 \%$

$60 \%$ 
CHALLENGE 2 >

\section{STRENGTHEN RULE OF LAW}

\section{Current Reality}

In 2004, a programme for judiciary reform was launched by the Ministry of Justice. Since that time, about 60,000 pending cases of penal affairs have been accelerated. Judges were appointed in all courts to accelerate and improve the processing of civil and commercial files. A Code of Deontology has been adopted and all the magistrates have been trained in it. Still, part of the judiciary is perceived as being corrup Also a large number of laws and regulations do not addres today's needs, in spite of the reforms undertaken and the revision of many texts.

Goals

1. There will be widespread reform of the judicial system to ensure equity, fairness and due process.

2. Trials will be transparent, fair and rapid.

3. Legislation will address the needs of rapid development and will facilitate a well functioning society.

4. The United Nations' Human Rights Charter will be respected.

5. No prisoner will be detained in jail for more than one year without a sentence ( 30 days for minor offences).

6. Humane living conditions in accord with the standards monitored by the International Red Cross will be guaranteed in all prisons.

Strategies

1. Establish the credibility and the independence of judge by ensuring their integrity.

2. Increase the transparency, accountability, and effectiveness of the legal system, and reform laws.

3. Distinguish effectively between big and minor cases, and develop fast track procedures for minor offences.

4. Improve living conditions in prisons.

5. Develop an educational rehabilitation system as an alternative to prison for child and adolescent offenders.

\section{PRIORITY PROJECTS AND ACTIVITIES}

PROJECT LEADER

1. Enhance penalties for corruption by members of the judiciary

Minister responsible for Justice

2. Continue the reform of laws, establish simplified court procedures to ensure the transparency and the rapidity of trials

3. Continue the catching up program of pending cases Minister responsible for Justice

\section{Review laws and regulations by an independent committee including EDBM}

Minister responsible for Justice

Strengthen the observation, the monitoring and the protection of human rights by Minister responsible for Justice the nationat commission and the Ombudsman

6. Change laws so that detainees do not spend more than one year without trial in prison Minister responsible for Justice for minor offences)

7. Enhance funding to improve medical and hygiene conditions in prisons and establish efficient penal camps to ensure sufficient nutrition for prisoners

8. Create educational and rehabilitation system for child/adolescent offenders

Minister responsible for Justice Minister responsible for Justice

\section{INDICATORS}

2005

2012

Rule of Law indicator released yearly by the World Bank (on a basis of 100 )

45

Trial timeliness (on a basis of 100 )

Share of judiciary annual budget in the total budget

100

$1.2 \%$

Ratio convicted vs prisoners waiting trial

Assessment of the conditions in prisons by the International Red Cross

$33 / 67$

Public satisfaction with Judicial System 


\section{crankenes. \\ REDUCE CORRUPTION}

\section{Current Reality}

In 2003, the High Council Against Corruption (CSLCC)

now the Committee for the Safeguard of Integrity (CSI),

and the Independent Bureau Against Corruption (BIANCO)

were established. They have been actively pursuing their

The trend of the perception of corruption by Transparency

International has improved from 1.7 in 2003 to 2.8 in 2005

International has inproved from 1.7 in 2003 to 2.8 in 2005

and national institutions.

Goals

Corruption will be substantially reduced through a change in

values mindsets and the enforcement of the Code of Conduct.

Ve will increase the confidence of people and companies to

We will in and to

ministration

(customs, tax, land tenure) and by security forces.

Strategies

1. Shift values from the negative aspects of self interest to

values to promote community and national interest.

2. Reduce circumstances and practices favourable to corruption.

3. Enforce severe punishments for violators.

4. Raise public awareness on corruption and on good governance practices.

\section{PRIORITY PROJECTS AND ACTIVITIES}

1. Ensure the implementation of the Code of Conduct by all public servants

2. Simplify procedures and install better controlling systems for all crucial administrative functions

3. Pass new laws to strengthen watchdog roles by non-government entities and protect whistleblowers

4. Increase funding of anti-corruption institutions

PROJECT LEADER

5. Strengthen and control the asset declaration by ministers, members of Parliament, magistrates, general secretaries, chefs de regions, chefs de districts, mayors, directors

of projects and other senior officials

6. Train authorities for improved efficiency, integrity and accountability

Minister responsible for Civil Service

\section{INDICATORS}

2005

Corruption perception index of Transparency International

2.8

Proportion of average expenditure by households on bribery for public services.

$3.6 \%$
Minister responsible for Public Service

eneral Director of BIANCO

Minister responsible for Budget

General Director of BIANCO ister responsible for Public Service

(Source: annual survey by CSI) 


\section{CHALLENGE 4 > \\ ESTABLISH AN EFFICIENT AND EFFECTIVE GOVERNMENT BUDGETARY PROCESS}

\section{Current Reality}

In 2006, the budgetary system was simplified and coordinated with the Public Finance Management Information System (SIGFP). Activities have been undertaken to rapidly increase revenues from tax and customs. Donors have helped the country through budgetary aid and debt relief in the last three years. Still, public resources are not sufficient because of loss of revenues due to exemptions, exonerations and poor management. Spending allocation, procedures and control are partially inadequate.

Goals

1. Laws, regulations and procedures of tax and custom systems will provide sufficient revenues for quality public services.

2. Allocation of public resources will be established through negotiations among ministries, regions and communes on priorities and needs, before parliamentary decision.

3. Budget formulation and actual spending will follow good governance principles.

Strategies

1. Enforce law and regulations of tax and customs.

2. Improve the transparency and the control of public finance and of budget spending.

3. Maximize revenues from tax collection and from a rational use of national assets.

4. Reduce wastage and ensure efficient resource allocation.
PRIORITY PROJECTS AND ACTIVITIES

PROJECT LEADER

1. Complete the public finance reform to coordinate all finance systems Minister responsible for Budget

2. Increase the efficiency of all the revenue and expenditure control mechanisms and merge controlling institutions

3. Review and harmonize policies, laws and regulations on taxes, rights and royalties Minister responsible for Budget

\section{Improve the tax and royalty collection system}

5. Establish a trust fund to manage the revenues from national assets

Minister responsible for Budget

6. Put public finance information online to ensure transparency and accountability The Presidency

7. Ensure the implementation of the new Code of Public Tender The Presidency and Public Tender Regulation Authority (ARMP)

PEFA Index [Public Expenditures and Finance Accountability)

The share of voted budget devoted to social sector actually spent 


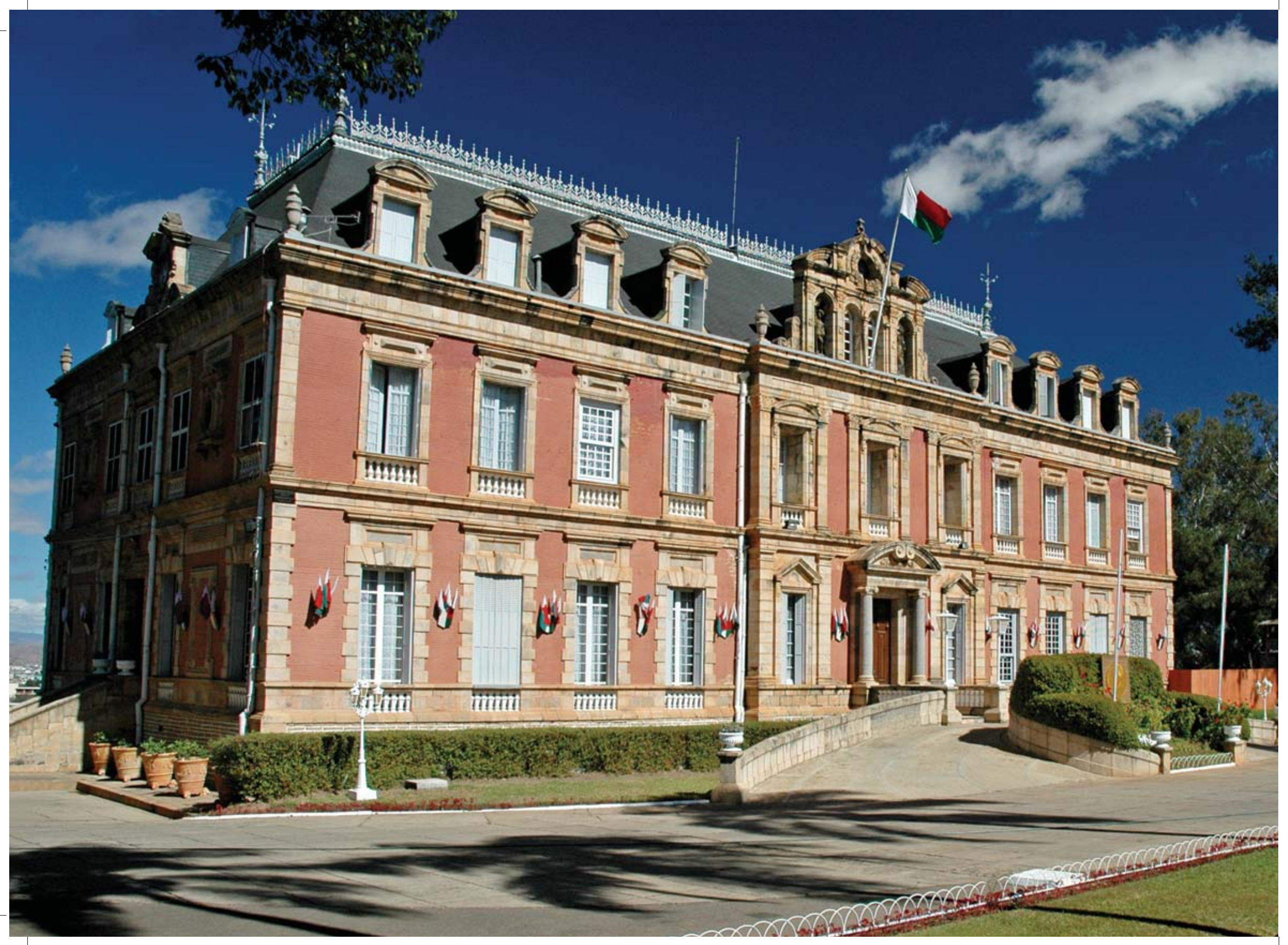




\section{Current Reality}

As of 2005, reforms have been conducted in many departments such as the customs, civil service and training institutions. The Administration Efficiency Reform Programme (PREA) has been set up to improve service delivery in many units. Processes have been streamlined to reduce paperwork especially in the decentralized administration. E-governance has started and is being mainstreamed to all services.

Still, the administration must be updated to improve timeliness, cost, proximity and professionalism in public service delivery. Goals

The administration will be professional and competent hroughout, and will consistently address people's expectations for fast, cooperative and quality service.

Strategie

Conduct a thorough reform of the public service - goals, strategy, structure, systems, staff, skills and remuneration to improve efficiency and customer service quality.

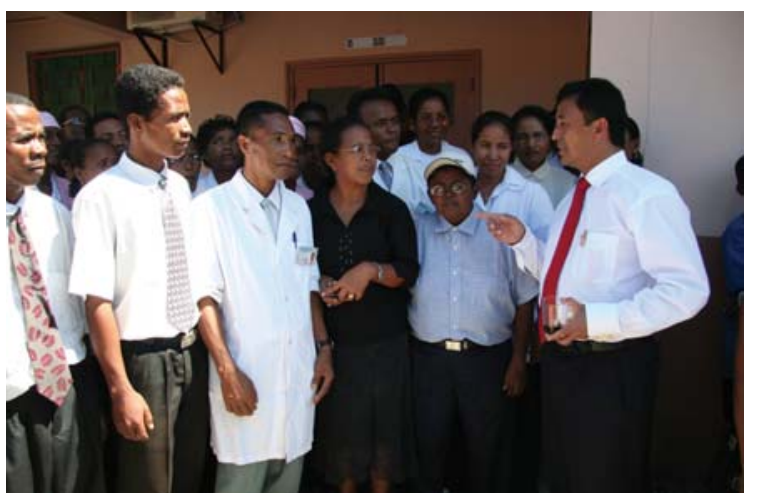

PRIORITY PROJECTS AND ACTIVITIES

PROJECT LEADER

1. Set up a performance based motivation system (salary, merit promotion,

Minister responsible for Public Service

performance appraisal, incentives and benefits)

\begin{tabular}{|c|c|}
\hline $\begin{array}{l}\text { 2. Simplify procedures for administrative functions that require swift results, } \\
\text { especially those with high public interaction }\end{array}$ & Minister responsible for Public Service \\
\hline $\begin{array}{l}\text { 3. Adopt and implement reforms related to e-services, e-administration } \\
\text { and e-participation }\end{array}$ & $\begin{array}{l}\text { The Presidency and the } \\
\text { Prime Minister's Office }\end{array}$ \\
\hline 4. Strengthen the leadership capacity of all mid to senior level executives & $\begin{array}{l}\text { The Presidency and the } \\
\text { Prime Minister's Office }\end{array}$ \\
\hline
\end{tabular}

5. Build the technical and managerial skills of all public servants

66




\section{CHALLENGE 6 > \\ DECENTRALIZE GOVERNMENT ADMINISTRATION}

\section{Current Reality}

With the creation of the 22 new Regions in 2004, political decision-making, development planning and administration have come closer to the people. Several laws have been passed to strengthen Communes and Regions. Administrators have also received training and support. Still, as of 2006 , policy making and administration remain excessively concentrated in the central government.

Goals

Communes and Regions will have enough authority and resources to address local and regional needs. They will be strong players in a participatory bottom-up process. The Regions will have Territorial Plans that will contribute to prioritizing growth areas and allocation of resources amongst sectors.

Strategies

1. Strengthen Regional Development Plans to ensure that they are based on sound analysis of the current realities, needs and potentials of the Region.

2. Improve the capacity of Regions and Communes to productively address all local and regional matters.

3. Improve the political and legal position of Regions and Communes in problem solving, decision-making and execution.

\section{PRIORITY PROJECTS AND ACTIVITIES}

1. Review all laws and regulations to transfer more power and responsibility to the Communes

PROJECT LEADER

and Regions

2. Update Regional Development Plans through Territorial Planning, including imaging and spatial analysis using cartographic tools to identify economic potentials

3. Pass laws and reforms to give Communes and Regions more tax revenues and the right of tax collection

Minister responsible for Decentralization

4. Develop and strengthen the Local Development Fund to improve the management of the resources and the funding of Communes

5. Create a forum and develop training programs to support Chefs de Region, Minister responsible for Territory Planning

Minister responsible or Decentralization Minister responsible

6. Foster the democratic control and the involvement of beneficiaries in the governance of local public institutions

INDICATORS

Public spending by Communes in \% of total public budget 


\section{CHALLENGE 7 > \\ BECOME A LEARNING NATION}

\section{Current Reality}

Madagascar has gone through decades of colonialism and socialism. Since 2002, the country has opened up significantly to the global environment - participating in international forums, students studying abroad, sourcing expertise from overseas, and study missions to learn international frest practice. Still, given the threats and opportunities that probalization presents, more people must be active partipant in the learning process to ensure Madagascar particip fre lively with any challenge that it must confront in orde o develop.

Goals

Madagascar will be a learning nation. Knowledge will be actively pursued locally and abroad in order to support the rapid development process.

Strategies

1. Create learning networks throughout the country to improve public problem solving and sharing.

2. Send missions abroad and call for international expertise to study and implement best practices on specific issues

3. Develop mechanisms for citizen training and

participation in the governance of their local, regional and national communities.

\section{PRIORITY PROJECTS AND ACTIVITIES}

PROJECT LEADER

1. Identify best practice success stories within Madagascar and promote key

National Leadership Institute

\section{Identify and learn from national and international best practices in all areas of} government and communities

The Presidency and
Prime Minister's Dffice

3. Actively encourage the values of experimentation, risk-taking and action learning

National Leadership Institute

4. Generate forums for sharing information, engaging in dialogue and contributing to the formulation of policy

5. Promote learning and engagement of youth in public problem solving National Leadership Institute and

6. Encourage and promote learning practices throughout the country that include

Encourage and promote learning practice
active citizen participation and dialogue Minister responsible

\section{INDICATORS}

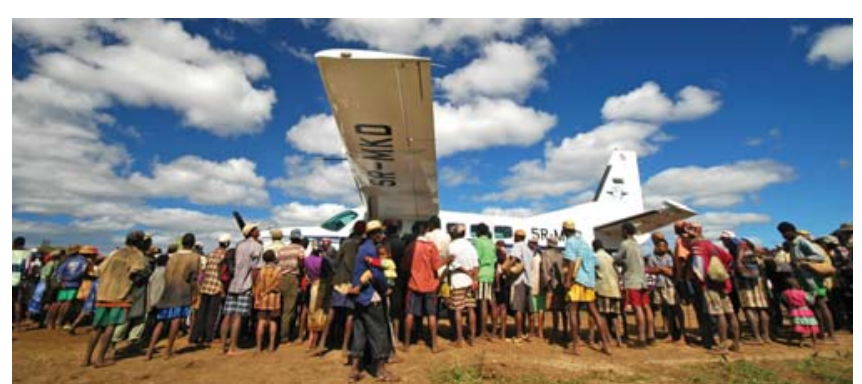




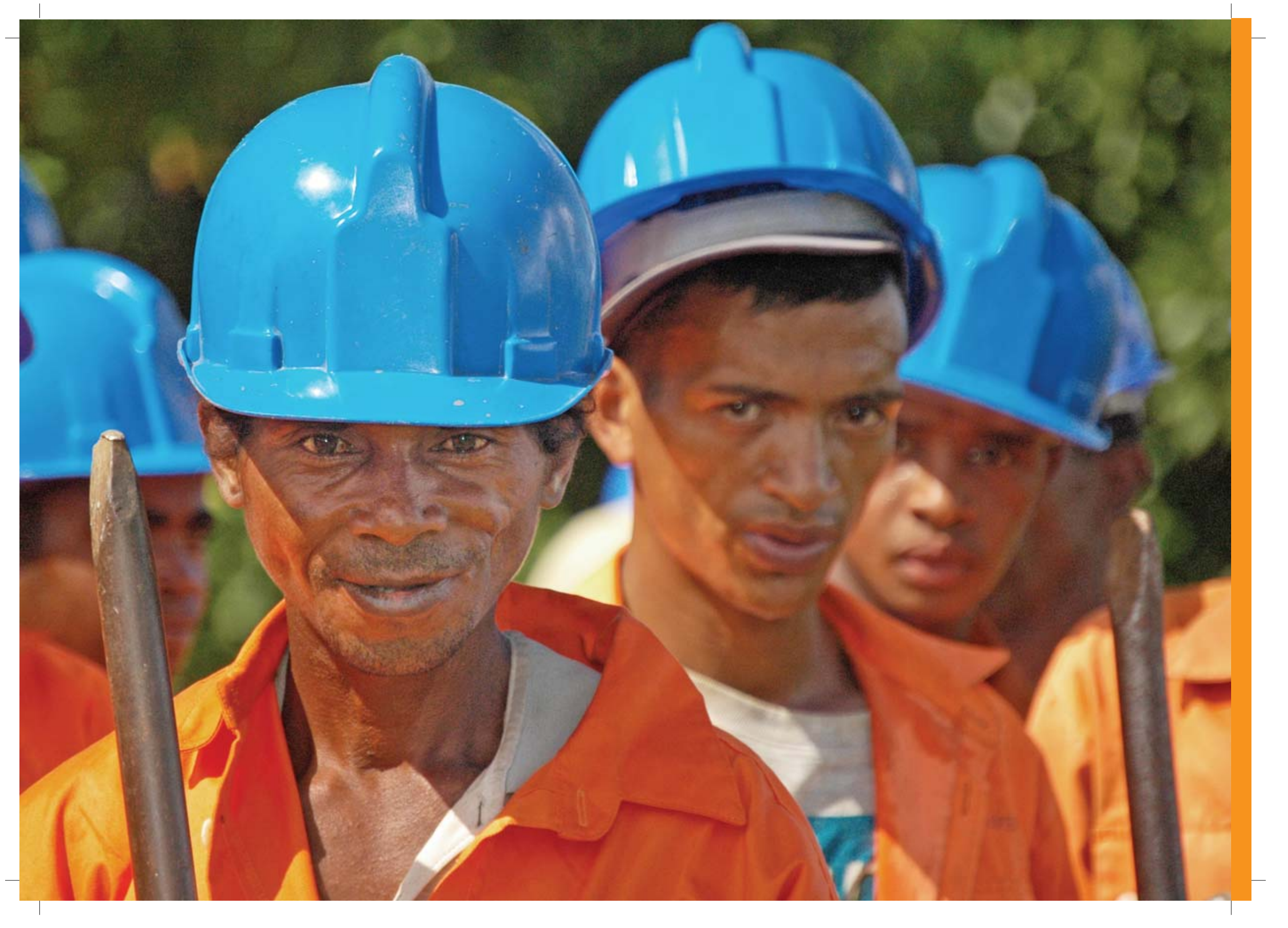




\section{COMMITMENT TWO CONNECTED INFRASTRUCTURE}

We will be a connected nation. We will build quality roads, railroads, ports, airports, and information technology systems all across the country to enable the process of rapid development, the facilitation of business and trade, communication amongst our citizens and visitors, and to ensure that the standard of living and the access to resources and global knowledge improves for all. 


\section{CHALLENGE 1 > \\ PRIORITIZE INFRASTRUCTURE DEVELOPMENT FOR KEY GROWTH AREAS}

Current Reality

Road building and rehabilitation has been a major activity since 2002. In 2005 alone, $8,982 \mathrm{~km}$ of roads were rehabilitated or maintained. There has been progress in railway, ports an airports but most activity has been limited to rehabilitation of existing infrastructure. Now we need to ensure long ter strategic infrastructure planning is linked to key areas of projected economic projected needs to be faster to readjust funding priorities in light of changing circumstances and there needs to be in light of changing cith the private sector. The emp to be a loser be not just on building new roeds but also maintaing should be not the proper maintenance of infrastructure.

Goals

1. Ensure that all key growth areas will have good access to the transport network.

2. Define clear infrastructure priorities with regard to full economic return on investment - transport will be treated as an investment rather than a cost.

3. Provide active assistance to high growth industries to access necessary infrastructure quickly and with minimal bureaucracy.

4. Involve the private sector as partners in strategic planning and development, especially for high growth areas.

5. Improve capacity and quality of companies, in construction and operation.

6. Promote private-public sector partnerships.

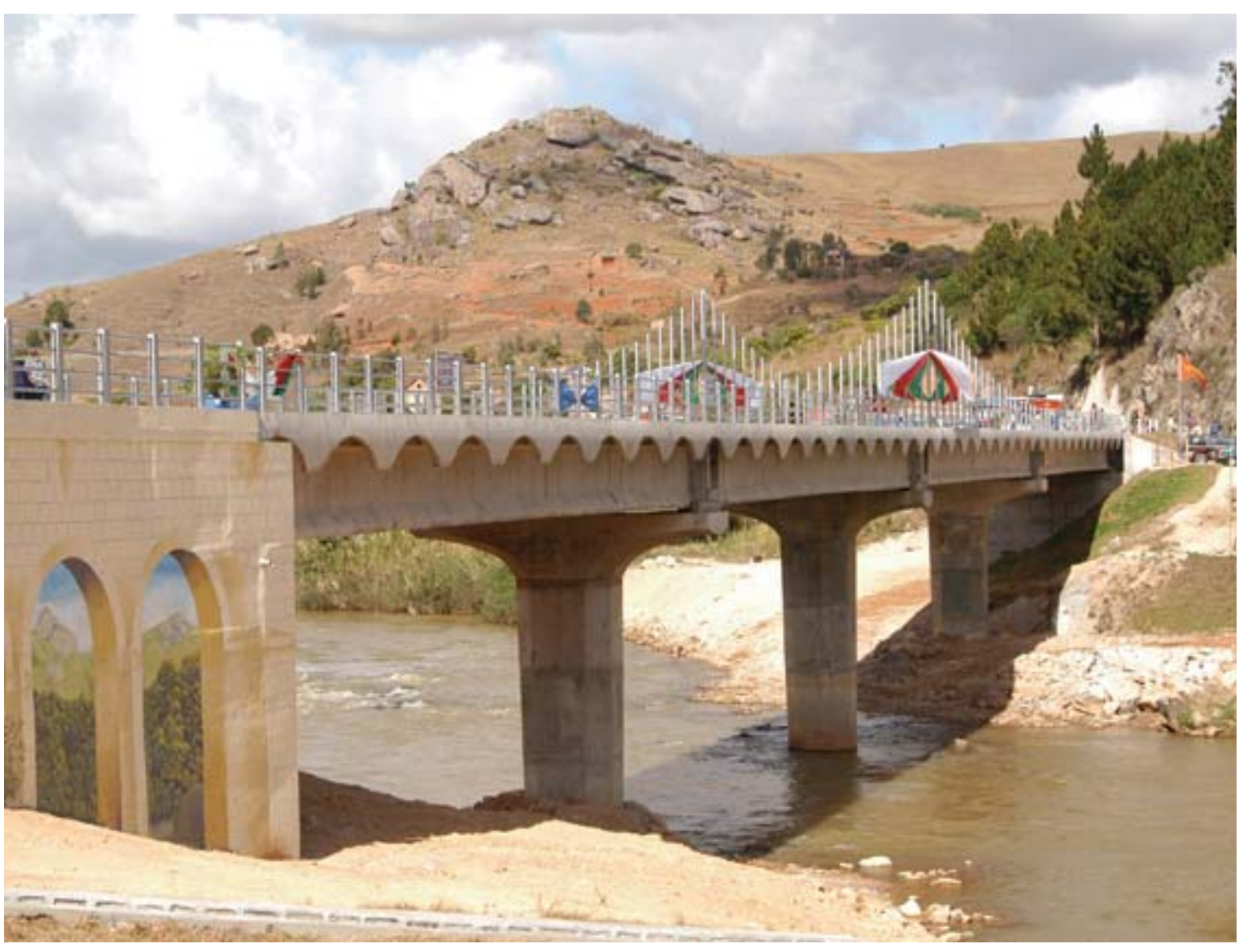


Strategies

1. Formulate and implement a strategic national infrastructure development program which can flexibly respond to fast changing global and national needs.

2. Develop and upgrade key transport interfaces (eg. Toamasina Port and Ivato airport) surrounding economic development zones and ensure regional development needs are addressed.

3. Prioritize development of transport and infrastructure networks and corridors linked to economic growth engines including tourism, mining and agriculture.

4. Reform the Ministry and agencies to shift from a "regulatory" to an "enabling" organization which is use focused and a sponsor of business investment and economic growth.

5. Ensure funding priorities reflect the full economic and efficiency return to the nation.

6. Increase capacity to build infrastructure by attracting high quality international firms to complete major projects and provide skill transfer and training.

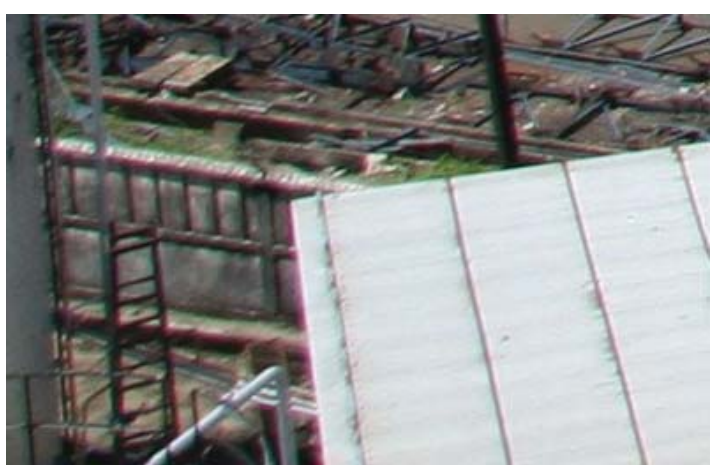

\section{PRIORITY PROJECTS AND ACTIVITIES}

PROJECT LEADER

1. Formulate and implement a strategic national infrastructure development program based on supporting a high growth economy

2. Upgrade existing port facilities, including major extension of Toamasina Port to accommodate large capacity vessels

Minister responsible for Transport and Public Works

3. Establish a National Transport Council of key private sector CEOs and chaired by the Minister to provide strategic direction on major infrastructure issues

4. Create a new international airport with integrated industrial and warehousing zone and develop other key international airports in other regions with economic growth and tourism potential

5. Complete upgrade and maintenance of the Fianarantsoa to Coast (FCE) and Northern Rail Line to facilitate trade and tourism

6. Build a transport network to connect all key growth areas with necessary infrastructure

7. Establish a new area in the Ministry specifically focused on supporting major investments and work with EDBM to support existing and emerging economic development zones

Minister responsible for Transport and Public Works Minister responsible for Transport and Public Works

Minister responsible for Transport and Public Works Minister responsible for Transport and Public Works Minister responsible for Transport and Public Works

Minister responsible for Transport and Public Works

\begin{tabular}{lll}
\hline INDICATORS & $\mathbf{2 0 0 5}$ & $\mathbf{2 0 1 2}$ \\
\hline Infrastructure sector growth rate & To be developed & To be developed \\
\hline Port and Airport handling Costs & To be developed & To be developed \\
\hline Port and Airport capacity & To be developed & To be developed \\
\hline
\end{tabular}



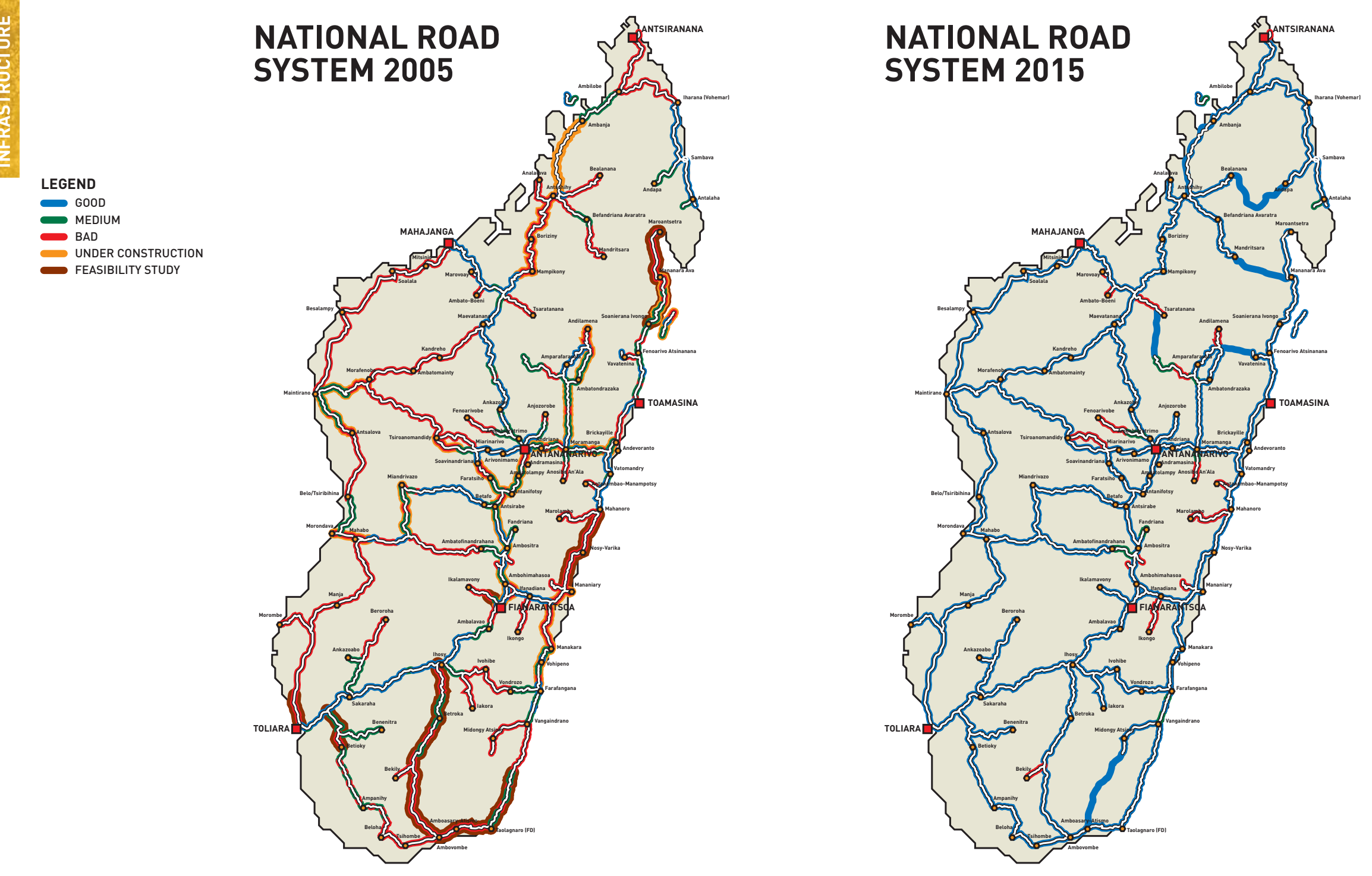

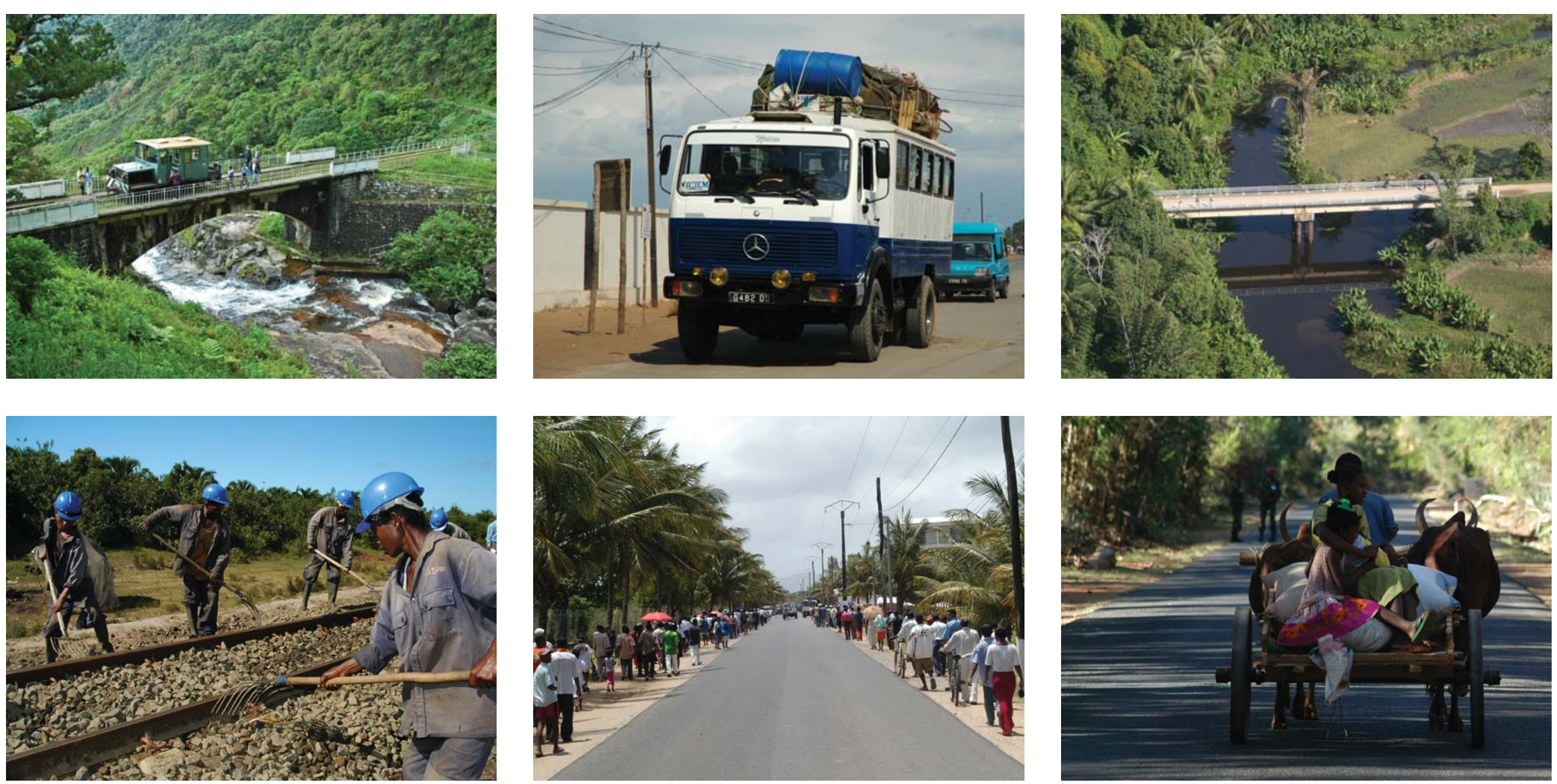


\section{CHALLENGE 2 > \\ EFFICIENTLY MOVE GOODS AND PEOPLE FROM ONE PLACE TO ANOTHER}

Current Reality

The development of the transport network in Madagascar has improved dramatically in the past few years with a significant focus on construction of rural roads and key majo routes. Still, planning needs to be better focused on developing a transport "network" with major transport corridors. More needs to be done to integrate all means of transport into the needs to be done to integrace artly improve multimodal national syste.s andy chain manamement practices are undeveloped and can be improved by better information and communication throughout the chain.

Goals

1. A culture of supply chain management throughout the industry will exist which actively seeks continuous the incing will exist which active

2. There will be a thriving competitive environment for transport services which has a reputation for reliability and service.

3. We will efficiently move goods and people rather than just the physical infrastructure.

4. We will have a sustainable transport system keenly aware of its social, environmental and economic impact.
Strategies

1. Transition to a supply chain and integrated logistics approach which is responsive to changing demands.

2. Increase competition to provide affordable transport both within and between modes of transport.

3. Develop a national and global reputation for reliability and service.

4. Address inefficient subsidies.

5. Develop solutions for improved economic and environmental impact through reducing congestion and inefficiencies.

6. Facilitate an Open Skies policy that increases the number of destinations, encourages competition and reduces the cost of air transport.

7. Establish a training system for project management, logistic and supply chain management, and infrastructure construction and operation.

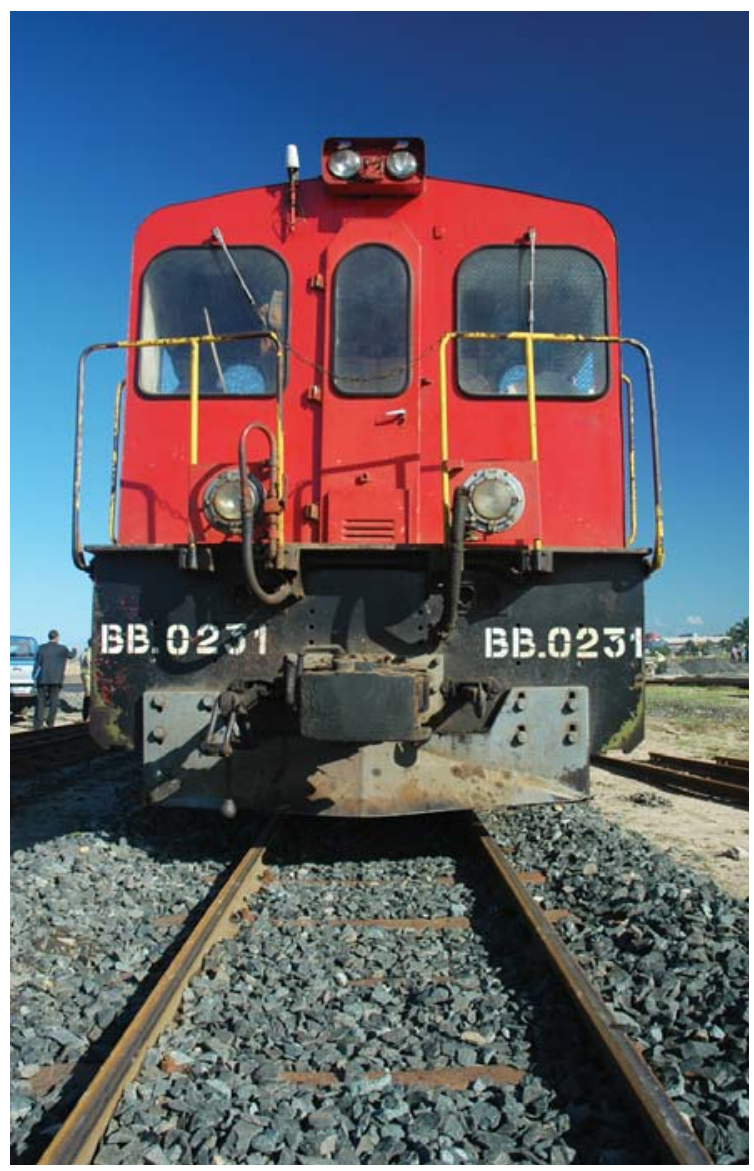




\begin{tabular}{|c|c|}
\hline PRIORITY PROJECTS AND ACTIVITIES & PROJECT LEADER \\
\hline $\begin{array}{l}\text { 1. Completion of key transport corridors which constitute } \\
\text { the backbone of the national system including: } \\
\text { - North-East corridor from Toamasina to Maroantsetra } \\
\text { - North corridor from Diego to Antananarivo } \\
\text { - South-East corridor from Fianarantsoa to Fort Dauphin } \\
\text { - South corridor from Ihosy to Fort Dauphin } \\
\text { - South corridor from Antsiranana to Fort Dauphin } \\
\text { - West corridor from Morondava to Antananarivo }\end{array}$ & $\begin{array}{l}\text { Minister responsible for } \\
\text { Transport and Public Works }\end{array}$ \\
\hline $\begin{array}{l}\text { 2. Rehabilitate the internal canal to make it navigable for } \\
\text { trade and transport including dredging as required }\end{array}$ & $\begin{array}{l}\text { Minister responsible for } \\
\text { Transport and Public Works }\end{array}$ \\
\hline $\begin{array}{l}\text { 3. Review all subsidies with a view to eliminating them } \\
\text { unless strong justification can be provided }\end{array}$ & $\begin{array}{l}\text { Minister responsible for } \\
\text { Transport and Public Works }\end{array}$ \\
\hline $\begin{array}{l}\text { 4. Eliminate all obstacles to full Open Skies policy as soon } \\
\text { as possible }\end{array}$ & $\begin{array}{l}\text { Minister responsible for } \\
\text { Transport and Public Works }\end{array}$ \\
\hline $\begin{array}{l}\text { 5. Improve multimode infrastructure (bus stations, railway } \\
\text { stations, airports, ports) }\end{array}$ & $\begin{array}{l}\text { Minister responsible for } \\
\text { Transport and Public Works }\end{array}$ \\
\hline $\begin{array}{l}\text { 6. Improving safety through education and putting } \\
\text { into operation the National Program for Safety and } \\
\text { Transportation (Programme National de Sécurité et } \\
\text { de Transports) }\end{array}$ & $\begin{array}{l}\text { Minister responsible for } \\
\text { Transport and Public Works }\end{array}$ \\
\hline
\end{tabular}

\begin{tabular}{|lll|}
\hline INDICATORS & $\mathbf{2 0 0 5}$ & $\mathbf{2 0 1 2}$ \\
\hline New or rehabilitated national roads & $805 \mathrm{Km}$ & $7,800 \mathrm{Km}$ \\
\hline New or rehabilitated rural roads & $977 \mathrm{Km}$ & $12,000 \mathrm{Km}$ \\
\hline Regularly maintained national roads & $5,700 \mathrm{Km}$ & $12,000 \mathrm{Km}$ \\
\hline Regularly maintained rural/gravel roads & $1,300 \mathrm{Km}$ & $18,000 \mathrm{Km}$ \\
\hline $\begin{array}{l}\text { Rates of satisfaction of the users in terms } \\
\text { of quality of services per means of } \\
\text { transport (comfort criteria, safety, time, } \\
\text { regularity v/s cost) }\end{array}$ & $\begin{array}{l}\text { Travellers: } \\
\text { Trade : 55\% } \%\end{array}$ & $\begin{array}{l}\text { Travellers: } \\
\text { Trade : } 80 \%\end{array}$ \\
\hline
\end{tabular}

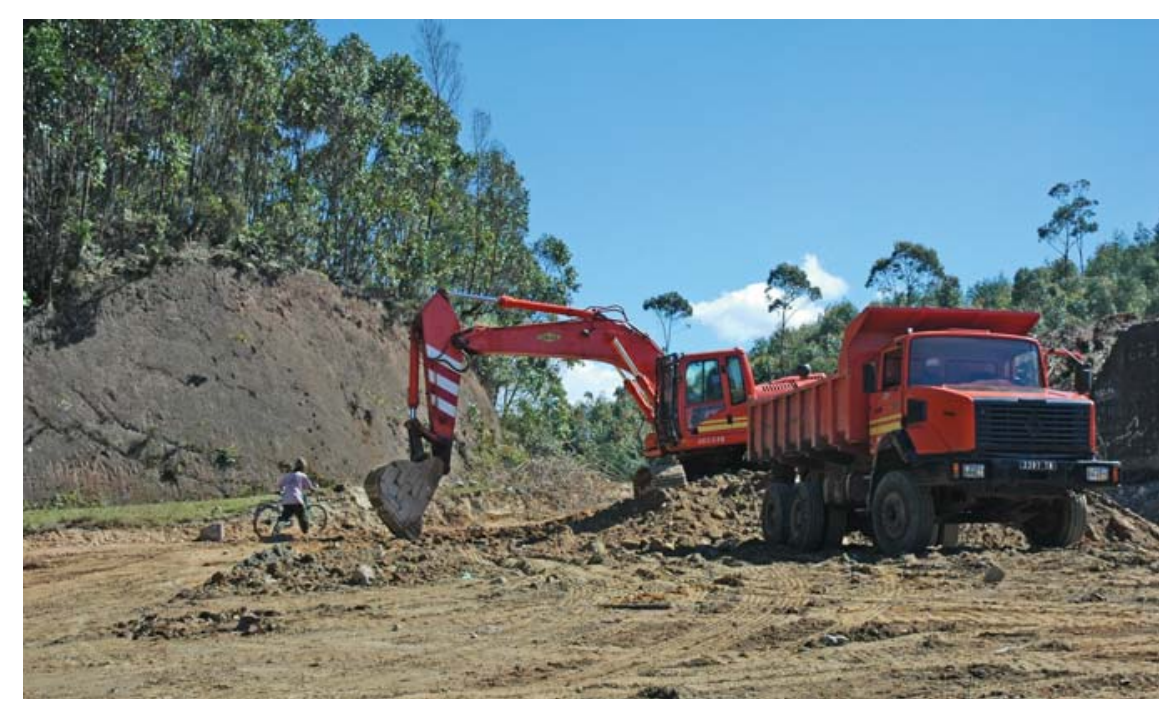




\section{CHALLENGE 3 > \\ IMPROVE ACCESS TO TRANSPORT SERVICES NATIONWIDE}

Current Reality

Access to transport services has been a major activity over the past three years. Maintenance needs to be given a highe priority as there are large losses of existing infrastructure, especially roads, each year. Many communities are still remote and ways of connecting them to the national infrastructure need to be actively pursued, includin alternative technologies. The number of isolated areas in Madagascar fell from $59 \%$ in 2003 to $33 \%$ in 2005 . Only about 600 of the 1,557 communes have access to regular transport (i.e. 10-12 months of the year). This has a flow on effect to most parts of the economy and a direct impact on poverty in the regions.

Goals

1. There will be an effective high quality national transport network for both urban and rural areas.

2. Expand maintenance programs with emphasis on maximizing the total volume of usable infrastructure.

3. We will seriously explore opportunities for alternative forms of transport as a way of connecting remote areas.

4. There will be an increase use of local materials and human resources and the provision of training.

Strategies

1. Manage existing infrastructure as a national asset which requires maintenance and investment.

2. Rehabilitation of key transport corridors and infrastructure which have fallen into disrepair including canals and remote airstrips.

3. Investigate alternative transport technologies for linking remote areas.

4. Encourage alternative forms of transport which use lowcost energy or energy produced locally.

5. Develop technologies and practices that use local materials, labor and competencies.

\begin{tabular}{|c|c|}
\hline PRIORITY PROJECTS AND ACTIVITIES & PROJECT LEADER \\
\hline $\begin{array}{l}\text { 1. Formulate and implement a strategic national infrastructure development program based } \\
\text { on supporting a high growth economy }\end{array}$ & $\begin{array}{l}\text { Minister responsible for } \\
\text { Transport and Public Works }\end{array}$ \\
\hline 2. Commence rehabilitation of remote airstrips to form a network in isolated rural areas & $\begin{array}{l}\text { Minister responsible for } \\
\text { Transport and Public Works }\end{array}$ \\
\hline $\begin{array}{l}\text { 3. Expand training opportunities to increase the capacity of the transport sector to operate } \\
\text { efficiently and profitably }\end{array}$ & $\begin{array}{l}\text { Minister responsible for } \\
\text { Transport and Public Works }\end{array}$ \\
\hline 4. Explore and expand alternative transport systems to link remote areas & $\begin{array}{l}\text { Minister responsible for } \\
\text { Transport and Public Works }\end{array}$ \\
\hline 5. Construct new major road axes which can operate sustainably and profitably & $\begin{array}{l}\text { Minister responsible for } \\
\text { Transport and Public Works }\end{array}$ \\
\hline
\end{tabular}

\begin{tabular}{|c|c|c|}
\hline INDICATORS & 2005 & 2012 \\
\hline $\begin{array}{l}\text { Percentage of communes with accessibility to all-season road all year } \\
\text { long (base 1,557 communes) }\end{array}$ & $\begin{array}{l}35 \% \\
\text { (i.e. } 500 \text { communes) }\end{array}$ & $\begin{array}{l}64 \% \\
\text { (i.e. } 1,000 \text { communes) }\end{array}$ \\
\hline Cost of transport services as a percentage of household expenditure & To be determined & To be determined \\
\hline
\end{tabular}

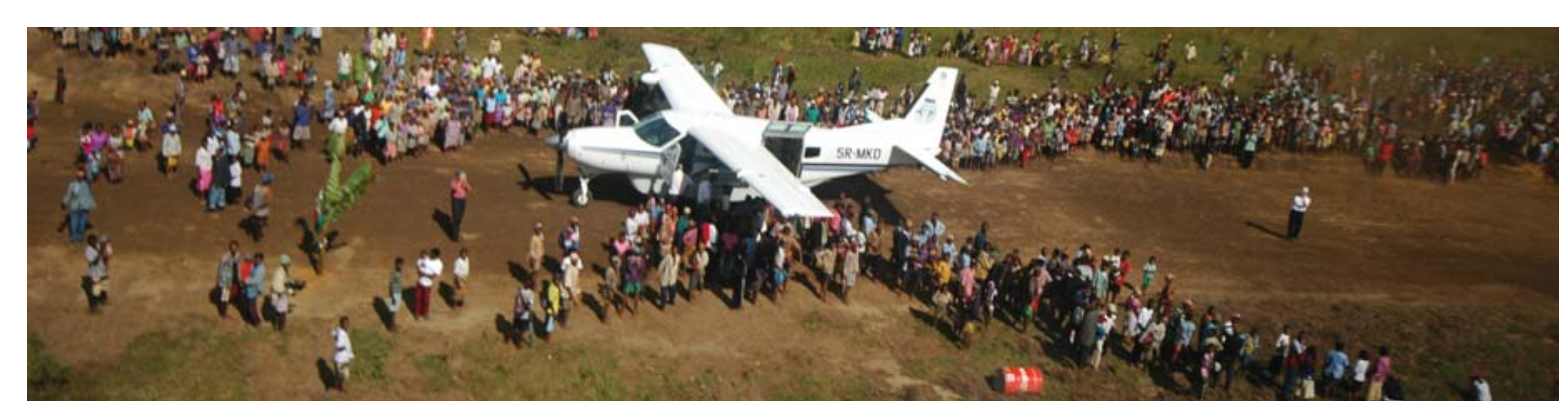




\section{CHALLENGE 4 > \\ ENSURE ACCESSIBLE AND ADEQUATE ENERGY SUPPLY AT AFFORDABLE AND COMPETITIVE COST}

\section{Current Reality}

While reliability and coverage of electricity has increased over the past four years, the national coverage rate is still only around $15 \%$ with access in rural areas lower than $5 \%$ As a net importer of oil, the sector remains vulnerable to external oil pricing fluctuations with the price of oil havin more than doubled between 2001 and 2005. Simultaneously, exteris pore por power generation in 1997 but rose to $35 \%$ by 2004 .

As of 2006, the national energy company JIRAMA has not been structured to meet the increasing demand for energy required for the high growth economy. This is due to lack of finance, old equipment and machinery, and an inadequate management system; significant reforms however are underway. JIRAMA has announced that throughout 2007, all the major power consumption centers will be equipped with new power stations which will meet the anticipated demand growth for the next 3 to 5 years.

Groals

1. All urban and rural areas will have access to a reliable, sustainable and affordable electricity supply including increased urban coverage of $74 \%$ by 2011 and rura coverage of $10 \%$ by 2011 .

2. We will have competition in the electricity sector and the development of Public Private Partnerships.

3. There will be sufficient supply to meet all new connections especially for high growth investments.

4. We will have an increased use of alternative and/or renewable energy sources including hydro, solar, wind, wave, coal, gas and bio energies to reduce dependence on oil products.

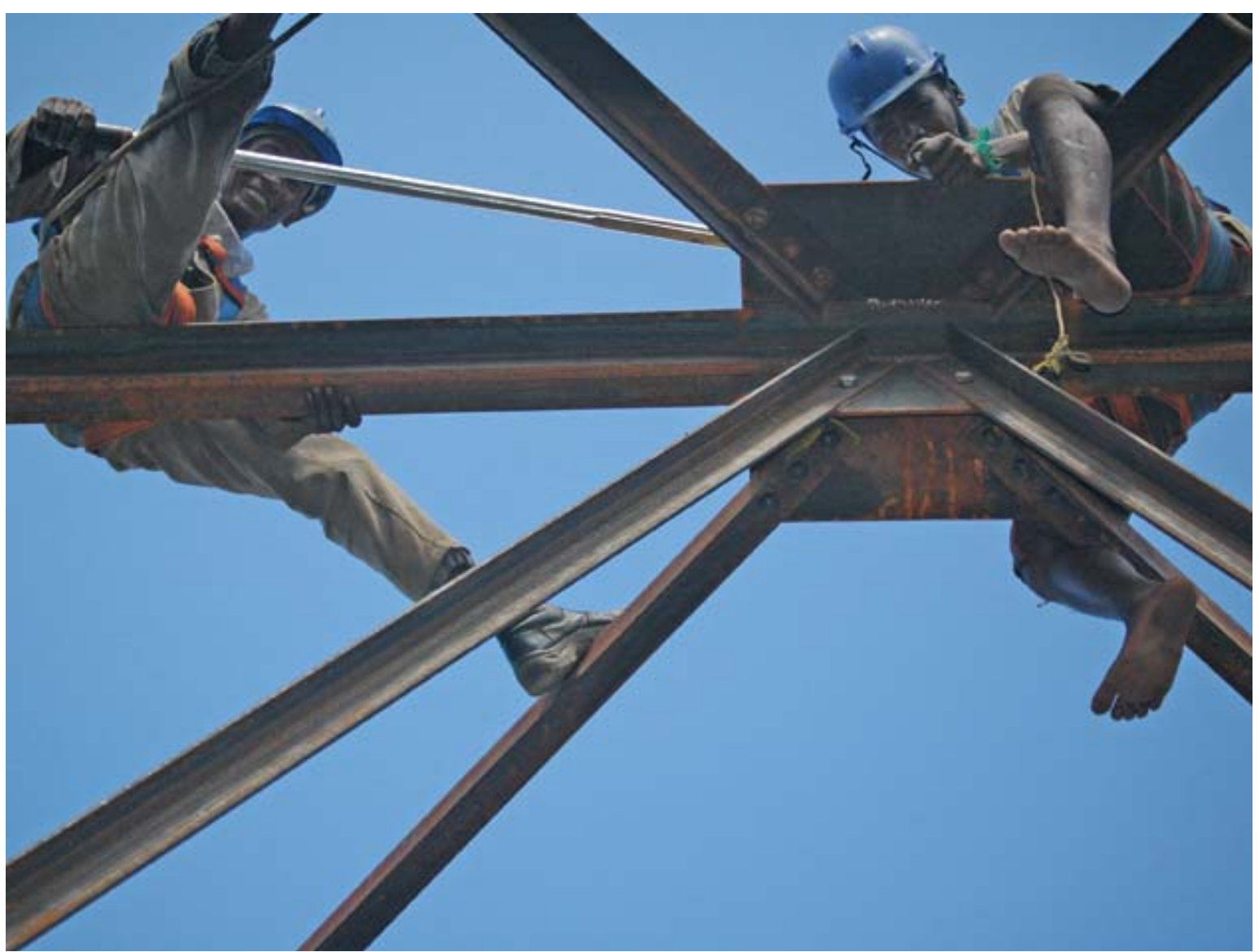




\section{CHALLENGE 4 > ENSURE ACCESSIBLE AND ADEQUATE ENERGY SUPPLY AT AFFORDABLE AND COMPETITIVE COST (CONTINUED)}

Strategies

1. Formulate and implement a strategic national energy development plan which can flexibly respond to

changing demands.

2. Seriously explore the possibility of Independent Power Producer (IPP) investment to dramatically lower the cost of electricity generation.

3. Restructure and reform JIRAMA.

4. Rehabilitate and introduce new generator capacity.

5. Prioritise electricity supply to key industrial estates and high economic growth engines including tourism, mining and agriculture.

6. Explore alternative sources of energy production especially focused on using local resources such as hydroelectricity.

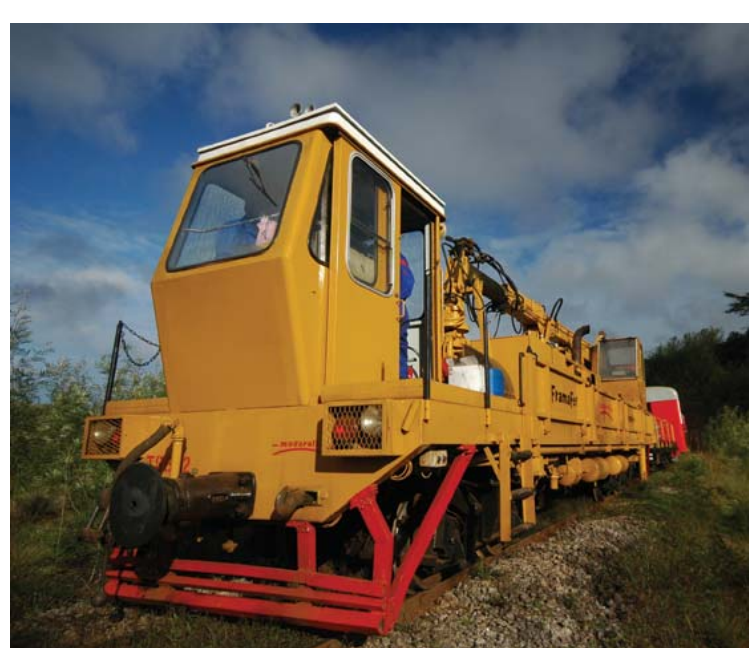

\section{PRIORITY PROJECTS AND ACTIVITIES}

1. Restructure JIRAMA to become a reliable and efficient producer and distributor of energy

PROJECT LEADER

. Increase the capacity of electricity production through

- new thermal generator using oil with $40 \mathrm{M}$

- a third generator in Andekaleka

3. Set up Independent Power Producers:

- new thermal generator using Fuel oil with 80 MW

4. Extend access to electricity in rural, semi urban area and high economic growth areas

5. Reduce the negative environmental effects on forestry resources, especially the use of the charcoal

6. Promote and use alternative and/or renewable sources of energy (eg: jatropha, ethanol)

\begin{tabular}{lll} 
INDICATORS & $\mathbf{2 0 0 5}$ & $\mathbf{2 0 1 2}$ \\
\hline Ratio of hydro energy production & $64 \%$ & $76 \%$ \\
\hline Electricity coverage of communes & $4 \%$ & $10 \%$ \\
\hline Composite index on energy price trends & To be determined & To be determined \\
Ratio of energy production through renewable sources (other than hydro) & $0 \%$ & $3 \%$ \\
\hline Average households expenditure on energy & To be determined & To be determined \\
Energy unit price (kwh) to business & To be determined & To be determined \\
\hline
\end{tabular}

Minister responsible for Energy

\section{Minister responsible for Energy}

Minister responsible for Energy

Minister responsible for Energy

Minister responsible for Energy

Minister responsible for Energy 


\section{. \\ ENSURE EFFICIENT AND AFFORDABLE COMMUNICATION SYSTEM}

\section{Current Reality}

2003-2005 saw strong growth in the number of users of fixed and mobile telephones, an expansion of the

telecommunications network, significant growth in the use of the internet and access to financial postal services. Nevertheless, the nation needs reliable international connections, at an affordable price to develop the economy and achieve regional integration. In 2005 , only $8 \%$ of

communes were connected by telephone and internet services. Moreover, the majority of those connections were via satellite with inadequate capacity and high costs. Also in 2005 , only $23 \%$ of com covered by the mail service.

Goals

1. We ensure that all urban and rural areas are covered by a reliable, accessible, affordable communication system.

2. Businesses will be able to communicate throughout the country.

3. Information flow to the regions through better access to radio and TV services.

4. We will promote partnerships with the private sector to provide new and better infrastructure.

Strategies

1. Reduce high cost of mobile phone and international calls. . Increase competition between mobile operators.

3. Develop wider access to ITC

(Information - Technology - Communications)

4. Implement a national information technology action plan.

5. Expand phone coverage throughout the nation.

6. Expand postal coverage throughout the nation, including financial services.

7. Improve TV and radio media coverage.

\section{PRIORITY PROJECTS AND ACTIVITIES}

PROJECT LEADER

1. Connect Madagascar into an international optical fibre network

Minister responsible for Telecommunications

2. Develop access to telecommunications services including ITC and Internet

3. Set up a national backbone system that includes fibre optic network associate with major infrastructure projects (eg. roads)

4. Create new ITC centers in each region (technopoles)

Minister responsible for Telecommunications

Minister responsible for Telecommunications

5. Improve the system of distribution and the flow of dispatching of postal services

Minister responsible for Telecommunications

6. Modernize the radio and television infrastructure and services based on Minister responsible for Telecommunications

7. Liberalize the telecommunication sector

Minister responsible for Telecommunications

8. Implement Voice over IP for all Minister responsible for Telecommunications

9. Replace the national regulator OMERT by a new regulator ARTEC Minister responsible for Telecommunications

\begin{tabular}{|lll|}
\hline INDICATORS & $\mathbf{2 0 0 5}$ & $\mathbf{2 0 1 2}$ \\
\hline Percentage of population with mobile phones & To be determined & To be determined \\
\hline Ratio of coverage in communes of quality postal services (public and private) & $39 \%$ & $65 \%$ \\
\hline $\begin{array}{l}\text { Ratio of coverage of communes with access to radio and television broadcast } \\
\text { and services }\end{array}$ & $\begin{array}{l}\text { TV : 23\% } \\
\text { FM Radio : 28\% }\end{array}$ & $\begin{array}{l}\text { TV: 70\% } \\
\text { FM Radio: 70\% }\end{array}$ \\
\hline \begin{tabular}{l} 
Composite Index of connection cost (index base 2005=100) \\
\hline
\end{tabular} & 100 & 70 \\
\hline
\end{tabular}




\section{CHALLENGE 6 > \\ BETTER WEATHER FORECASTING - AND WARNINGS OF POTENTIAL DISASTERS SUCH AS CYCLONES}

Current Reality

Madagascar is frequently hit by cyclones, storms and

heavy rains which cause damage to villages, infrastructure

and crops. The weather forecasting system needs to improve

its reliability, accuracy, access and timeliness to

minimize damage.

Goals

1. Weather forecast will be timely and more accurate.

2. Awareness, access and distribution of reliable and relevant information on weather forecasts across the nation will be improved.

Strategies

1. Expand and modernize the national weather observation network.

2. Establish a national weather forecast information system and extend weather forecasts to regions.

3. Promote regional and international cooperation on meteorological issues, especially major events such as cyclones.

4. Provide specialised services for industries such as agribusiness.

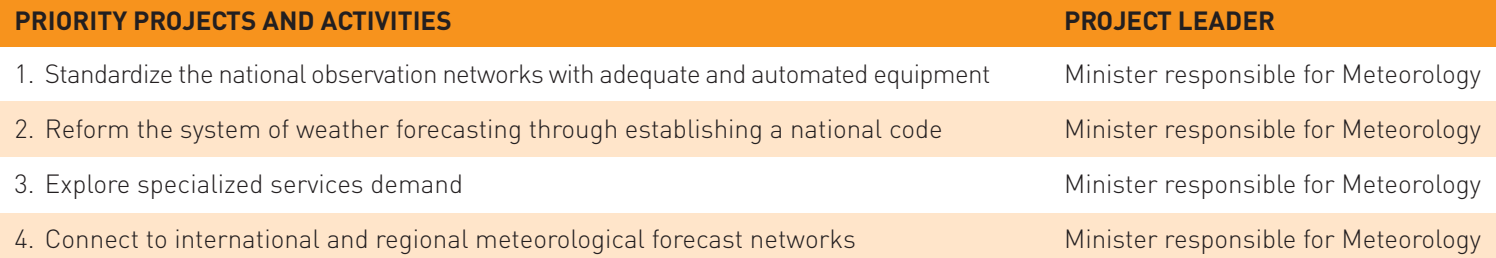

1. Standardize the national observation networks with adequate and automated equipment

Minister responsible for Meteorology

2. Reform the system of weather forecasting through establishing a national code Minister responsible for Meteorology

3. Explore specialized services demand Minister responsible for Meteorology

4. Connect to international and regional meteorological forecast networks Minister responsible for Meteorology

\begin{tabular}{lll}
\hline INDICATORS & $\mathbf{2 0 0 5}$ & $\mathbf{2 0 1 2}$ \\
\hline Main user satisfaction ratio & 25 & 80 \\
\hline Reliability of forecasts & Low & High \\
\hline Number of operational weather stations (index base $2005=100$ ) & 100 & 300
\end{tabular}

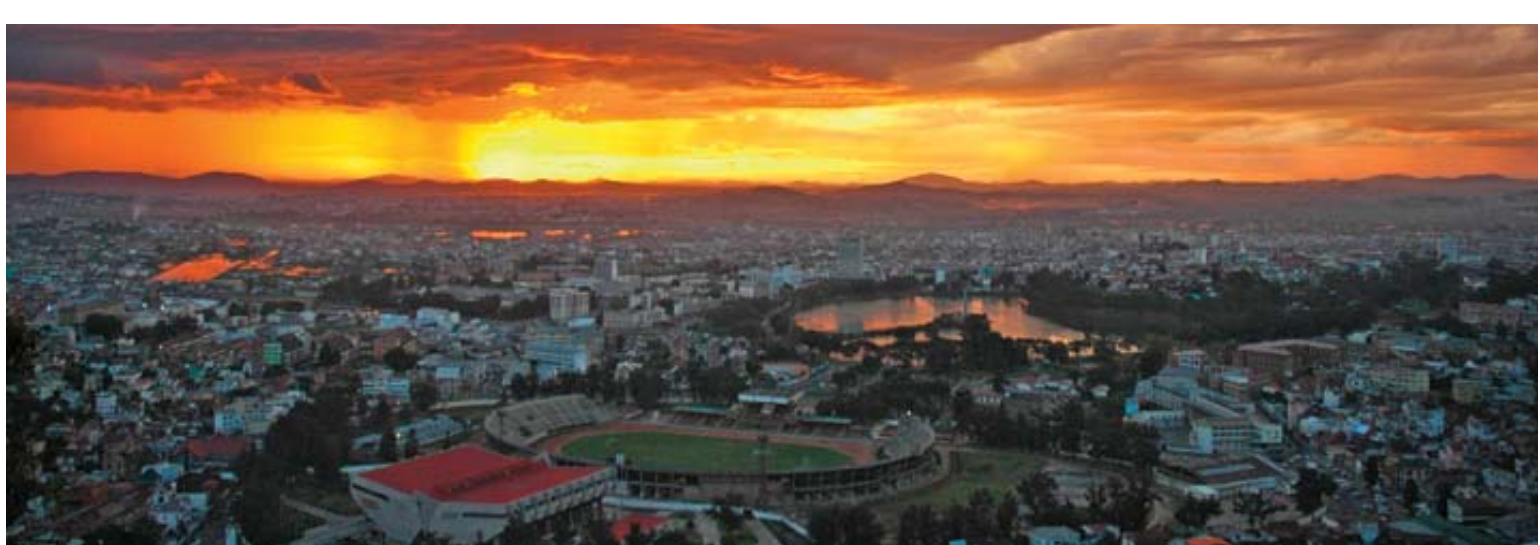




\section{CHALLENGE 7 > \\ SUBSTANTIALLY IMPROVE ACCESS TO DRINKING WATER AND SANITATION}

Current Reality

As of 2006 , only $35 \%$ of the population has access to safe drinking water. The majority of the people must go to rivers, wells and springs for water, often walking long distances.

The flow of water is unreliable and often unsanitary resulting in diarrhoeal diseases.

Goals

By $2012,65 \%$ of the population will have easy access to safe hygienic drinking water and basic sanitary condition.

Strategies

1. Develop and implement Water and Sanitation National Program to cover all aspects of water supply and usage including safe drinking water, water tables, irrigation, industrial uses, environmental protection and

2. Build more community wells.

3. Set up community-managed integrated water system.

4. Promote Private Public Partnership.

\begin{tabular}{|c|c|}
\hline PRIORITY PROJECTS AND ACTIVITIES & PROJECT LEADER \\
\hline 1. Decentralize water and sanitation project management & $\begin{array}{l}\text { Minister responsible for } \\
\text { Water and Sanitation }\end{array}$ \\
\hline $\begin{array}{l}\text { 2. Build } 6000 \text { water and sanitation infrastructures including drillings, pumps and water } \\
\text { conveyance systems and access terminals }\end{array}$ & $\begin{array}{l}\text { Minister responsible for } \\
\text { Water and Sanitation }\end{array}$ \\
\hline 3. Build 27000 latrines & $\begin{array}{l}\text { Minister responsible for } \\
\text { Water and Sanitation }\end{array}$ \\
\hline INDICATORS & 2005 \\
\hline Population with sustainable access to improved drinking water & $35 \%$ \\
\hline Population with sustainable access to improved sanitation & $54 \%$ \\
\hline
\end{tabular}

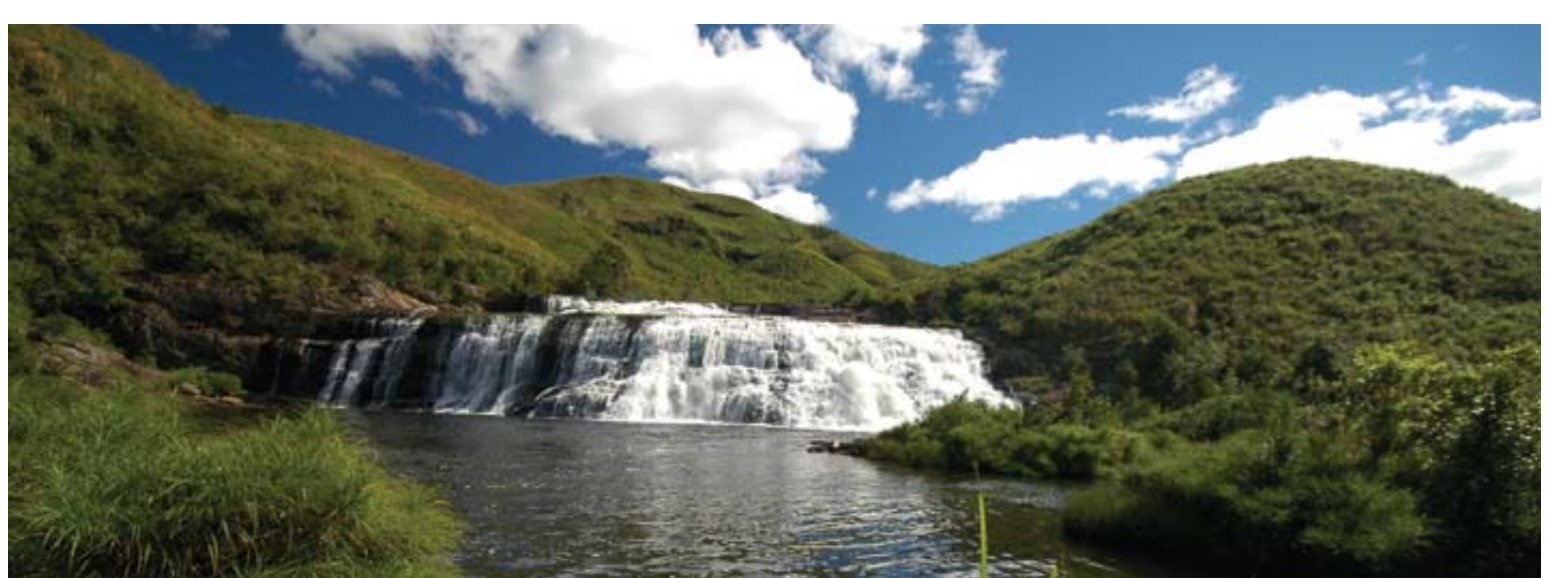




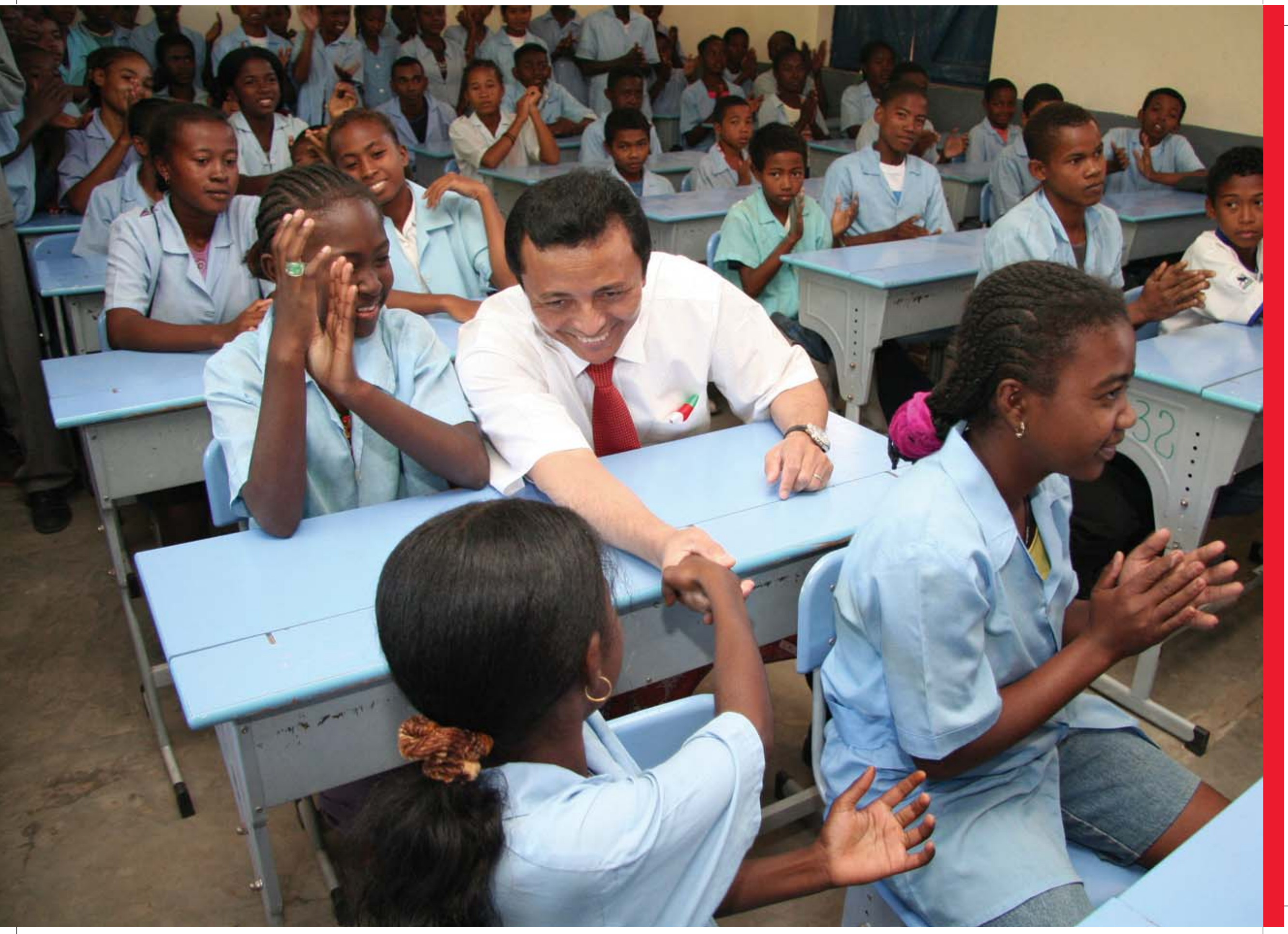




\section{COMMITMENT THREE EDUCATIONAL TRANSFORMATION}

We will create an education system with world class standards in quality and in effectiveness, which stimulates creativity and helps our students to actually transform their dreams into reality, and which provides Madagascar with the necessary human resources to become a competitive nation and a successful player in the world economy. 


\section{CHALLENGE 1 \\ ENSURE ACCESS OF ALL CHILDREN TO DEVELOPMENTAL OPPORTUNITIES BEFORE OFFICIAL SCHOOL ENTRY}

\section{Current Reality}

As of $2006,5 \%$ of the children from 3 to 5 years of age attended a pre-school establishment; in other words only 1 pupil out of 20 who enters primary school was provided with a preschool education. This partly explains the fact that in first year of the primary school, approximately one out of four pupils drops out of school. Development projects of the preschool centers were indeed carried out during several decades, but the pre-school cover rate remains very low. The great majority of children who attend pre-school are from urbon areas that have many private

Goals

1. All children between 0 and 5 years old will be receiving care and support for development through parental education.

2. The pre-school education system will be available all across Madagascar with an enrolment rate of at least $20 \%$.

3. The teachers of pre-school will have received good training, and will be motivated through appropriate remuneration and the recognition of their importance.

4. The local authorities and communities will bring sustainable support to the pre-school centres of their locality.

Strategies

1. Develop a national pre-school strategy.

2. Involve local community members

3. Ensure availability of high-quality teachers.

4. Ensure sustainable financial scheme for pre-schools.

5. Develop a nutrition program for pre-school centres.

6. Train community workers in parental education.
PRIORITY PROJECTS AND ACTIVITIES

1. Train community workers to conduct parental education workshops

PROJECT LEADER

2. Set up legal and institutional framework for pre-school education

Minister responsible for Population

3. Involve communities in the development of pre-school projects through awareness igh consultations

4. Train and recruit teachers in pre-schools on a two-year contract Minister responsible for Population

Minister responsible for Population

Minister responsible for Population

5. Set up sustainable financing schemes for pre-schools: initially subsidize local communities to allow financing of necessary expenses, and in the long run set up self-

6evelop appropriate curricula and ensure coherence with first year of primary school so that a smooth transition can be made

Minister responsible for Population

INDICATORS

Percentage of children aged 3-5 years attending pre-school 
CHALLENGE 2 >

\section{CREATE A SUCCESSFUL PRIMARY EDUCATION SYSTEM}

\section{Current Reality}

From a social and civic point of view, education is a right for the citizen and a duty for the government. It represents a necessary stage for the development of the society and for the eradication of poverty. From an economic point of view, education is an investment: today it represents an expenditure which will produce a supplement of wealth as well as wellbeing tomorrow.

The Malagasy Government began to reform the education system in 2003 with the launch of the national plan "Education For All" (EPT). Progress has been made with the total number of pupils in primary education increasing from 1.7 million during the school year 1997-1998 to 3.7 million in 2005-2006. However, this success in terms of schooling remains relative insofar as the school retention rate and the interna effectiveness has yet to be significantly improved.

There are differences on the level of the access and the internal effectiveness of the educational system according to the socio-economic origin of the pupils and between rus and urban zone. It is proven now that 5 years of mandatory schooling are not sufficient to allow a sustainable elimination of illiteracy, the building of job competencies and the development of human capital for the nation.

The government therefore has proposed to reform the education system, which is currently structured as 5 years of primary, 4 years of lower secondary and 3 years of uppe secondary to lengthen the primary cycle to 7 years and re-organize the lower and upper secondary cycles in line with this reform.

The reform of fundamental education will make it possible for Madagascar to increase the average number of years of tudies, and to improve the educational level of the population.

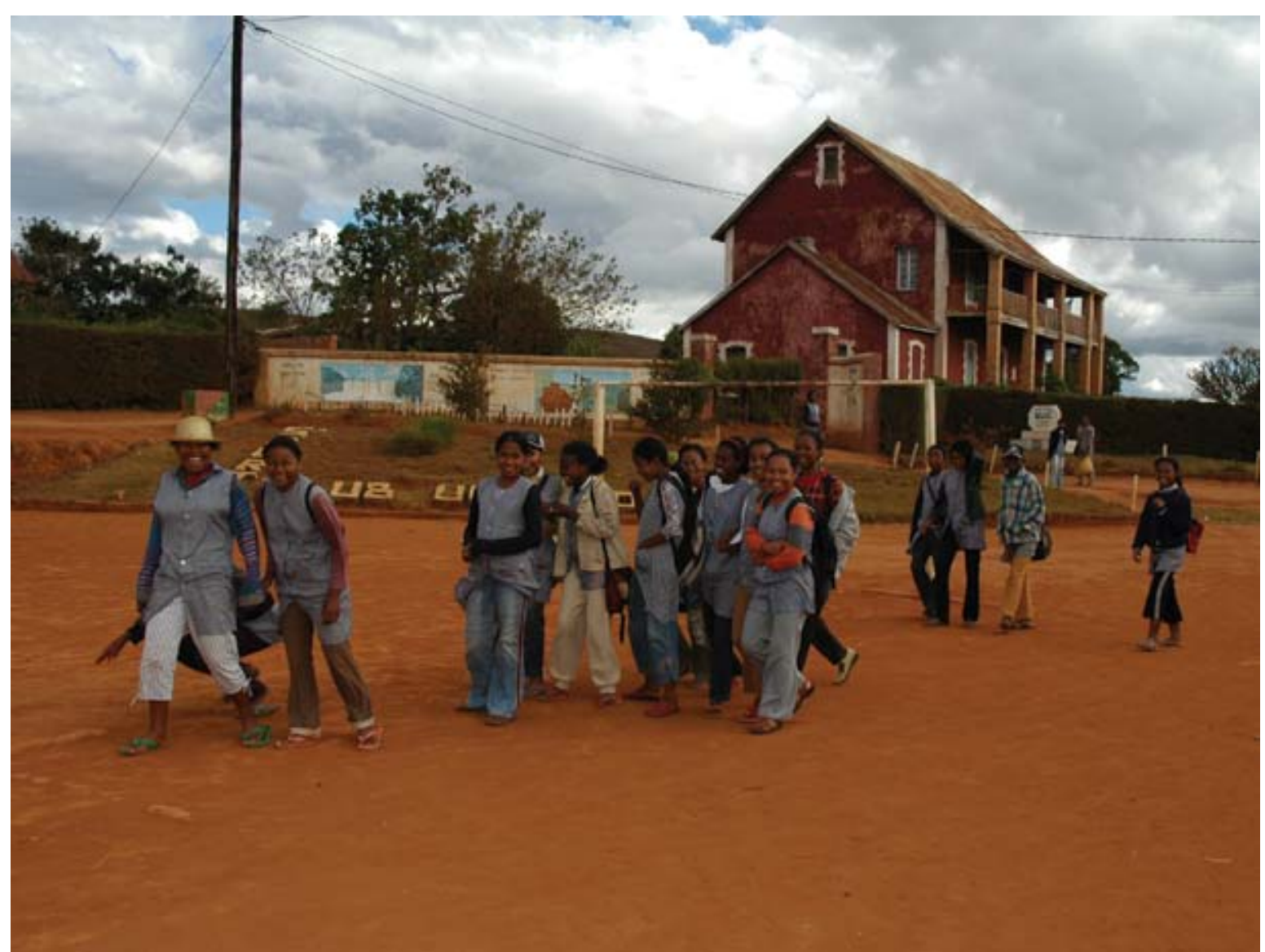




\section{CHALLENGE 2 > CREATE A SUCCESSFUL PRIMARY EDUCATION SYSTEM (CONTINUED)}

Goals

1. All Malagasy children will be provided with primary education of 7 years.

2. The consolidation and the sustainability of knowledge, acquired competences as well as literacy will be guaranteed

3. Differences between genders, social categories, regions, urban and rural will be diminished.

4. The completion rate of primary school will go from $57 \%$ to $95 \%$.

Strategies

1. Increase school capacities especially in vulnerable zones, through the development of school infrastructures, the training and the recruitment of new teachers.

2. Develop a longer commitment of teachers recruited at the local level through a better management of their career.

3. Ensure a universal access through communication and awareness raising with parents of the importance of keeping their children in school.

4. Reduce parental financial contribution (loads).

5. Support and encourage children from vulnerable and underprivileged zones.

6. Improve the curricula by strengthening the teaching of mathematics, sciences and technologies, foreign languages and social sciences and through the

development of cross cutting competences (creativity, competitiveness, entrepreneurship).

7. Improve the training of school teachers and principals

8. Produce and equip schools with more textbooks in Malagasy, with French and English being secondary languages.

\begin{tabular}{|c|c|}
\hline PRIORITY PROJECTS AND ACTIVITIES & PROJECT LEADER \\
\hline 1. Construct at least 3,000 classrooms & Minister responsible for Education \\
\hline 2. Train and recruit 7,000 new teachers per year & Minister responsible for Education \\
\hline $\begin{array}{l}\text { 3. Increase subsidy of parent teachers (FRAM) to reach } 70 \% \text { of the remuneration of } \\
\text { civil servant teachers }\end{array}$ & Minister responsible for Education \\
\hline 4. Support local initiatives in terms of maintaining functioning community schools & Minister responsible for Education \\
\hline 5. Create sustainable school feeding activities in vulnerable zones & Minister responsible for Education \\
\hline $\begin{array}{l}\text { 6. Review and rewrite the curricula for primary school to ensure relevancy and } \\
\text { consistency with the national vision }\end{array}$ & Minister responsible for Education \\
\hline 7. Training of teachers on new pedagogical methods and teaching innovations & Minister responsible for Education \\
\hline 8. Increase the training of school principals and communal education authorities & Minister responsible for Education \\
\hline 9. Improve the development of remote education & Minister responsible for Education \\
\hline 10. Produce and distribute new textbooks and teaching tools & Minister responsible for Education \\
\hline INDICATORS & 2006 \\
\hline Primary education completion rates & $85 \%$ \\
\hline Percentage of students repeating class & $20 \%$ \\
\hline Pupils/teacher ratio & $30-40$ \\
\hline Budget of education as a percentage GDP & $3.8 \%$ \\
\hline $\begin{array}{l}\text { Budget of primary education in the total budget of education } \\
\text { (recurring expenses) }\end{array}$ & $58 \%$ \\
\hline
\end{tabular}




\section{CHALLENGE 3 > \\ CREATE A SUCCESSFUL LOWER SECONDARY EDUCATION SYSTEM}

\section{Current Reality}

With regards to the lower secondary school system, there is one public college for 18 primary schools. The percentage of young people age 11 to 14 years who attend secondary school is only $27 \%$. It is among the weakest in the world and even lower than the average of sub-Saharan Africa. Too many students leave school early to work on family farms, small businesses and factories.

Goals

1. By 2012, we will have an excellent lower secondary school system.

2. To significantly increase the enrolment level in lower secondary education.

3. To ensure the retention of the pupils admitted in the system.

4. To ensure the relevance of the education by

strengthening competencies and key knowledge necessary to prepare the country for rapid economic growth and international integration.

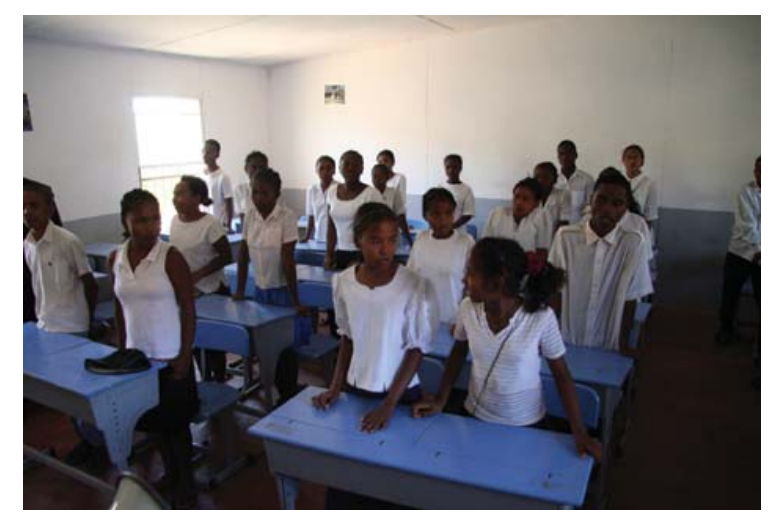

\section{Strategies}

1. Increase school capacities through development of school infrastructures, training and recruitment of new teachers.

2. Support the children from vulnerable zones (climate, access, security, social categories).

3. Develop collaboration with the private sector.

4. Improve the curricula by strengthening the teaching of mathematics, sciences and technologies, foreign languages and social sciences, and ensure its relevancy to the economic and social challenges facing the country.

5. Develop teaching practices that promote creativity,

competition, entrepreneurship spirit and professionalism. 6 . Set up system for training teachers.

7. Create teaching toolkits and new and relevant didactic materials.

\section{PRIORITY PROJECTS AND ACTIVITIES}

1. Build 4000 classrooms for lower secondary schools

2. Recruit and train 4400 new teachers

3. Create 22 colleges "of excellence" - one in each Region

4. Revise the curricula and produce related textbooks

5. Train all teachers on teaching innovations

6. Training of all principals in school management and leadership

7. Build school libraries and provide scientific equipment in all public and private schools

INDICATORS

2006

Enrolment rate in lower secondary school (college)
PROJECT LEADER

Minister responsible for Education Minister responsible for Education Minister responsible for Education Minister responsible for Education Minister responsible for Education Minister responsible for Education Minister responsible for Education 


\section{CHALLENGE 4 > \\ IMPROVE UPPER SECONDARY SCHOOL AND DEVELOP VOCATIONAL TRAINING}

Current Reality

As of 2006, very few students enter upper secondary school. Those who enter have few options in their choice of study. There needs to be a diversification and an increase in offers and quality of technical and vocational courses that focus on skill building and meeting the demands of the labor market. Goals

1. The number of students who enter and complete general and technical secondary school will be doubled.

2. Technical and professional secondary education will become more important than the general secondary education in order to match directly the needs of the growing sectors of the economy.

3. Vocational training centers will provide $90 \%$ of the newly opened technical and professional positions.

4. The private sector will be actively involved in the development of vocational training system.

5. The quality of our education will be aligned to international standards.

Strategies

1. Enhance schools capacity to take in more students: building of infrastructure, recruitment and training of new teachers.

2. Develop partnership with the private sector and diversify the sources of financing to promote vocational and professional education.

3. Transform the curricula to integrate new subjects: ITC, economy, communications, languages and sciences.

4. Transform the secondary professional education system to meet the local needs in Regions and Communes.

5. Develop creativity, competitiveness and self-learning.

6. Transform teachers' training program to ensure

high-quality skills.

7. Increase quality of education through monitoring and standardization.
PRIORITY PROJECTS AND ACTIVITIES

1. Build and rehabilitate 1200 classrooms for general upper secondary schools

PROJECT LEADER

2. Recruit new teachers and set up training system for all teachers in public and private sector

3. Revise the curricula to allow matching of students' abilities to the requirements of Minister responsible for Education

entrance to universities and to the needs of the labour market

4. Create Information and Communication Technology centres at the level of upper secondary schoo

5. Enhance school libraries and scientific learning equipments Minister responsible for Education

Minister responsible for Education Minister responsible for Education

Minister responsible for Education

Create technical and vocational training centres targeting priority sectors: tourism, 6inition, Information and Communication Technology

7. Set up National Training Authority Minister responsible for Education

8. Set up grant system for professional training based on performance criteria Minister responsible for Education

\section{INDICATORS}

Enrolment rate (percentage of young people in the age range of $15-18$ years

registered in secondary schooll) in the general upper secondary school

Completion rate (percentage of young people in the age range of $15-18$ years finishing secondary schooll in the general upper secondary school

Numbers of vocational trainees per 100000 inhabitants

Rate of job entry for vocational trainees

To be determined 

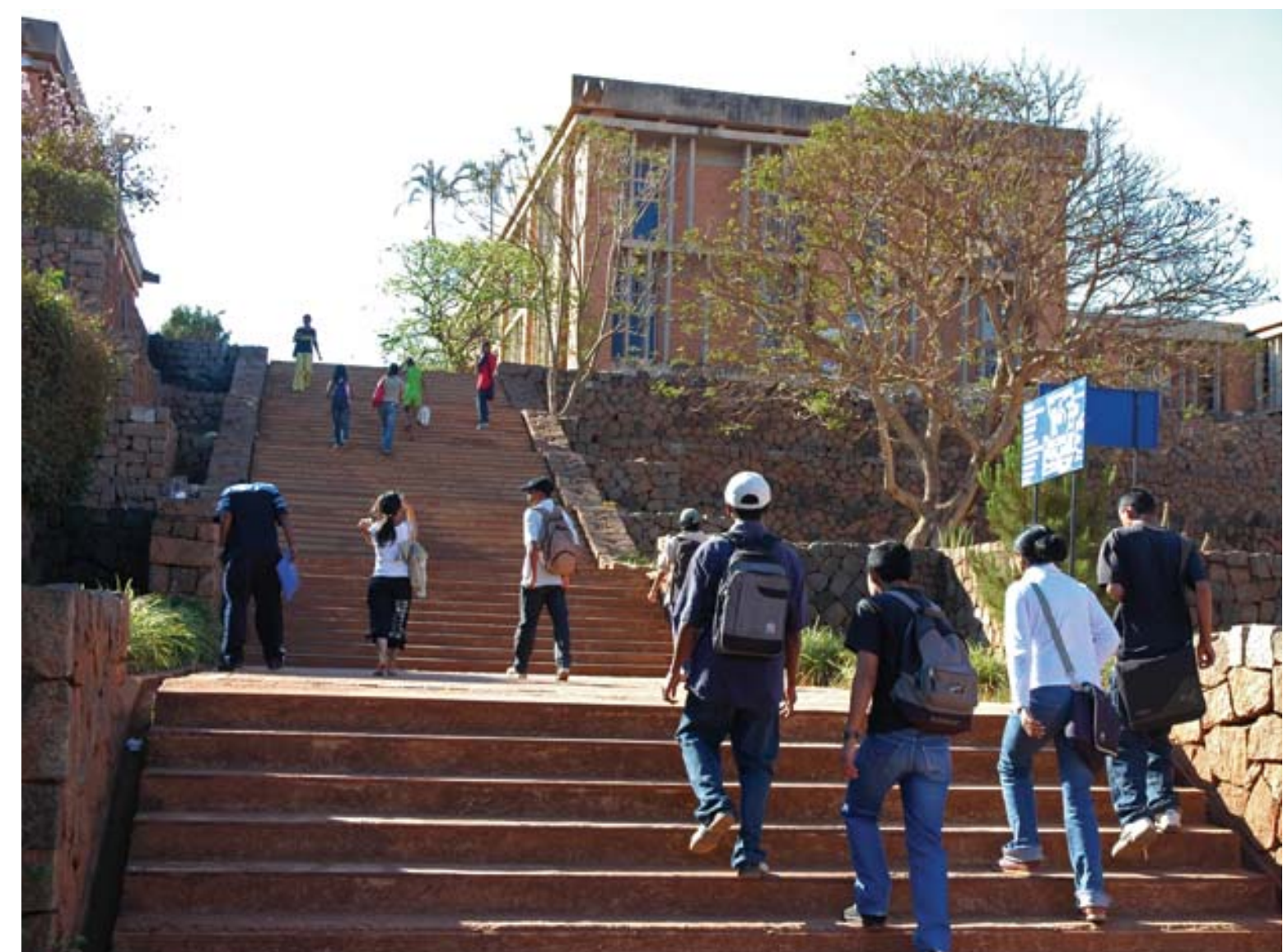

\section{Current Reality}

The tertiary education sector is insufficiently developed in Madagascar. The rate of tertiary education enrolment is $3 \%$ (whereas 8\% for Sub-Saharan African countries) with 260 students per 100,000 inhabitants. There is a very weak match between the programs offered and the needs of employers. Recently there has been an increase in the number of private techical instutes; however, the quality and the organization of the programs provided require improvement. While the five universities have begun to structure (ant

Goals

1. We will ensure competitiveness, creativity, employability of the graduates.

2. Scientific and technological research and innovation will meet the needs of the socio-economic and cultural development

3. The higher education system will offer diversified courses to meet the economic and social needs for the Madagascar Action Plan.

4. The governance of public universities will be improved.

5. High quality private universities and technical institutes will be developed. 


\section{CHALLENGE $5>$ TRANSFORM HIGHER EDUCATION (CONTINUED)}

\section{Strategies}

1. Transition the degree programs to international norms and standards that includes the system LMD

(Licence, Master, Doctorate).

2. Diversify training through promotion of technical institutions providing short training courses.

3. Develop distance learning system, particularly for the rural areas.

4. Develop partnership among domestic training institutions.

5. Promote partnership with, and establishment of, foreign higher education institutions.

6. Ensure continuity and development of new generation of talented teachers and professors.

7. Create coordination and synergy between public and private training institutions.

8. Transform scientific research centres to ensure research and development is carried out on behalf of practical problems and the development needs of the country.

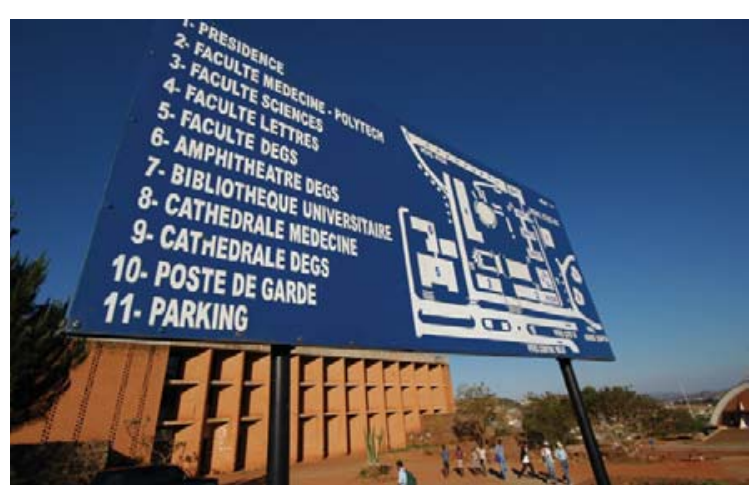

PRIORITY PROJECTS AND ACTIVITIES

1. Modernize the management of universities through computerization

PROJECT LEADER

2. Support the transition to LMD system through awareness raising, development of adequate programs and appropriate infrastructure

3. Establish Doctoral programs in priority fields by attracting international experts and Minister responsible for Education sending students overseas to develop greater expertise

4. Set up an accreditation and monitoring system to ensure quality education Minister responsible for Education

5. Create new institutions and promote distance learning to increase the diversity of programs Minister responsible for Education offered and ensure the programs address the development needs of the country

6. Set up digital library Minister responsible for Education

7. Transform selected academic universities and/or research institutions to centres Minister responsible for Education of excellence

8. Develop and implement a national policy of research to be sustainable and to ensure Minister responsible for Education invaluable outcomes for the development

9. Set up a Support Funds for Scientific research

Minister responsible for Education

$\begin{array}{lll}\text { INDICATORS } & \mathbf{2 0 0 6} & \mathbf{2 0 1 2} \\ \text { Number of students in tertiary education per 100 000 habitants } & 280 & 550 \\ \text { Number of graduates from tertiary education per year } & 4,750 & 10,000 \\ \text { Share of budget allocated to scientific research } & 0.05 \% & 0.10 \% \\ \text { National program on research (Law) } & 0 & 1 \\ \text { Numbers of centres of excellency } & 0 & 8 \\ \text { Numbers of research outcome applied } & \text { To be determined } & \text { To be determined }\end{array}$




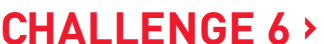 END ILLITERACY}

\section{Current Reality}

The United Nations' Millennium Development Goals and the "Education For All" declaration from the Forum of Dakar in 2000 emphasize the commitment to the elimination of illiteracy of adolescents and adults. As of 2006, in Madagascar

approximately $48 \%$ of the population 15 year old and above are illiterate. There are more than 1 million youn $\mathrm{g}$ people from 11 to 17 years who are illiterate. Training methodologies training trane Currently, finesial but the 政 well as from international partners are limited.

\section{Goals}

Madagascar will reach the Millennium Development Goals of halving the illiteracy rate of adolescents adults from its of hal in 1990 to 2015 . Reducing illiteracy will also fom level linst ro to pros. catalyst role to prople, risk and initiative taking.

Strategies

1. To intensify literacy education activities outside the regular school programs to target young and adult illiterate.

2. To provide specific curricula to 11 - 17 years old young illiterate people to allow them to catch up with the regular school programs, particularly through ASAMA activities (alternative education).

3. To carry out large campaign of awareness raising on fight against illiteracy.

4. Develop a national strategy to reintegrate out-of-school children into the formal sector by providing literacy and life-skills training and counselling.
2. Produce and distribute 750000 literacy materials per year Minister responsible for Literacy

3. Build 570 classrooms per year for literacy program outside regular school system such as Asama

4. Set up new literacy centres and broaden their activities: nutrition program, basic technical and vocational training program

5. Implement national strategy to reintegrate out-of-school children into formal sector

Minister responsible for Literacy

Minister responsible for Literacy
2006

Literacy rate of adolescents/adults of more than 15 years

$52 \%$ 2012

$20 \%$

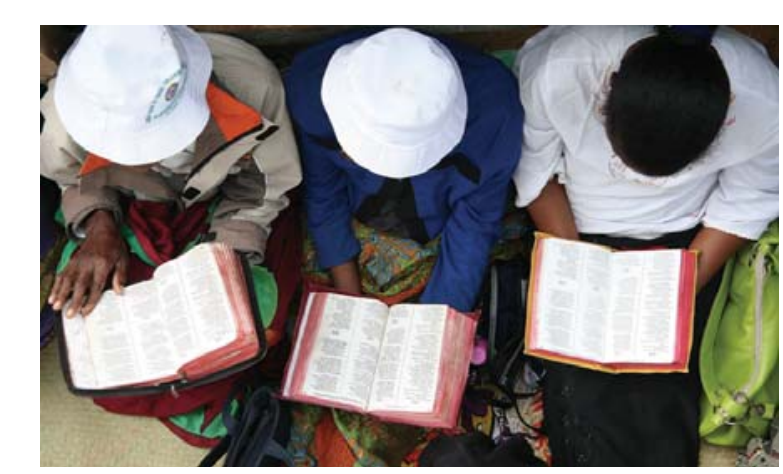




\section{CHALLENGE 7 > \\ DEVELOP CAPACITIES AND MINDSETS OF YOUNG PEOPLE THROUGH SPORTS AND CIVIC PARTICIPATION}

Current Reality

In order for the young people to have a competitive spirit, a performance orientation and entrepreneurial mindset, extraschool and sports activities are indispensable to complement formal and regular school programs. These activities are currently carried out by youth associations and in Youth Sports Centers (CAPJ and Youth Houses). Sports and Youth events are organizer and insill discipline.

The Boy-scouts and Girl-scouts are active in Madagascar and make important contribution most churches have youth organizations that teach young people values and social service. These activities must continue to be encouraged.

Goals

The spirit and mentality shaped through sports ethics and extra-school activities will lead to a better way of life for the Malagasy young people. Participation of young people in youth associations, sports programs and community organizations will contribute to smoother job-entry, jobstability and civic responsibility. The sports ethics will motivate fair and constructive competition, in all areas of the life of the Nation (politics, economy and society).

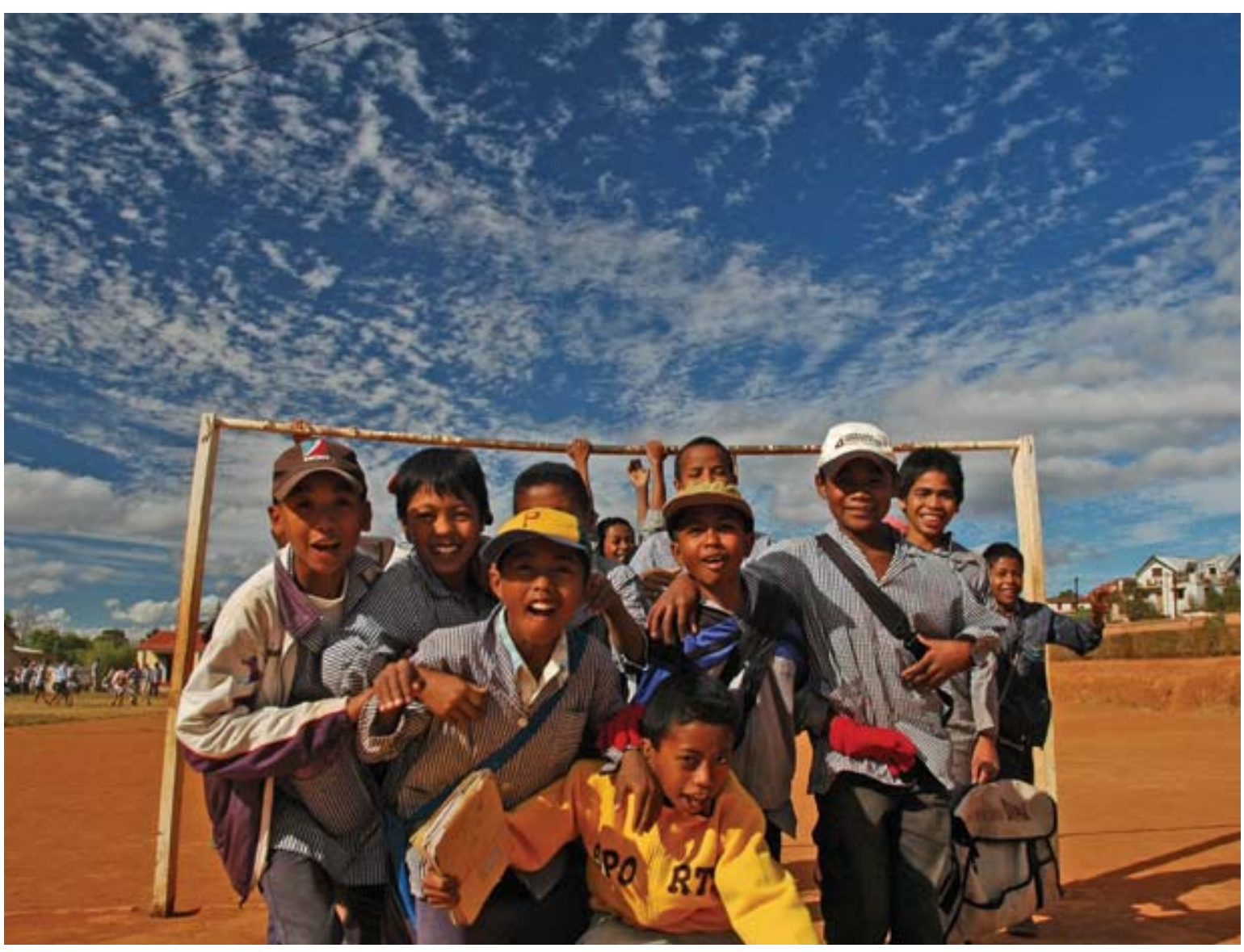


Strategies

1. Formulate a national sports strategy.

2. Encourage participation in competitive sports at the local, regional, national and international level.

3. Develop a mass sports program to maximize participation in sporting activities.

4. Build more Youth Houses and sports centres and recreation fields.

5. Train sports and youth teachers and coaches.

6. Determine priority sports for regional and international competition.

7. Promote traditional sports.

8. Broaden activities of Youth's houses in rural areas to include entrepreneurial practices.

9. Ensure girls/females are given the same attention as boys/men and are encouraged to participate in sports and youth activities.

10. Ensure prominent and successful men and women become role models for youth.

\section{PRIORITY PROJECTS AND ACTIVITIES}

1. Promote creation of youth associations, and in current ones encourage diversification of activities

2. Encourage young people to participate in the scouting program. Minister responsible for Yout

3. In all schools, implement a civic education course Minister responsible for Youth

4. Strengthen the national coaches' school Minister responsible for Youth

5. Strengthen local youth and sports centres Minister responsible for Youth

6. Mobilize funds and resources to significantly develop sports programs Minister responsible for Youth

7. Develop a scheme to insure participants in sports programs Minister responsible for Youth

8. Develop local, regional and national competition framework for selected sports programs Minister responsible for Youth

9. Ensure availability of sports infrastructures at the local, regional and national level Minister responsible for Youth

\section{INDICATORS}

2006

Proportion of young people participating in sports programs

Unknown

2012

Proportion of young people participating in scout programs

Proportion of young people participating in church and civic organizations

Percentage of young people (15 - 35 years old) registered in Youth and

sports centers (index base $2006=100$ ) 


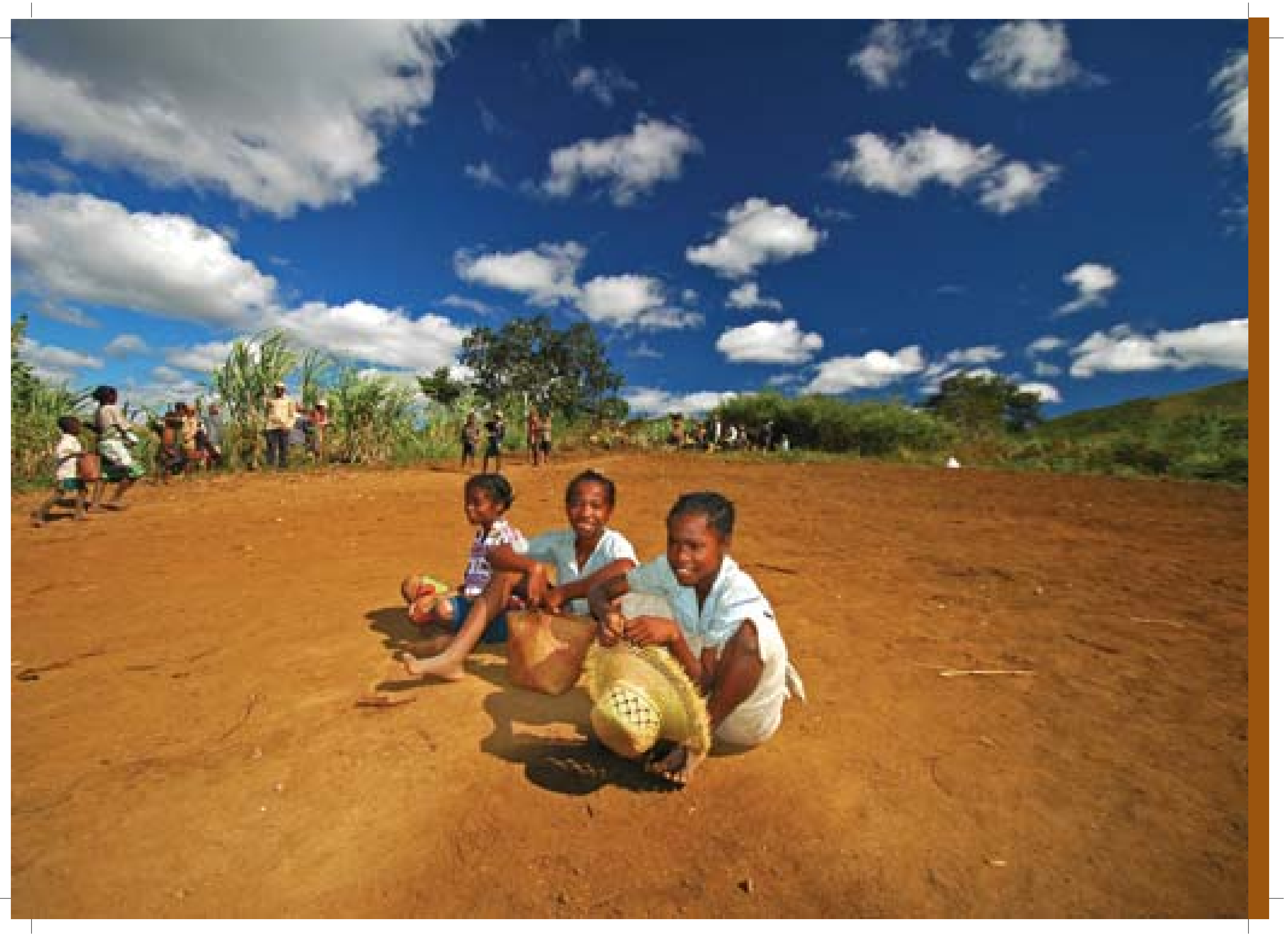




\section{COMMITMENT FOUR RURAL DEVELOPMENT AND A GREEN REVOLUTION}

Dynamic rural development and real poverty alleviation is at the core of the government's endeavors. Our rural areas will flourish and prosper through a green revolution that will substantially increase agricultural production. Agri-business centers will be established in every region to assist in training and the provision of farming resources such as irrigation, seeds, fertilizer and storage facilities.

To further support rapid rural development, better roads and communication networks will be established and the Government will work to create conditions that encourage entrepreneurial activity and allow private sector initiatives to flourish. 


\section{CHALLENGE $1>$ \\ SECURE LAND TENURE}

Current Reality

Over the last century, 330,000 titles have been issued. The delivering rhythm is 1,000 per year. As of 2006,10 percent of the national territory was legally occupied with title or

certificates. In 2005, the Government launched the National Land Tenure Program including the facilitation of land tenure transaction and the setting up of 21 land tenure offices (one stop shop) till December 2006. However, to allow strong stop shop) till Decerivation of private actors in. However, to allow strong motivation of private actors in prodiction, the spatial covera of land tiling anhanced. The current legal system be substantally end

Goals

The land tenure system will be responsibly employed for the following ecological objective. The land tenure system will actively encourage private initiative in production, for small as well

Strategies

1. Modernize and computerize the land property and topographic records.

2. Decentralize land property management at commune (region) level.

3. Reform the legal framework.

4. Strengthen the capacity of the staff of land tenure services.

5. Create land bank for investments in tourism, agribusiness and manufacturing.

6. Harmonize the intervention of development partners in the National Land Tenure Policy.

\section{PRIORITY PROJECTS AND ACTIVITIES}

1. Make an inventory, restore, and digitize land property documents

PROJECT LEADER

2. Computerize the records

3. Set up standard services/Unique Offices and Land Property Offices

Minister responsible for Land Tenure

4. Purchase satellite imaging Minister responsible for Land Tenure

5. Set up a Land Occupation Plan Minister responsible for Land Tenure

6. Update legal texts and carry out campaign of popularization Minister responsible for Land Tenure

7. Develop land property certificates to allow their allocation in guarantee Minister responsible for Land Tenure

8. Promote the profession of Independent Sworn Land Surveyors Minister responsible for Land Tenure

INDICATORS

2005

Percentage of farmers having land titles or certificates

$10 \%$

2012

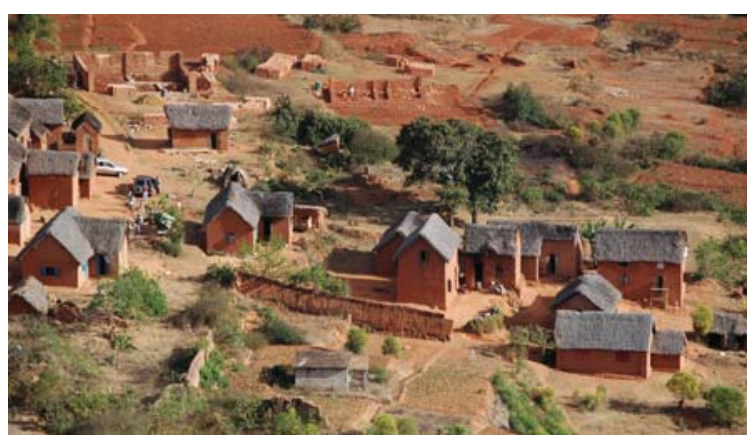


CHALLENGE 2 >

\section{IMPROVE ACCESS TO AFFORDABLE RURAL FINANCING}

\section{Current Reality}

The banking system is extremely limited in rural areas.

To address the need, microfinance institutions have

established some rural offices. As of 2006, seven authorized microfinance institutions are operating, along with other onthe-field running initiatives. It emerges from the present situation that the access to credit remains limited although the rate of penetration has markedly improved over the years (from $3 \%$ in 2003 to $6 \%$ in 2005). This is closely linked to the (igh interest retes and excessive guar intees from the financial institutions.

Goals

Financing methods in rural areas, at accessible rates, will enable the financing of investments in the medium and long term allotted to the development of ativities of mor long term allotted to the development of activities of rura operators. Poor a to undertake income-generating activities.

Strategies

1. Extend the networks of microfinance and banking institutions.

2. Promote and adapt the system of credit with joint guarantee.

3. Support alternative forms of financing.
PRIORITY PROJECTS AND ACTIVITIES

PROJECT LEADER

1. Promote the obtaining of approval from the Commission of Bank and Financial Supervision

Minister responsible for Finance

2. Support extension into new areas Minister responsible for Finance

3. Ensure the refinancing of microfinance institutions Minister responsible for Finance

4. Set up an Agricultural Development Fund Minister responsible for Finance

Rate of penetration of financial institutions $6 \%$ $13 \%$

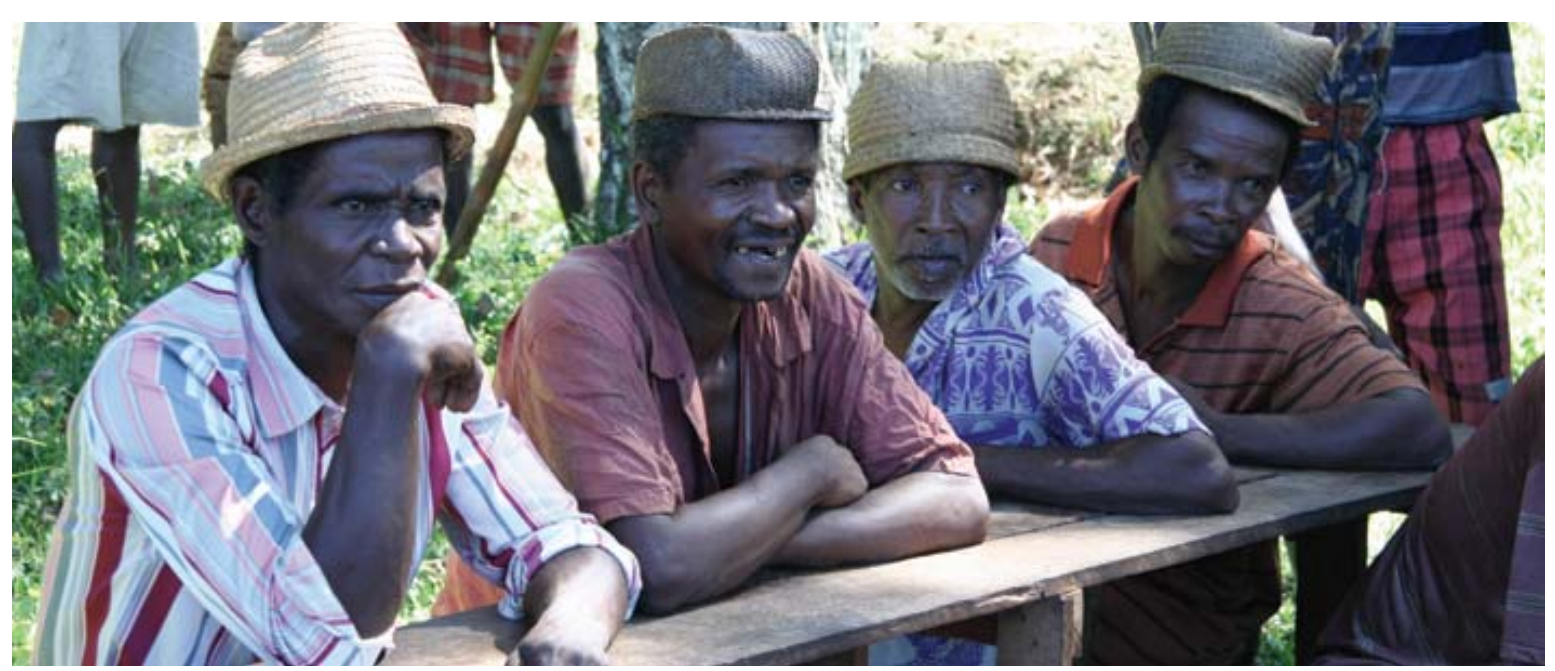




\section{CHALLENGE 3 >}

\section{LAUNCH A SUSTAINABLE GREEN REVOLUTION}

Current Reality

At present, projects for small scale agricultural mechanization, like plows and motor cultivators, and improved technical

itineraries, such as an intensive rice-growing system, have been undertaken. In 2005 , rice production rose to $3,420,000$ tons, that is an increase of $13 \%$ compared to the level of 2004 . However, Malasasy ariculture is characterized by its low productivity with average yields of around 2 tons per hectare. productivity whe average yields of around 2 tons per hectare. agricultural equipment.

Goals

Agricultural mechanization will be expanded and new agricultural techniques will be implemented. Substantial increase of both production and productivity will enantial increase of bol pre surplus for export. The green revolution secuily ar bove nos will improve income levels.

Strategies

1. Intensification and improvement of productivity.

2. Extension and increase of cultivated surfaces.

3. Provision and assistance with seed and fertilizer.

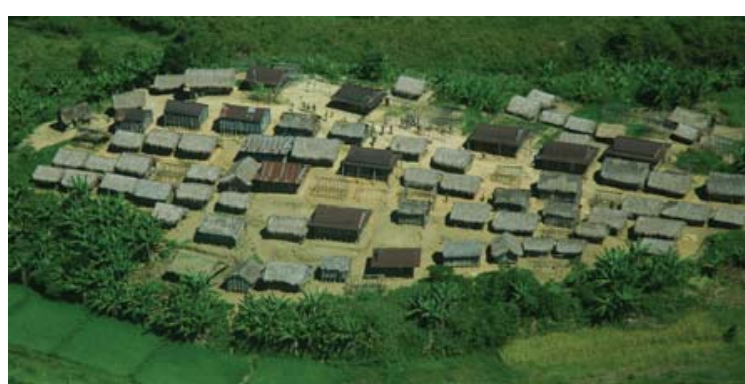

PRIORITY PROJECTS AND ACTIVITIES

PROJECT LEADER

1. Develop, rehabilitate and maintain hydroagricultural networks

Minister responsible for Agriculture

2. Ensure fertilizers, seeds and equipment are available to dramatically increase yields for food self-sufficiency and surplus for market

3. Reform and modernize agricultural practices through training and education and Minister responsible for Agriculture knowledge of world best practice

$\begin{array}{ll}\text { 4. Promote cooperatives for the use of agricultural equipments } & \text { Minister responsible for Agriculture } \\ \text { 5. Identify and exploit new zones of farming } & \text { Minister responsible for Agriculture } \\ \text { 6. Promote agricultural mechanization and industrialization } & \text { Minister responsible for Agriculture } \\ \text { 7. Integrate environmental dimensions and land clearing stabilization } & \text { Minister responsible for Agriculture } \\ \text { 8. Encourage crop rotation and crop diversification } & \text { Minister responsible for Agriculture }\end{array}$

$\begin{array}{lll}\text { INDICATORS } & \mathbf{2 0 0 5} & \mathbf{2 0 1 2} \\ \text { Rice production } & 3,420,000 & 7,000,000 \\ \text { Productivity laverage tonnage yield per hal } & 1.8 \text { to } 2.57 & 3 \text { to } 5\end{array}$


CHALLENGE 4 >

\section{PROMOTE MARKET ORIENTED ACTIVITIES}

\section{Current Reality}

The main factors that impede the development of market oriented production in rural areas lie in the fact that infrastructures and channels for the transmission of market signals to producers are inadequate. Some initiatives have been taken by the public as well as the private sector, like the building of market places and the institution of the Rice Observatory Platform. To date, activities relating to the agricultural sector do not meet the market needs in terms of quantity, quality, and reliability.

Goals

Information on the opportunities offered by the market will be available and accessible so as to guide in a better way the development initiatives. Profitability for all stakeholders in the agricultural, stock breeding, and fishing systems will be optimized through the intra and inter regional exchanges. Operators will benefit from infrastructures of exploitation such as abattoirs, cold chains, and warehouses; and from markets that will allow them to control their activities. Strategies

1. Develop a system for the spreading of information about the market.

2. Enhance intra and inter-regions domestic trade.

3. Develop infrastructure to provide better access to markets.

4. Improve the fairness and the fluidity of the market.

\section{PRIORITY PROJECTS AND ACTIVITIES}

1. Extend the access to the existing international and regional data base networks (market map, trade map)

2. Pass market signals on to producers through media, decentralized communities, and farmers' sector organizations

3. Strengthen the capacity of farmers' organizations Minister responsible for Agriculture

4. Intensify and optimize organization of and participation to shows and fairs for the Minister responsible for Agriculture

5. Maintain and build exploitation infrastructure such as abattoirs, cold chains, warehouses and markets

6. Facilitate the acquisition of equipments and tools for conditioning and processing agricultural products

Minister responsible for Agriculture Minister responsible for Agriculture

Synthetic index of the evolution/development of commercialization

100

300 (Index base 2005=100)
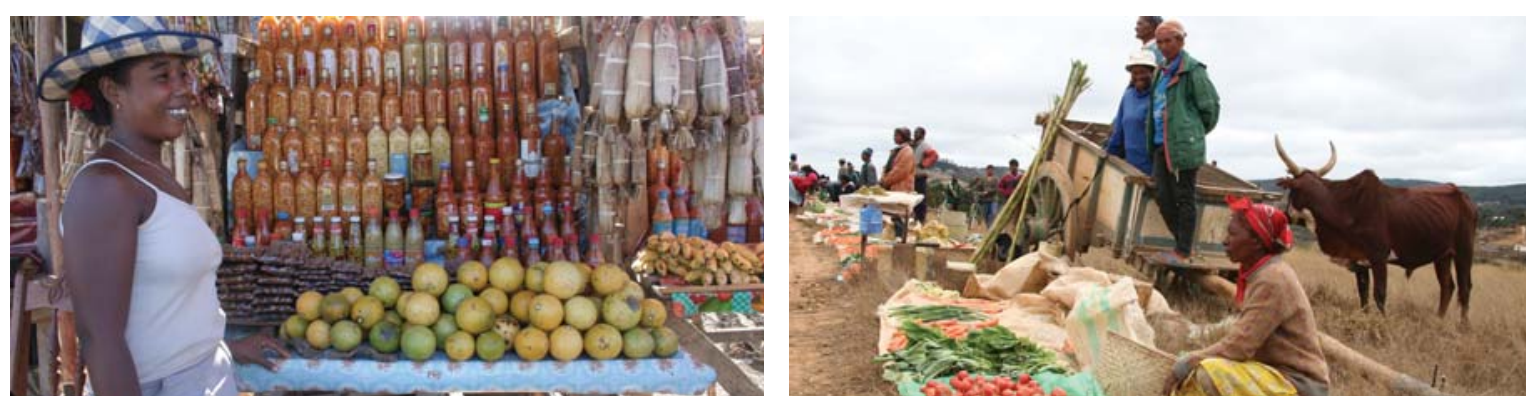


\section{CHALLENGE 5 > \\ DIVERSIFY RURAL ACTIVITIES}

Current Reality

To Madagascar, many farmers rely on one crop to sustain their livelihood. The lack of research, development and training constrains experimentation with diversification.

Goals

Producers will get the opportunity to improve their incomes. The development of potential sectors in each region will

constitute the mainstay of its growth.

Strategies

1. Conduct research on alternative crop potential and market opportunities.

2. Encourage diversification of activities for additional income and in order to reduce vulnerability caused by world price fluctuations and bad weather.

3. Develop and implement an organic agriculture strategy.

4. Identify and develop regional sector specializations.

5. Promote secondary activities : handicrafts, ecotourism, etc.

\begin{tabular}{|c|c|}
\hline PRIORITY PROJECTS AND ACTIVITIES & PROJECT LEADER \\
\hline 1. Encourage partnerships between research centers and private producers & Minister responsible for Agriculture \\
\hline 2. Decentralize services of seeds certification & Minister responsible for Agriculture \\
\hline 3. Stimulate producers' organization in each new sector & Minister responsible for Agriculture \\
\hline 4. Organize the supports to new sectors: inputs and technological package & Minister responsible for Agriculture \\
\hline 5. Identify potential zones and specialize them in organic produce & Minister responsible for Agriculture \\
\hline 6. Carry out campaigns of information and popularization relating to biological agriculture & Minister responsible for Agriculture \\
\hline $\begin{array}{l}\text { 7. Promote the approach « One village - One product » within pilot zones, develop leading } \\
\text { sectors in the regions }\end{array}$ & Minister responsible for Agriculture \\
\hline
\end{tabular}

INDICATORS

2005

2012

Average income of rural households (\$US)

123

370
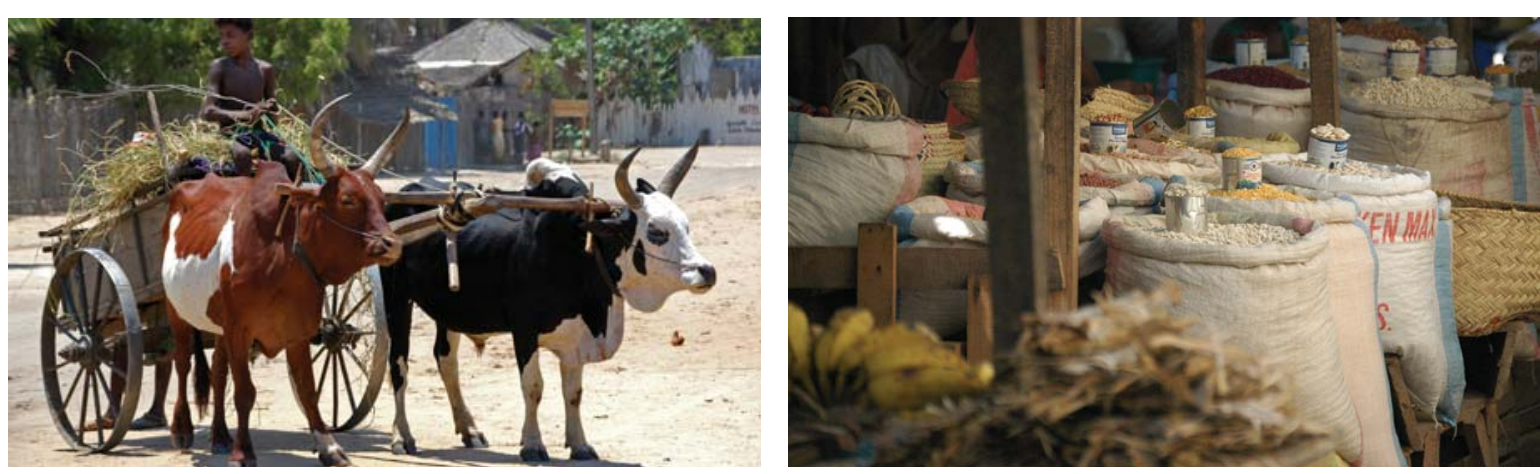


\section{CHALLENGE 6 > \\ INCREASE THE AGRICULTURAL VALUE ADDED AND PROMOTE AGRIBUSINESS}

\section{Current Reality}

The production system is characterized by the sale/export of non-processed products. Vertical integration exists only for very few products resulting in low value added. Supply chains are not sufficiently developed and organized. Great potential can be exploited by extending the value chain in various agricultural sectors in order to increase substantially the value added from agriculture, stock breeding, and fisheries.

Goals

Farmers will consistently provide the market with more value added processed products that meet the demand of end consumers, that will equally benefit the buyers. Most of the processing of the products for exports will be carred of processing of the prodr mich

Strategies

1. Enhance and co-ordinate the agricultural value chain: production and processing.

2. Set up agribusiness centers (ABCs) to train and support farmers in processing, marketing and supply chain management.

3. Promote modern production practices (standards and quality).

4. Develop contractual agriculture between large buyers and small scale farmers.
PRIORITY PROJECTS AND ACTIVITIES

PROJECT LEADER

. In each specific sector, bring together key stakeholders to maximize value chain

2. Across sectors, organize key actors across different value chains to

3. Set up agricultural productivity centers : agro-technopoles

4. Set up Agribusiness Centers to connect producers to market

5. Implement system of Hazard Analysis and Critical Control Point Director Millennium Challenge Account

6. Ensure the system of products tracking : zoning, varieties, genetics

Minister responsible for Agriculture

7. Promote branding of regional products nister responsible for Agriculture

8. Open up and and make viable zones for agribusiness investment

Minister responsible for Agriculture

9. Set up and secure large agricultural investment areas Minister responsible for Agriculture 


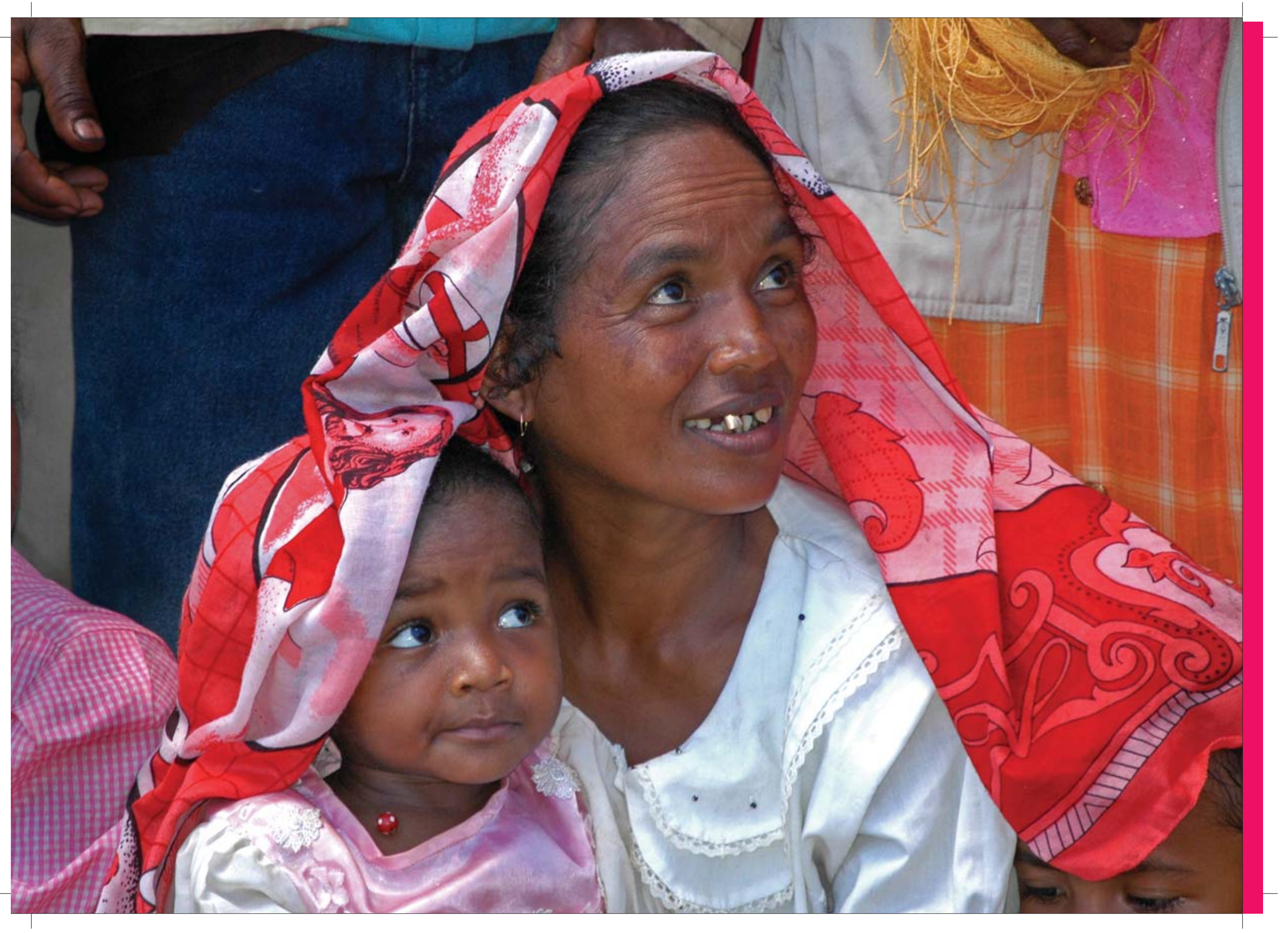




\section{COMMITMENT FIVE HEALTH, FAMILY PLANNING AND THE FIGHT AGAINST HIV/AIDS}

We will work to ensure that all of our people are healthy and can contribute productively to the development of the nation and lead long and fruitful lives. The problems of malnutrition and malaria will be brought to a halt. HIV and AIDS will not advance any further; safe drinking water will become accessible; and, through education and the provision of health services the average size of the Malagasy family will be reduced. 


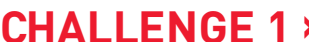 \\ PROVIDE QUALITY HEALTH SERVICES TO ALL}

\section{Current Reality}

As of 2006, 197 Basic Health Centers have been rehabilitated and equipped with essential drugs. Still, $65 \%$ of the population in rural areas are more than $5 \mathrm{~km}$ away from a Basic Health Center. Many Basic Health Centres remain understaffed and ill-equipped.

Goals

1. Adequate and quality health services will be increased to ensure easy access, affordability and reliability.

2. We will have an educated population which understands and uses quality health services and treatment options.

3. There will be partnerships with Community Agents and the private sector at local levels.

Strategies

1. Ensure all existing health centers and first referral hospitals are staffed by medically qualified professionals who can are staffed by medically qualified profes
provide the basic package of services.

2. Ensure rural areas have access to medical care.

3. Attract more medical professionals to rural areas by providing appropriate incentives such as improved housing.

4. Ensure medical graduates are attracted to work in the medical field.

5. Decentralize the management and the system of health financing and decision making at Regional and Commune level.

6. Implement a national policy of contracts for public, private, medical, para-medical and other human resources.

7. Build synergies between traditional medicines and modern practices.
PRIORITY PROJECTS AND ACTIVITIES

PROJECT LEADER

1. Contract and redeploy midwives and nurses for all Basic Health Centers to established

Minister responsible for Health standards (level 1 and 2)

2. Revitalize continuous training at all levels with special priority for initial training of midwives and paramedical

3. Improve working conditions of health agents (salary, career development, Minister responsible for Health

Improve working conditio
housing, allowances)

4. Provide mobile Health Center for remote areas or areas with low density of population Minister responsible for Health Minister responsible for Health Rehabilitate and equip all Health Centers in the country to be able to deliver the quality Minister responsible for Health basic health package of services for a Level 2 facility

6. Establish a quality control system for drugs at the remote heath facilities including:
training. logistics, and community control (centrale d'achat, pharmacie de gros, FS). training, logistics, and community control (centrale d'achat, pharmacie de gros, FS).

7. Define competencies and responsibilities of medical hierarchy levels

Minister responsible for Health

Transfer competencies and resources to the decentralized level

Minister responsible for Health

9. Introduce innovative financing methods for the sector to provide consistent quality Minister responsible for Health services and to increase the use of these services by the poor, through mechanisms such as mutual insurance or social security

Percentage of new consultations using Basic Health Centers

49

70

Percentage of childbirth occurring in Basic Health Centers

Average life expectancy 


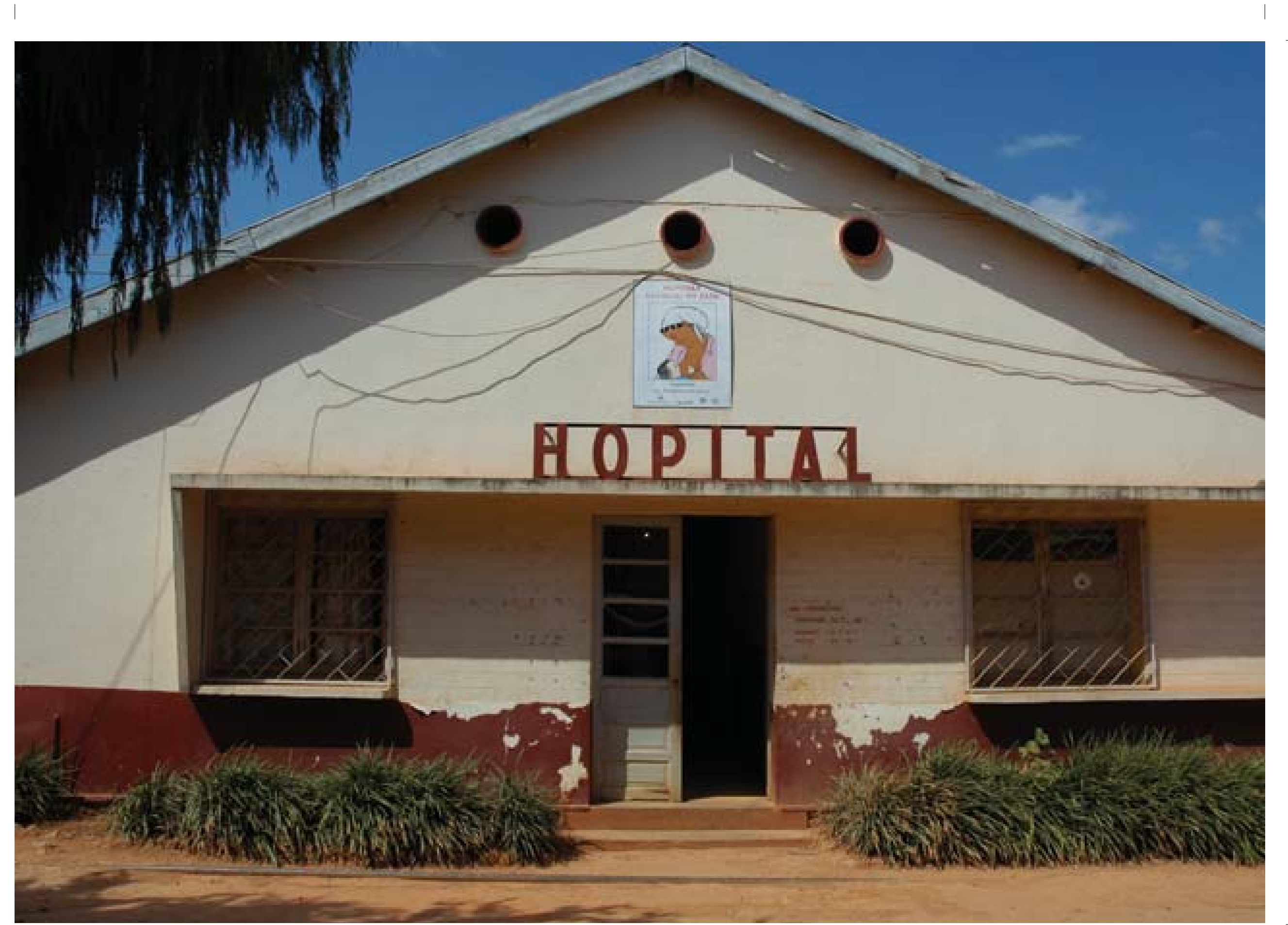




\section{CHALLENGE 2 > \\ ERADICATION OF MAJOR DISEASES}

\section{Current Reality}

As of 2006, more than 1 million bed nets have been distributed for malaria prevention in highly vulnerable zones (coastal and tourism areas). Still, there remains a high rate of malaria mortality. Additionally, the prevalence of sexually transmitted diseases (mostly congenital syphilis) is still very high throughout the country. Tuberculosis treatment is low due to poor understanding of the disease by the population

Goals

1. We will have effectively controlled malaria.

2. We will have eradicated congenital syphilis and tuberculosis.

3. There will be a reduced prevalence of main endemic epidemic diseases and tropical diseases.

\section{Strategies}

1. Ensure $100 \%$ coverage for malaria prevention and treatment.

2. Sexually Transmitted Diseases treatment kits are fully available throughout the country.

3. Improve capacity of health centers to prevent, diagnose and treat tuberculosis through immunization, education and social mobilization.

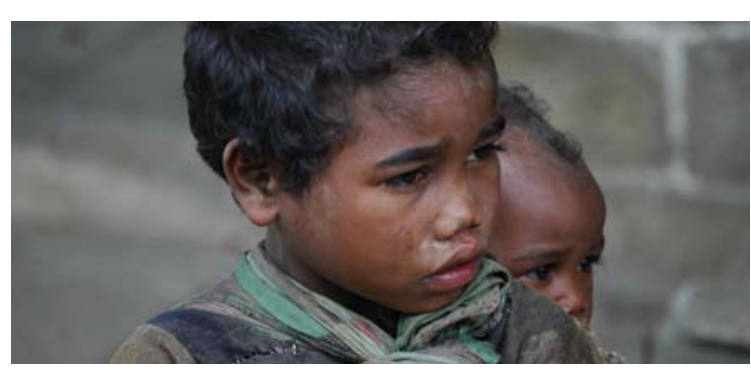

\section{PRIORITY PROJECTS AND ACTIVITIES}

1. Implement all available services for effective control of malaria including indoor and outdoor spraying, distribution of bed nets and adequate treatment

2. Link and coordinate national campaigns (eg vaccination, family planning etc) in order to Minister responsible for Health maximize coverage and effectiveness

3. Improve training for health agents in order to prevent, diagnose and adequately Minister responsible for Health treat tuberculosis

4. Standardize testing, treatment and equipment in health centers for sexually transmitted diseases management

5. Strengthen the capacities of private services providers to diagnose and treat sexually transmitted diseases

6. Ensure that people with Sexually Transmitted Diseases seek treatment

\begin{tabular}{lll} 
INDICATORS & $\mathbf{2 0 0 5}$ & $\mathbf{2 0 1 2}$ \\
Number of presumed Malaria cases & $1,234,520$ & 320,000 \\
\hline Percentage of malaria mortality in hospitals (\%) & 17.5 & 9 \\
Percentage of cured patients on tuberculosis(\%) & 72 & 90 \\
Percentage of detected new case of tuberculosis & 62 & 90 \\
Percentage of syphilis among pregnant women & 4.2 & 1
\end{tabular}
Minister responsible for Health

\section{PROJECT LEADER}

Minister responsible for Health

Minister responsible for Health 


\section{CHALLENGE 3 >}

\section{WIN THE FIGHT AGAINST HIV AND AIDS}

\section{Current Reality}

In 2006, Madagascar remains a low HIV prevalence country, with a rate of less than $2 \%$ in vulnerable groups and an

estimated $0.95 \%$ in the general population. With Madagascar going global with increased international mobility, trade and tourism the threat of HIV expansion is very real. The main

component of the national response includes:

Three ones (one coordination unit, one strategic framework and one monitoring and evaluation system),

- Clinical preventive and treatment services,

- Communication for Behavioral Change Communication (BCC) and social transformation, and local response, implemented as part of partnership between the public based organizations (CBOs), religious organizations an the private sector.

The response focuses on primary and secondary prevention for the control and impact mitigation of HIV infection. The major aspects of the response include:

1. Advocacy and awareness campaign for the general population and with a focus on women, youth and vopulation and with a

2. Reduction of stigma and discrimination.

3. Effective community response.

4. Sexually transmitted infection (STI) control.

5. Voluntary counseling and testing.

6. Universal precautions.

7. Mother to child prevention.

8. Blood safety.

9. Opportunistic infections prevention, AIDS and Opportunistic infections treatment.

10. Care and support for orphans made vulnerable by HIV/AIDS.

11. To improve cost efficiency, the response

needs to be further integrated and decentralised.

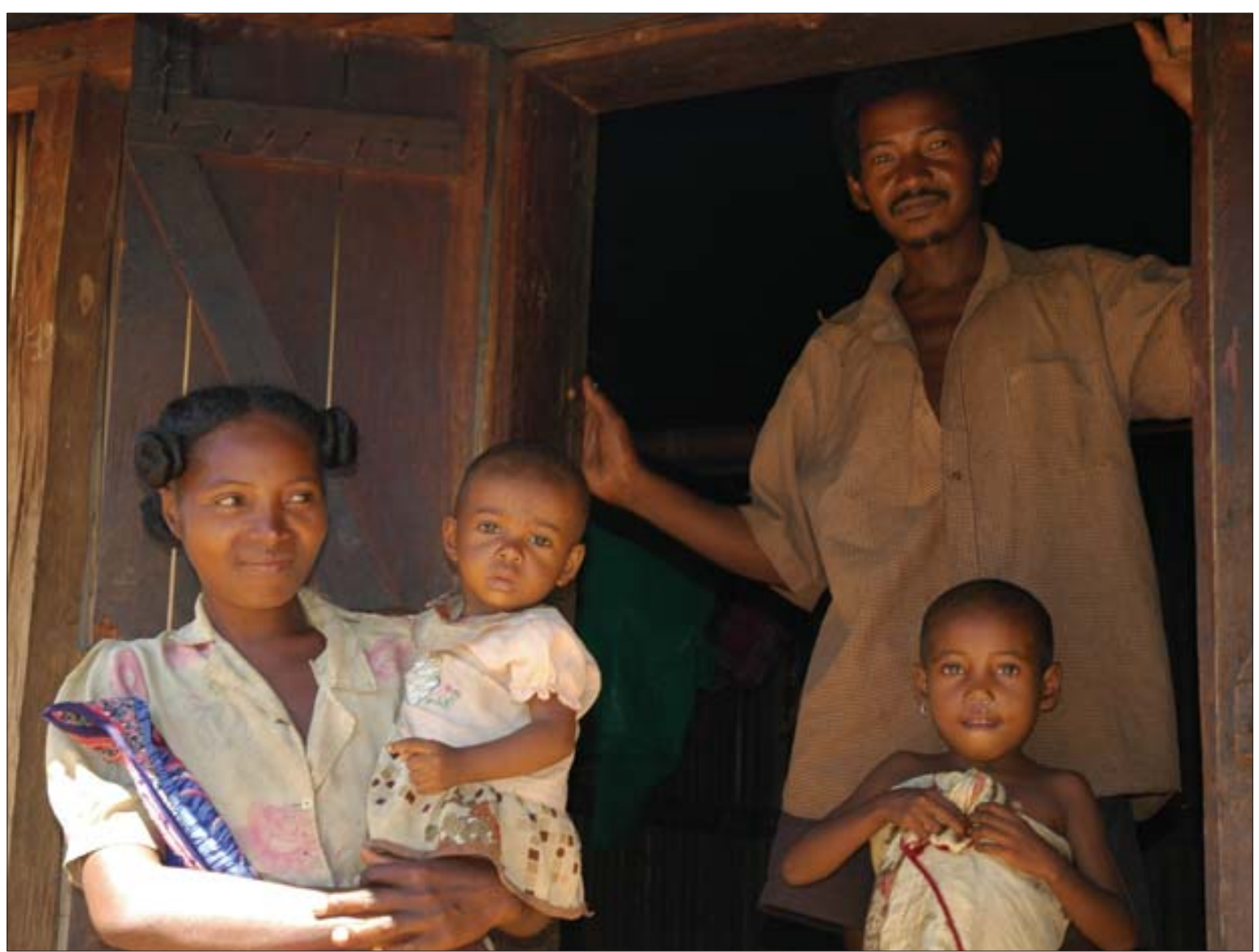




\section{CHALLENGE 3 > WIN THE FIGHT AGAINST HIV AND AIDS (CONTINUED)}

Goals

1. We will maintain HIV prevalence below $1 \%$ in the genera population, while ensuring care for HIV/AIDS patients.

2. We will have reduced the number of new HIV infections.

3. We will have increased the number of HIV/AIDS patients receiving treatment.

Strategies

1. Improve access to promotional and clinical services for vulnerable groups and general population living in areas at risk of HIV

2. Improve and ensure implementation of quality standards for delivery of integrated services at all levels.

3. Strengthen leadership, technical and managerial skills as well as inter and intra-sectoral coordination at all levels of the national response, according to the three ones principles.

4. Strengthen the partnership between public and private sectors.

5. Improve results based management especially focused on linking demand creation and service delivery.

6. Improve access to and management of drugs and diagnostic supplies for Sexually transmitted infections and HIV/AIDS, including anti retro viral (ARV) drugs.

\section{PRIORITY PROJECTS AND ACTIVITIES}

1. Strengthen managerial and technical skills at all levels for effective decentralization of the national response.

2. Consolidate, reinforce the implementation of the three ones in the context of$$
\text { universal access. }
$$

3. Ensure national coverage of communication for behavioral change and social transformation Minister of Health and ES/NAA ( including reduction of stigma and fighting discrimination )

4. Strengthen and empower communities to promote local response Minister of Health and ES/NAA

5. Increase access and utilization of Voluntary Counselling and Testing, establish Minister of Health and ES/NAA

6. Improve access to primary prevention of all pregnant women and ensure Antiretroviral treatment for HIV positive women and their infants

7. Ensure blood bank in all 22 regions Minister of Health and ES/NAA

Ensure implementation of the national policy for Universal precautions at all levels Minister of Health and ES/NAA

9. Improve access of HIV/AIDS patients to Opportunistic Infections prevention and care and Antiretroviral treatment (linkages with Tuberculosis and psycho-social support)

Minister of Health and ES/NAA

Minister of Health and ES/NAA

\begin{tabular}{|lll|}
\hline INDICATORS & $\mathbf{2 0 0 5}$ & $\mathbf{2 0 1 2}$ \\
\hline Prevalence of HIV among pregnant women & $0.95 \%$ & $<0.8 \%$ \\
\hline $\begin{array}{l}\text { Prevalence of condom use for males and females in high risk category, } \\
15 \text { to } 24 \text { years old }\end{array}$ & Not available & M: $45 \%$ \\
F: $20 \%$
\end{tabular}




\section{CHALLENGE 4 > \\ IMPLEMENT A HIGHLY SUCCESSFUL FAMILY PLANNING STRATEGY}

\section{Current Reality}

The population of Madagascar has doubled over the past 25 years. This puts added strain on national and local resources including the environment, food supply and infrastructure needs. In some areas of the country, $70 \%$ of 16 year old girls have already had a child. Contraceptive use is increasing but overall prevalence is still low. There is high unmet deman for family plang foying they would use colratives if they were available Curre Croviding adve and contratives but the size of the choultenge requires

Goals

1. There will be a reduction in the average size of the Malagasy family to improve the well-being of each family member, he community and the nation.

2. The demand for contraceptives and family planning will be met.

Strategies

1. Increase access and provision of contraceptives.

2. Provide educational programs to men, women and youth.

3. Specifically reduce unwanted teenage pregnancies through family planning services.

4. Integrate family planning into other key health campaigns (eg vaccination and HIV/AIDS).
PRIORITY PROJECTS AND ACTIVITIES

PROJECT LEADER

1. Accelerate implementation of a sectoral plan and carry out a national campaign

2. Strengthen the capacities of health agents on family planning

3. Promote long lasting contraceptive methods

4. Identify and implement an innovative financing strategy to ensure sustainability and general availability of Family Planning programs

5. Ensure the application of agreed quality standards and procedures for services at Minister responsible for Family Planning all levels

6. Extend services on family planning for teenagers through youth centers

7. Integrate reproductive health and family planning in HIV/AIDS programs

\begin{tabular}{lll}
\hline INDICATORS & $\mathbf{2 0 0 5}$ & $\mathbf{2 0 1 2}$ \\
\hline Total Fertility Rate & 5.4 & 3 \\
\hline Fertility Rate - Urban & 3.7 & 3 \\
\hline Fertility Rate - Rural ( some regions have higher fertility rates than others ) & 5 to 8 & 3 to 5 \\
\hline Contraceptive Prevalence Rate among population & 18 & 30 \\
\hline Contraceptive Prevalence Rate among teenagers & 15 & 45 \\
$\begin{array}{l}\text { Percentage of teenagers ( 15-24) having access to information on } \\
\text { family planning }\end{array}$ & 45 & 100 \\
\hline
\end{tabular}
Minister responsible for Family Planning
Minister responsible for Family Planning Minister responsible for Family Planning Minister responsible for Family Planning Minister responsible for Family Planning Minister responsible for Family Planning 


\section{CHALLENGE 5 > \\ REDUCE INFANT MORTALITY}

\section{Current Reality}

As of 2006, there have been national campaigns for vaccination (vitamin A, measles) and increased treatment of diarrhea and malaria at community level. Still, a high infant mortality ratio of 94:1000 persists.

Goals

1. We will have reduced by half the infant mortality ratio.

2. There will be an increased demand for Basic Health Centers pregnancy services.

3. Broader community participation in child health will have been achieved.

Strategies

1. Increase focus on prevention programs in child health.

2. Combine child care package and services that include nutrition and vaccinations.

3. Increase the number of nurses and midwives available at Basic Health Centres.

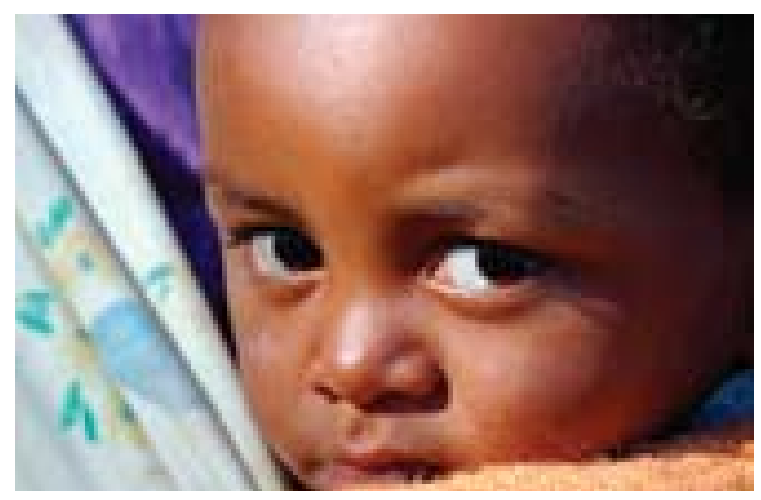

PRIORITY PROJECTS AND ACTIVITIES

1. Provide adequate packages of services (Vitamin $\mathrm{A}, \mathrm{PEV}^{*}+$ ) including epidemiology

PROJECT LEADER surveillance in all Basic Health Centers

2. Organize and coordinate community agents and health workers on uniform procedures Minister responsible for Health for dealing with diseases in children under 5

3. Guarantee that all staff in first referral hospitals and health centers have competency Minister responsible for Health in treating children and newborn babies

4. Sensitize families on behaviour change through community programs such as PCIME Minister responsible for Health (Integrated Management of Children Diseases)

Ratio of infant mortality (out of 1.000)

94

Percentage of DTCP coverage

Percentage of children getting supplementary micronutriment

Percentage of one-year olds immunized against Tuberculosis

Percentage of one-year olds immunized against Measles

$80-100$

83.8

100

00
0




\section{CHALLENGE 6 > \\ REDUCE MATERNAL AND NEONATAL MORTALITY}

\section{Current Reality}

Since 2002, Madagascar has committed to reduce maternal mortality. A national roadmap has been elaborated but still needs to be implemented. There is still a lack of qualified professionals in rural areas and lack of access to obstetrica emergency care. On average, each day, 8 women die of complications related to childbirth.

Goals

1. Increase the demand for antenatal care and preventative

2. Ensure all urban and rural areas have reliable obstetrical emergency services.

3. Promote adequate home-based care for mother and child health

Strategies

1. Develop demand for preventive care among pregnant women.

2. Improve management of high risk pregnancies and complicated deliveries.

3. Increase the availability of midwives, especially in rural areas.

4. Education programs aimed at mothers for homebased care.
PRIORITY PROJECTS AND ACTIVITIES

1. Guarantee that all Basic Health Centers and first referral hospitals have adequate equipment and drugs for pregnancies and deliveries management

2. Accelerate implementation of the roadmap for maternal mortality reduction through community mobilisation, homebased care, and medical support in Health Centers Minister responsible for Health

INDICATORS 2005

Ratio of maternal mortality out of 100.000 living births

Ratio of neonatal mortality out of 1.000 living births
PROJECT LEADER

Minister responsible for Health 


\section{CHALLENGE 7 > \\ IMPROVE NUTRITION AND FOOD SECURITY}

Current Reality

Food insecurity (less than 2300 calories required per person per day) is a problem for the majority of Malagasy households and there is a high malnutrition ratio among children under 5 years. The government has established the National Office of Nutrition to focus exclusively on the nutritional needs of the most vulnerable of the population.

Goals

We will have significantly reduced both the ratio of malnutrition among children under 5 years and ratio of food insecurity among households and vulnerable groups.

Strategies

1. Focus on malnutrition among children under 5 especially addressing micronutrient deficiencies (vitamin A, iodine and iron).

2. Target food insecurity among vulnerable groups such as the very poor and victims of natural disasters.

3. Coordinate surveillance structures on nutrition at national, regional and local level.

4. New emphasis on prevention of malnutrition and food insecurity through labor intensive activities.

5. Consolidate and extend the national community nutrition program.

6. Address micro-nutrient deficiencies among pregnant and lacating women at community level to reduce low birth weights.

\begin{tabular}{|c|c|}
\hline PRIORITY PROJECTS AND ACTIVITIES & PROJECT LEADER \\
\hline $\begin{array}{l}\text { 1. Provide adequate food and nutrition for children who have severe or } \\
\text { moderate malnutrition }\end{array}$ & Director of National Office for Nutrition \\
\hline $\begin{array}{l}\text { 2. Extend and implement the national community based program on nutrition } \\
\text { in the } 116 \text { districts }\end{array}$ & Director of National Office for Nutrition \\
\hline 3. Integrate nutrition into schools program and health promotion activities & Director of National Office for Nutrition \\
\hline $\begin{array}{l}\text { 4. Lead appropriate activities for social protection targeting the most } \\
\text { vulnerables groups }\end{array}$ & Ministers responsible for Health and Education \\
\hline INDICATORS & 2005 \\
\hline Percentage of malnutrition among children under 5 years & 42 \\
\hline Percentage of food insecurity among households & 65 \\
\hline
\end{tabular}

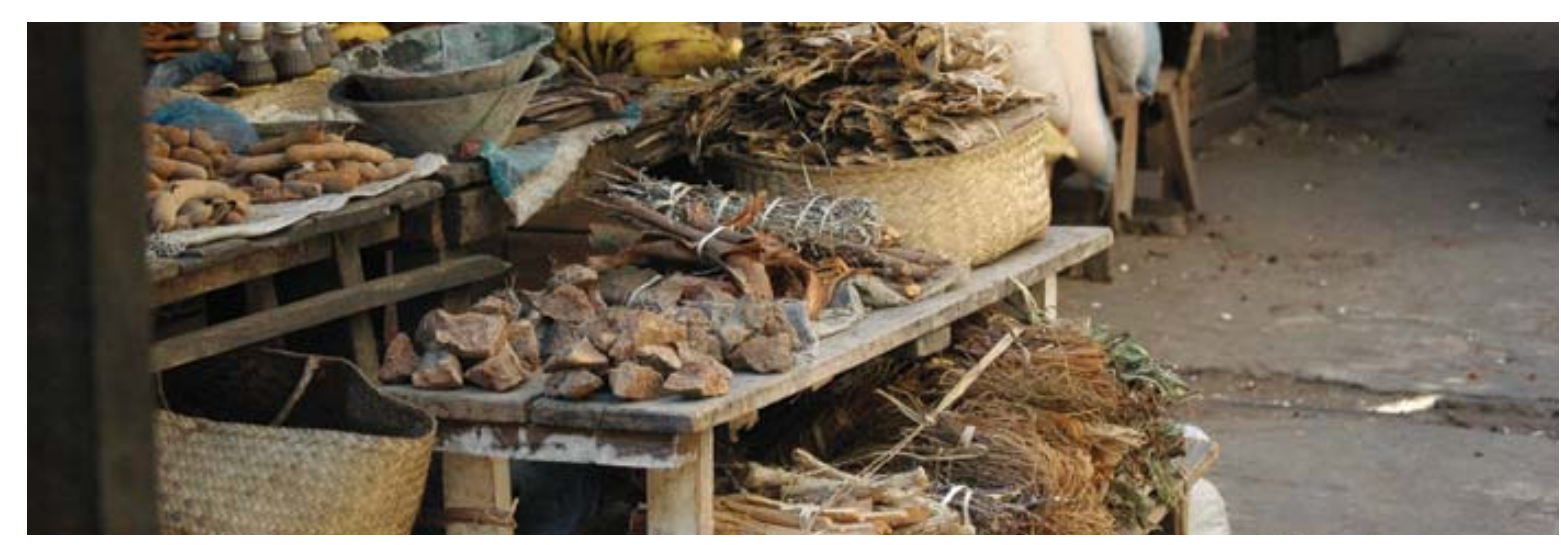




\section{CHALLENGE 8 >}

\section{PROVIDE SAFE WATER AND WIDESPREAD USE OF} HYGIENIC PRACTICES

\section{Current Reality}

As of 2006, more than half the children of Madagascar suffer from water-related diseases and it is the second highest cause of infant mortality. While hygienic programs are in place, besides the needless loss of life, water-related diseases such es diarrhea still cost approximately 6 million lost working days and 3.5 million

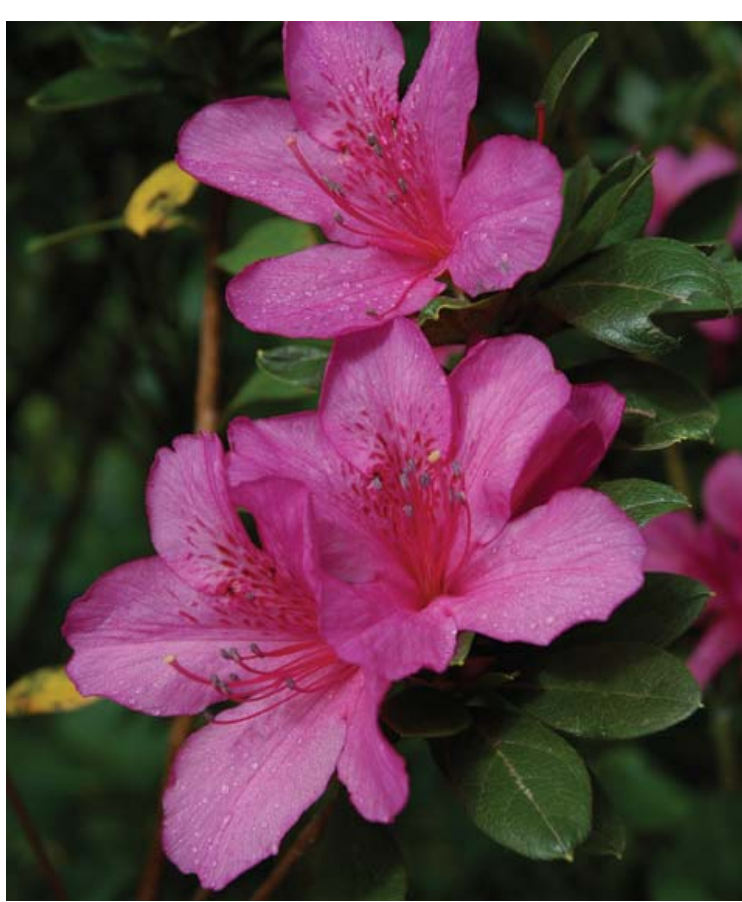

Goals

1. All children will have to be educated in safe sanitary and hygienic practices.

2. Infant mortality due to water related diseases will be significantly decreased.

3. The number of lost working days and school days will be significantly decreased.

\section{Strategies}

1. Ensure adequate access to safe drinking water for all people.

2. Educate all people, particularly parents and children, in safe sanitary and hygienic practices.

3. Implement the international WASH strategy.

\section{PROJECT LEADER}

Minister responsible for Health

1. Centralize different areas of the Ministry of Health to focus on water related diseases

2. Strengthen the cooperation between different Ministries to implement the WASH strategy

3. Promote and widespread educative campaign on WASH strategy Minister responsible for Health

Minister responsible for Health and Minister responsible for Education

4. Integrate safe sanitary and hygienic practices into school programs

Minister responsible for Health and Minister responsible for Health and
Minister responsible for Education 


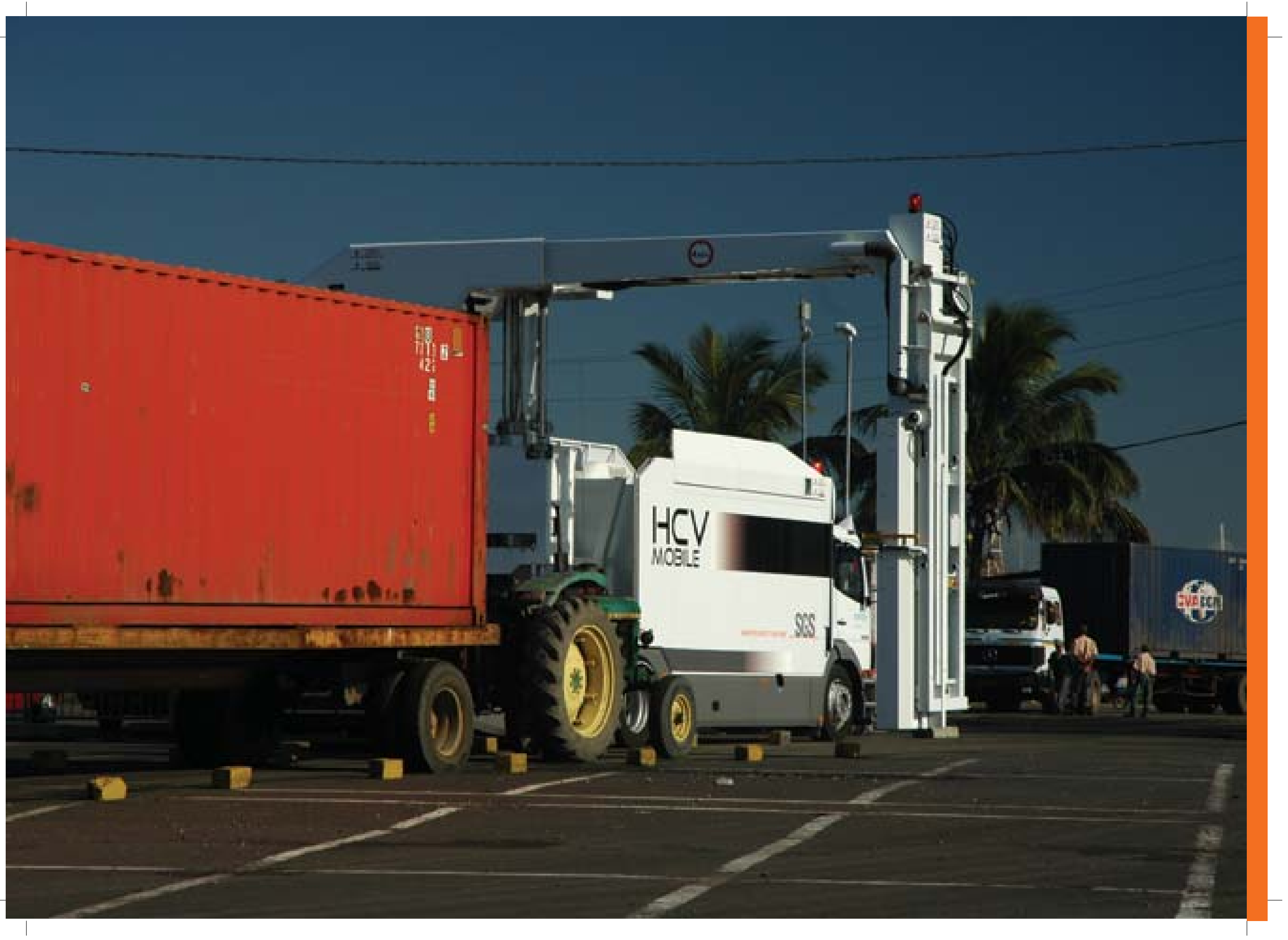




\section{COMMITMENT SIX HIGH GROWTH ECONOMY}

Madagascar will have a high growth economy with growth rates reaching between $7 \%$ to $10 \%$ by 2012 . We will ensure that we have a diversified and strong private sector driven by local and international investment and trade. The Government will generate the fundamental conditions that will support the facilitation of business. We will encourage the pursuit of the best ideas and cutting edge techniques, technologies, and strategies to ensure that we as a nation are responsive to the challenges of globalization, productive in the workplace, and gain a competitive advantage. 


\section{CHALLENGE 1 > \\ ENSURE A STABLE MACROECONOMIC ENVIRONMENT}

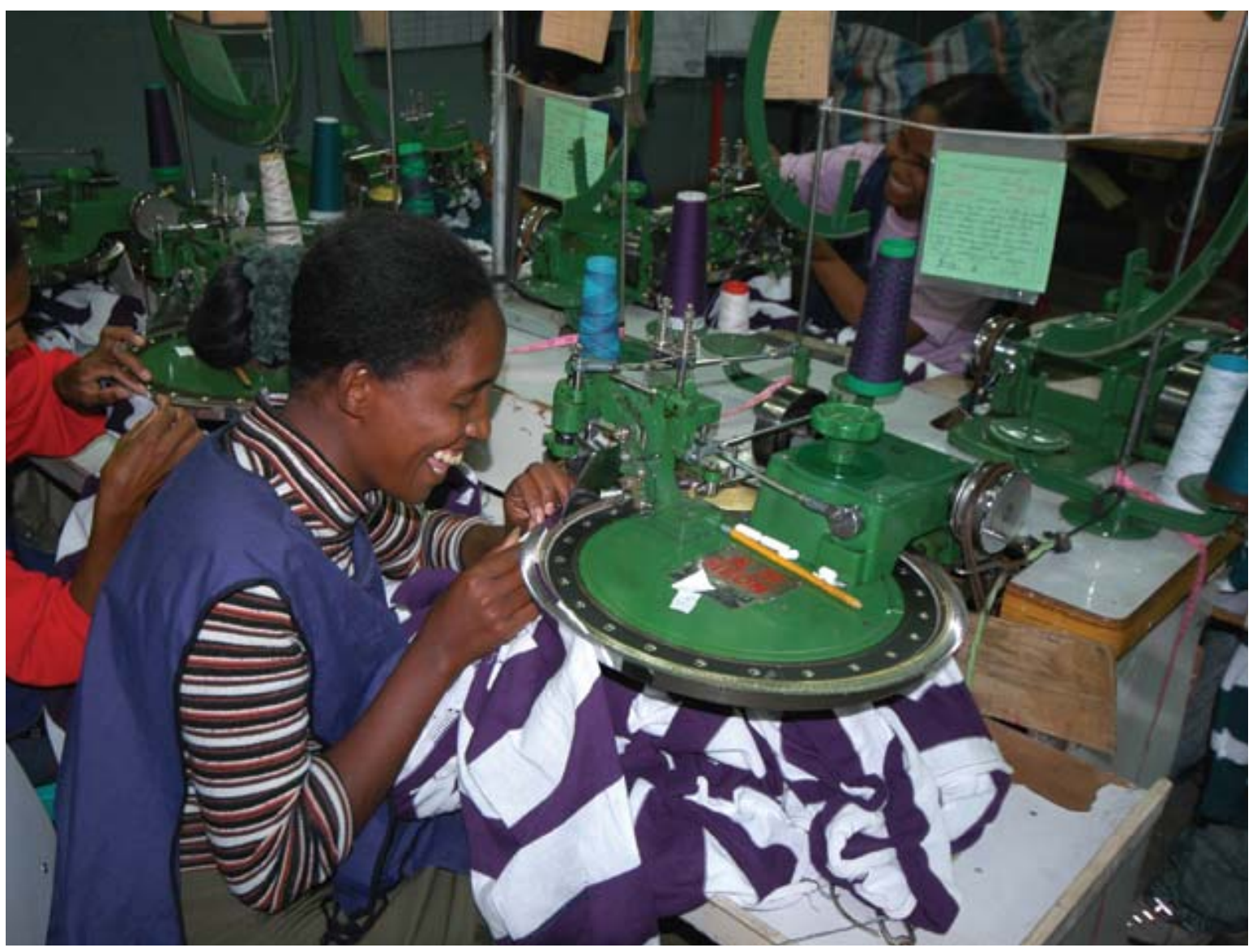

Current Reality

Macroeconomic performance has strengthened but is still uneven, characterized by double-digit inflation due to high oil prices, sharp rise in power and water tariffs and the depreciation of the Ariary in 2005. Import demand has kept depreciating. Exports have suffered from the phasing out of the Multi-Fibre Agreement and from the low price of vanill in the world market. Export Processing Zones have lost 10,000 jobs due to competition in garments from China and India. External sector outlook and economic growth will depend very much on how attractive Madagascar will be for

international investors and how fast the country can develop its minerals and oil resources. Current account deficit has been high, reaching $11.7 \%$ of GDP in 2005 . Economic orow was $4.6 \%$ in 2005 . While the budget deficit is expected to fall to $4 \%$ of GDP for 2006 , there has been a significant shortfoll in revenue collection by the government.

Goals

1. Achieve sustainable macroeconomic stability with low inflation.

2. Eliminate macroeconomic imbalances.

Strategies

1. Pursue a firm monetary policy to contain inflation and promote stability in the foreign exchange market.

2. Rationalize the management of the public finances and eliminate wasteful government expenditures so as to help ensure fiscal discipline.

3. Reduce the budget deficit.

4. Undertake a major overhaul and simplification of the tax system in order to stimulate private initiative and enhance government revenue.

5. Strengthen the analytical and forecasting capabilities within the public administration. 


\section{PRIORITY PROJECTS AND ACTIVITIES}

Reform the national and local tax system to provide a more effective way to generate and collect revenues while improving 作

2. Develop indirect instruments of monetary control, including the securitization of government debt to the Central Bank, appropriate restraint in the growth of the money supply and domestic demand.

3. Progressively reduce the extension of Central Bank credit to the Treasury

4. Progressively reduce and eventually eliminate the arrears of the Public Administration.

5. Computerize the tax centers and customs offices

6. Strengthen the fight against customs fraud, including the reinforcement of the surveillance of the national territory

7. Put in place a system of reliable and up-to-date statistical data in conformity with the National Strategy for the Development of Statistics, and a sharing of information within and across Ministries

8. Develop analytical tools and macroeconomic and sector models of forecasting

\section{PROJECT LEADER}

Minister responsible

for Finance

Governor of Central Bank

Governor of Central Bank

Minister responsible for the Budget

Minister responsible or Finance

Minister responsible for Finance

Minister responsible for Economy

Minister responsible for Economy
INDICATORS

2005

2012

Annual Inflation rate $1 \%$

Budget deficit (\% of GDP)

$11.4 \quad 5.0$

$\begin{array}{lll}4.3 & 3.0\end{array}$

$10 \quad 5$
of the last yearl

Foreign currency reserves (in imports month) $\quad 2.9 \quad 6$

Current account balance (\% of GDP) $\quad-11.7 \quad-8.0$

$\begin{array}{lll}\text { Total public debt (\% of GDP) } & 81.4 & 60\end{array}$

Economic growth rate (\%) $\quad 4.6 \quad 7$ to 10

Investment rate (\% of GDP) 22.5

GDP per capita (USD) $\quad 309 \quad 476$

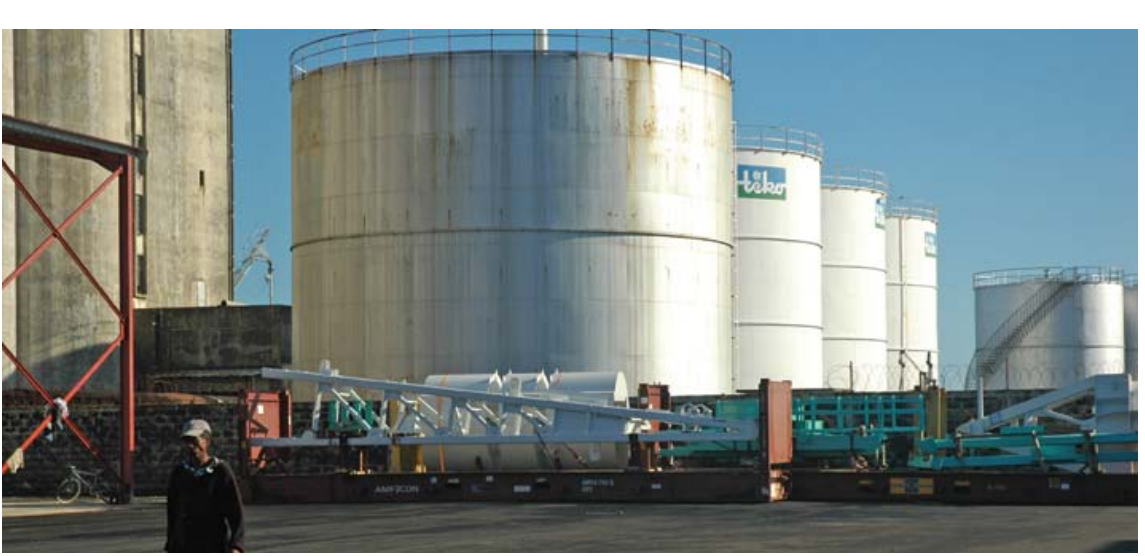




\section{CHALLENGE 2 > INCREASE FOREIGN DIRECT INVESTMENT}

Current Reality

Since 2002, the Malagasy Government has pursued a policy of attracting foreign direct investments as one of the key strategies for the development of the country. However, FDI has been very low for a well-endowed country like Madagascar. The country attracted only USD 85 million in 2005. It is ranked $131 \mathrm{ST}$ in the "Doing Business Indicators' (DBI) of the World Bank, a very low ranking for a country that has not seen major political and social upheaval. In 2006 the Government established the Economic Development Board of Madagascar to improve the investment climate an also created a new investment law that would cut red tape and provide a package of incentives that would serve to enhance Madagascar's attractiveness and promote a much higher level of FDI as well as encourage existing industries to expand production.

Goals

1. Madagascar will be the best place to invest in sub-Saharan Africa and the Indian Ocean.

2. Madagascar will achieve double-digit economic growth by 2012.

3. We will broaden the tax base in the medium to long term.

4. Foreign investments will be especially promoted in sectors where value added, job creation, integration, and multiplie effects on other sectors will be maximized.

Strategies

1. Create a competitive business environment.

2. Secure investments and commerce.

3. Aggressively promote Madagascar to attract investment.

4. Provide enabling infrastructure, including EPZ, IPP,

land tenure.

5. Pursue international agreements to increase investors

confidence and market access.

6. Remove distortions in the economy.
PRIORITY PROJECTS AND ACTIVITIES

1. Render EDBM fully operational to actively promote FDI and improve investment climate

CEO of the Economic Development Board of Madagascar

2. Carry out a "Guillotine" approach of administrative procedures that are an impediment CEO of EDBM to investment

3. Implement the new law on investments CEO of EDBM

4. Develop a new and targeted marketing strategy for attracting FDIs CEO of EDBM

5. Set up an industrial zone to speed up and facilitate investment in export-oriented activities CEO of EDBM

6. Create a land bank to facilitate and speed up investment project implementation in CEO of EDBM tourism and agribusiness

7. Initiate and ratify priority bilateral, regional and international investment protection CEO of EDBM agreement and non-double taxation agreement to increase investor confidence

8. Strengthen the industrial arbitration court to solve disputes between employers and CEO of EDBM employees and between investors and government agencies/other investors

9. Extend the insurance system on international transactions (Trade Insurance Agency)

CEO of EDBM

INDICATORS

2005

Foreign Direct Investments (Millions US\$)

84

2012

Ranking in investment climate 


\section{Current Reality}

The demographic structure shows that in 2005, the segment of the active population accounts for $64.6 \%$ of total population. $82 \%$ of the labor force is employed in the agricultural sector. $13.4 \%$ are employed in the formal sector of which about 150000 are employed in the public sector. The Export Processing zones have been an important employment provider, but this role has stagnated due to the phasing out of the Multi-fibre Agreement. Although the registered unemployment rate is relatively low, the real unemployment rate is significantly higher.

The cost of labor is relatively low in absolute terms; while the median wages for an unskilled production worker are approximately 36 USD in Madagasear, the figure stands at 85 USD in China and 44 USD in India. However, labour productivity is weak; the work force lacks qualifications an there is a substantial underutilization of labour resources. The labor market is characterized by inadequate matching of education and employment needs.

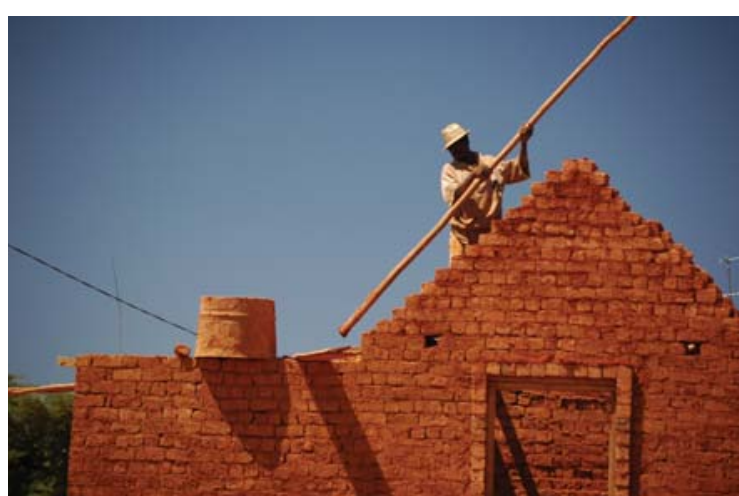

Goals

1. We will ensure that the labour force is well qualified and able to respond to the needs of the economy.

2. Labor will exhibit substantially higher productivity.

3. Full employment will be pursued.
Strategie

1. Stimulate job-generating sectors.

2. Reform labor laws including establishing Industrial Arbitration Court.

3. Develop a National Manpower Plan to align labor to the needs of the economy.

4. Provide vocational training to support the priority industries e high growth economy.

5. Shift mindset to support efficient economic activity.

\section{PRIORITY PROJECTS AND ACTIVITIES}

PROJECT LEADER

1. Support on the job training and vocational training programme in Chamber of Commerce, Minister responsible for Labour Industries and Public Institutions

2. Draw up and implement strategies for promoting and creating productive jobs Minister responsible for Labour SME creation, vocational training, improvement of informal employmen

3. Integrate employment into the mechanisms of programming and monitoring - evaluation Minister responsible for Labour

4. Adapt the building of local skills to the opportunities in the regions Minister responsible for Labour

5. Set up centers for employment and training advice/guidance in the 22 regions Minister responsible for Education

6. Develop initial and continuous vocational training Minister responsible for Labour

7. Set up Regional Centers of Research and Training to Techniques (High Labor Intensity) Minister responsible for Labour 8. Develop accurate labor statistics Minister responsible for labour

INDICATORS

2005

2012

Unemployment rate

High

Number of enrolment in vocational schools (index base $2005=100$ )
100

500 


\section{CHALLENGE 4 > \\ REFORM THE BANKING AND FINANCIAL SYSTEM}

Current Reality

As of 2006, there are 6 commercial banks operating in

Madagascar (4 French and 2 Mauritian). The financial system suffers from limited competition and access to medium or long term financing is low. The financial institutions are risk averse and the cost of financial intermediation is high. As a result, a substantial part of the financing requirements of private firms remains unsatisfied; SMEs have limited access

even to short term credit. The proportion of the population even thas a cess to bation that has stock Exchange. There are several micro-fine is . rate of around $3 \%$ per month is very high.

Goals

We will ensure the development of a well functioning financial system that is capable of meeting the short and long term financing needs of the private sector at affordable rates of interest and provides a wide range of financial products to a significant part of the population.

Strategies

1. Enhance competition in the banking sector.

2. Strengthen the regulatory and supervisory framework.

3. Strengthen the efficiency and network of microfinance institutions.

4. Establish the conditions for the development of financial markets, including the creation of a Stock Exchange.

5. Encourage the increase in savings.

\begin{tabular}{ll} 
PRIORITY PROJECTS AND ACTIVITIES & PROJECT LEADER \\
$\begin{array}{l}\text { 1. Attract more foreign banks and provide banking licences to create a competitive } \\
\text { environment and encourage the set up of rural branches }\end{array}$ & $\begin{array}{l}\text { Supervision Committee of Banks } \\
\text { and Financial Institution }\end{array}$ \\
$\begin{array}{l}\text { 2. Encourage the development of financial markets, including stock exchange, and new } \\
\text { financial products (collateral funds, participation funds, investments funds) }\end{array}$ & $\begin{array}{l}\text { Minister responsible for } \\
\text { the Economy }\end{array}$ \\
$\begin{array}{l}\text { 3. Provide nationwide access to affordable microfinance and set up a refinancing system } \\
\text { for microfinance institutions }\end{array}$ & $\begin{array}{l}\text { Minister responsible for } \\
\text { the Economy }\end{array}$ \\
$\begin{array}{l}\text { 4. Support the development of financial services such as leasing and factoring } \\
\text { 5. Reform the insurance system to support productive activities }\end{array}$ & $\begin{array}{l}\text { Minister responsible for } \\
\text { the Economy }\end{array}$ \\
\hline $\begin{array}{l}\text { INDICATORS } \\
\text { Private saving rate }\end{array}$ & Minister responsible for Finance \\
\hline Difference between credit and debit interest & $\mathbf{2 0 0 5}$ \\
\hline Long term bank credit to private sector (\% Total credit) & 12.1 \\
\hline
\end{tabular}




\section{CHALLENGE 5 >}

\section{STRENGTHEN DOMESTIC ENTERPRISES, SMES} AND HANDICRAFT INDUSTRY

\section{Current Reality}

Since 2002, the Government has promoted small and medium enterprises (SMEs) through the Chamber of Commerce, Industry, Agriculture, and Craft Industry, as well as the Chambers of Profession, while the centers for Promoting Craft Industry have been strengthened. Besides providin programs for training the craftsmen, some sectors of production have been restructured through the creation of clusters.

The productivity of SMEs and craftsmen remains low mainly predominant. The access to foreign markets is limited. Entrepreneurship is staying at a limited stage. A key potential can be tapped through the vertical integration and clustering of manufacturing enterprises. The capacity utilization rate is low ranging from 45 to $50 \%$. The contribution of the secondary sector to the GDP is around $13 \%$.

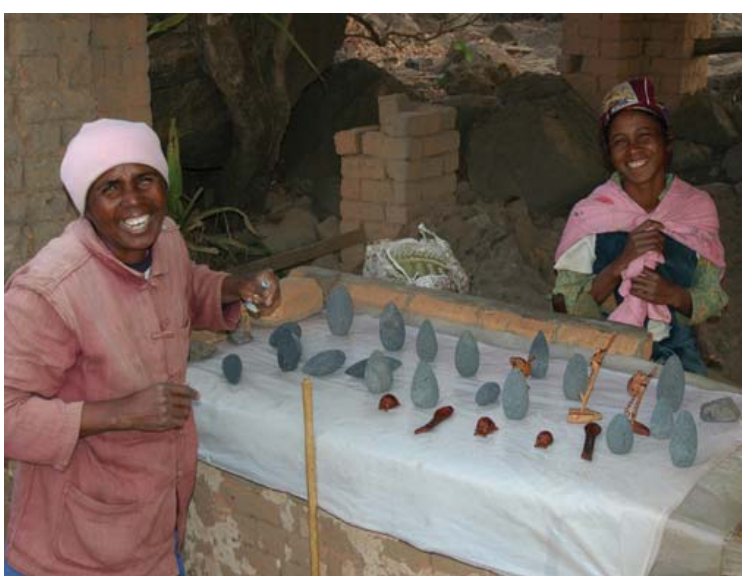

Goals

Firms, SMEs, and craft industry, at the local level, will be stimulated so that they can efficiently contribute to economic growth, integrate into the national economy, and in increasingly fulfill their production capabilities through improved technology and managerial methods. Actions for the restructuring of sectors and capacity strengthening of businessmen will be pursued.

\begin{tabular}{|c|c|}
\hline PRIORITY PROJECTS AND ACTIVITIES & PROJECT LEADER \\
\hline 1. Set up Regional Centers for Industrial and Commercial Development & $\begin{array}{l}\text { Minister responsible for Industry } \\
\text { and Commerce }\end{array}$ \\
\hline 2. Extend the Chambers of Profession to the rural areas & $\begin{array}{l}\text { Minister responsible for Industry } \\
\text { and Commerce }\end{array}$ \\
\hline 3. Strengthen the operating capacity of centers for the promotion of craft industry & $\begin{array}{l}\text { Minister responsible for Industry } \\
\text { and Commerce }\end{array}$ \\
\hline $\begin{array}{l}\text { 4. Increase the incentives for the integration of the informal sector into the formal sector: } \\
\text { training, access to credits and to technologies, information about the market }\end{array}$ & $\begin{array}{l}\text { Minister responsible for Industry } \\
\text { and Commerce }\end{array}$ \\
\hline $\begin{array}{l}\text { 5. Draw up and implement the national policy for the promotion of SMIs/SMEs as well as } \\
\text { craft industry and trade }\end{array}$ & CEO of EDBM \\
\hline 6. Develop an information system on employment and activities & Minister responsible for Commerce \\
\hline INDICATORS & 2005 \\
\hline Number of created enterprises & 2,000 \\
\hline Share of informal sector in GDP (documented figure) & 20 \\
\hline
\end{tabular}

\section{Strategie}

1. Establish productivity support centers

2. Transition from informal sector to formal sector 


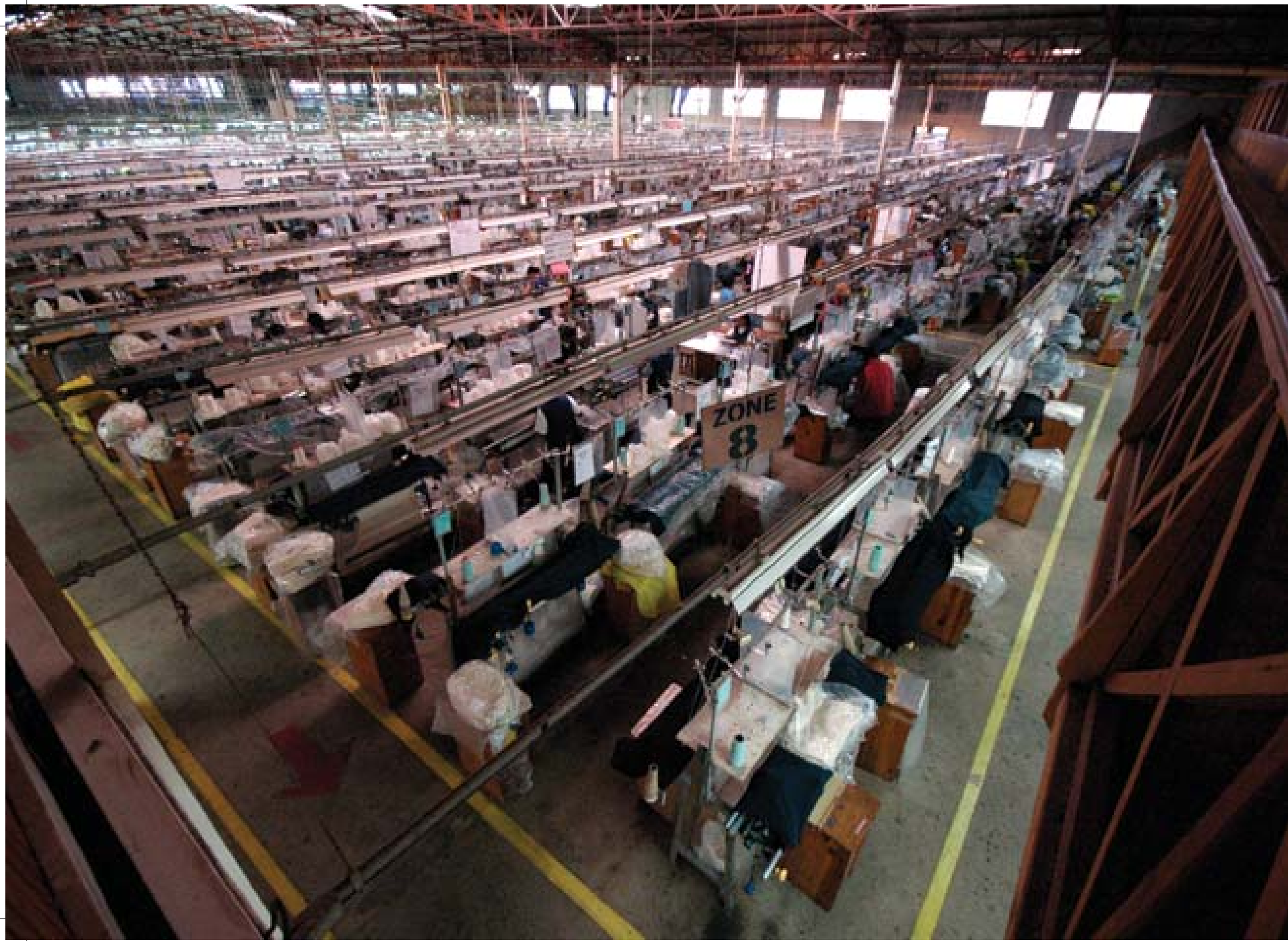




\section{CHALLENGE 6 > \\ ENHANCE INTERNATIONAL TRADE COMPETITIVENESS}

\section{Current Reality}

Traditional exports account for the bulk of international trade, making the economy vulnerable to different shocks. In 2005 , exports were impacted by deteriorated terms of trade and the dismantling of the multi-fibre agreement. The value of exports declined by $20.7 \%$ as compared to its level in 2004 . The lack of conformity to international quality standards and norms remains one of the main factors impeding the

expansion of exports.

Goals

Export diversification will be intensified. National products will meet the standards in quality required in the internation level and exports of products with high value added will substantially increase.

Strategies

1. Facilitate export marketing, insurance and financing.

2. Provide enabling infrastructure, policies and administration.

3. Develop mechanisms for product standardization and certification, implement a program to support the producers.

4. Adopt a new industrial strategy to penetrate markets with products with high value added.
PRIORITY PROJECTS AND ACTIVITIES

1. Set up One Stop Shop for Exports

2. Facilitate the access to credits by instituting the special fund for exports

3. Encourage promotional work by Embassies and Consulates

4. Set up export agencies in the targeted countries and organize activities for promoting Madagascar and its products

5. Carry out a campaign for promotion of high quality standards Minister responsible for foreign affairs

Accredit chemical, microbiological, and metrological laboratories

7. Adopt an approach for industrial transformation of proximity by drawing together raw materials in each sector and in each region

8. Develop accurate trade statistics and indicators Minister responsible for foreign affairs

Minister responsible for foreign affairs Minister responsible for agriculture

Minister responsible for industry INSTAT

\begin{tabular}{lll}
\hline INDICATORS & 2005 & 2012 \\
\hline Increase of exports of goods (\% of GDP) & 16.7 & 22.3 \\
\hline Rate of coverage of imports by exports & 65.5 & 83.8
\end{tabular}




\section{CHALLENGE 7 > \\ INTENSIVELY DEVELOP THE MINING SECTOR}

Current Reality

For almost two decades, the mining and oil potential of Madagascar was neglected by the previous governments. The country failed to generate tangible benefits in terms of Since 2003, this has begun to change. Officially, mining activities contribute to less than $4 \%$ of GDP. If all current proven reserves are put to production, the industry should account for at least $30 \%$ of GDP in 2011 .

In 2006, the Government initiated platform meeting of representatives of stakeholders including private companies, donors, communes and government helped identify the priority actions to trigger the boom of the industry (Strategic Decision Meeting)

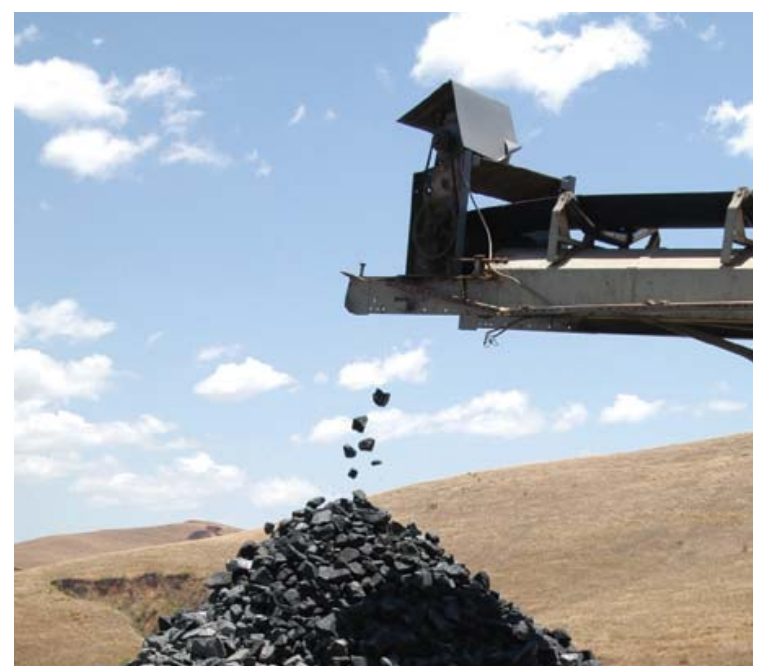

Goals

Madagascar will help current mining projects enter the production phase quickly while respecting its communities and the environment. It will unleash its extractive potential by attracting more explorers and promoting its natural assets.

Strategies

1. Ministries, companies and donors to team up to eliminate existing "speed bumps".

2. Improve existing environment based on the feedbacks of private companies.

3. Involve citizens in developing extractive projects (consultation during design stage and monitoring).

4. Integrate the small scale minors in the formal economy.

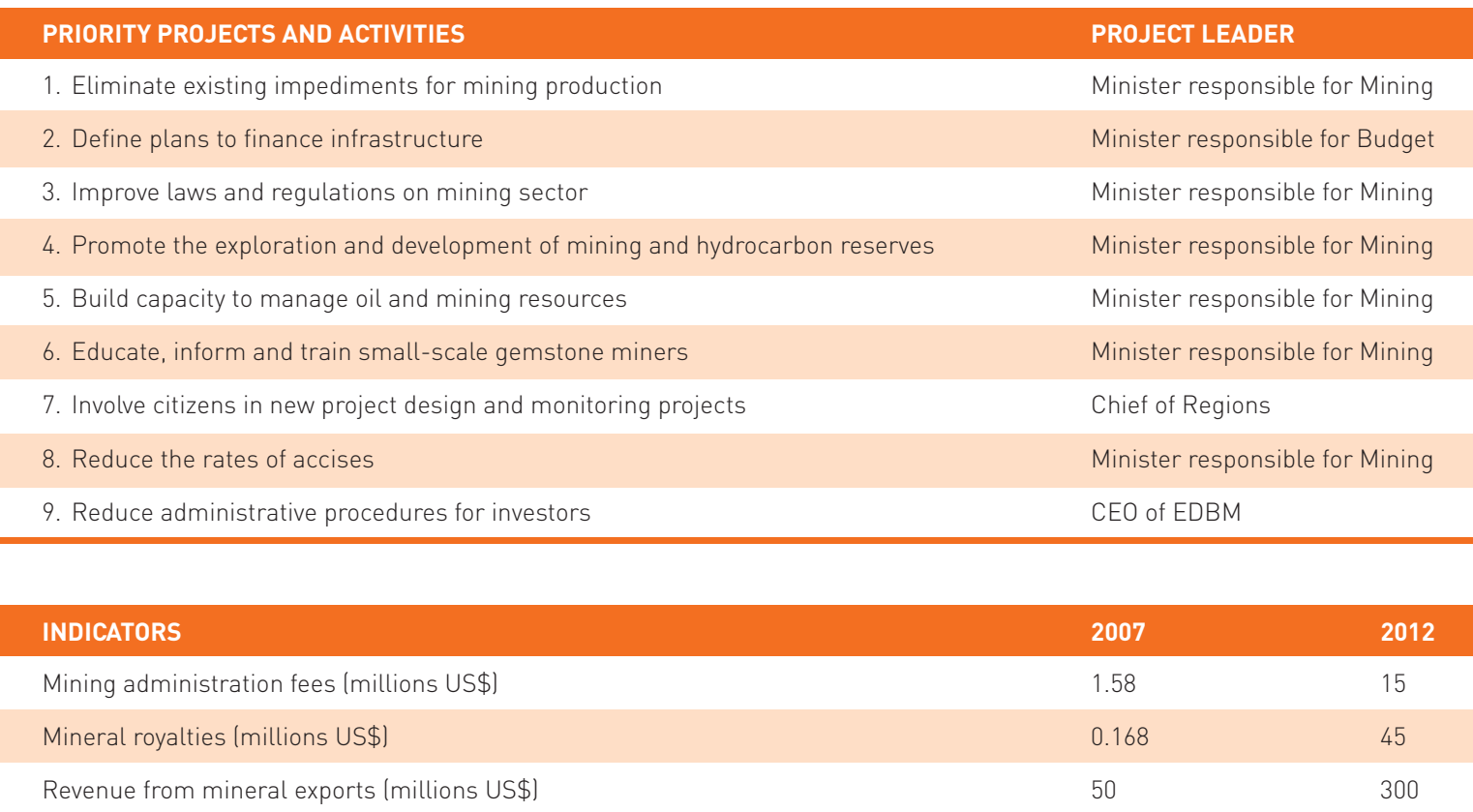




\section{CHALLENGE 8 > \\ INTENSIVELY PROMOTE AND DEVELOP THE TOURISM SECTOR}

\section{Current Reality}

Madagascar is endowed with exceptional fauna and flora, most of which are endemic. As an island, Madagascar has 5,000 unspoiled kilometres of coastline and a climate which is favorable to the development of all forms of eco-tourism. However, because of the lack of infrastructure, suitable accommodation and connection to some regional hubs, the number of tourists coming to Madagascar is only about 150,000 per year, generating a revenue of about \$US 200 millions. However, inspite of the constraints, tourism ranks among the main providers of foreign currencies for the Malagasy economy. The sector is in constant expansion with $19 \%$ increase in revenues in 2005. The Government is committed to aggressively developing and promoting tourism.

Groals

Madagascar will be a privileged destination for all categories of tourism, with a primary focus given to eco-tourism.

International hotel chains will be encouraged to invest in Madagascar, so as to solve the problem linked to the lack of infrastructure and suitable accommodation. Local domestic operators will be encouraged to develop further the breadth and standard of their facilities and programs. Madagascar will be amongst the leading countries in Sub-saharan Africa and the Indian Ocean in the promotion of a high-quality ecotourism experience.

Strategies

1. Attract high quality investors by the provision of incentives, access to land, and general support.

2. Promote the destination "Madagascar" as a superior and unique eco-tourism destination.

3. Support management development and professionalism of the tourist sector

4. Improve the range of tourism products and services.

\begin{tabular}{|c|c|c|}
\hline PRIORITY PROJECTS AND ACTIVITIES & \multicolumn{2}{|c|}{ PROJECT LEADER } \\
\hline 1. Identify and launch new tourist sites and products & \multicolumn{2}{|c|}{ Minister responsible for Tourism } \\
\hline 2. Set up a tourist database & \multicolumn{2}{|c|}{ Minister responsible for Tourism } \\
\hline 3. Broaden the network of tourism agencies & \multicolumn{2}{|c|}{ Minister responsible for Tourism } \\
\hline 4. Develop e-tourism (on-line purchase, electronic payment terminal, credit cards, ...) & \multicolumn{2}{|c|}{ Minister responsible for Tourism } \\
\hline $\begin{array}{l}\text { 5. Identify priority tourist sites which are favorable to investments; speed up and } \\
\text { facilitate the procedures for the setting up and exploitation of investment projects }\end{array}$ & \multicolumn{2}{|c|}{ CEO of EDBM } \\
\hline 6. Rationalize the management of hotel assets with public participation & \multicolumn{2}{|c|}{ Minister responsible for Tourism } \\
\hline 7. Support the training activities in the tourism sector & \multicolumn{2}{|c|}{ Minister responsible for Tourism } \\
\hline INDICATORS & 2005 & 2012 \\
\hline Revenue generated by the tourist sector (millions US $\$$ ) & 184 & 577 \\
\hline Number of direct jobs created within the sector of tourism & 21,167 & 40,100 \\
\hline Number of tourists visiting Madagascar & 150,000 & 500,000 \\
\hline
\end{tabular}
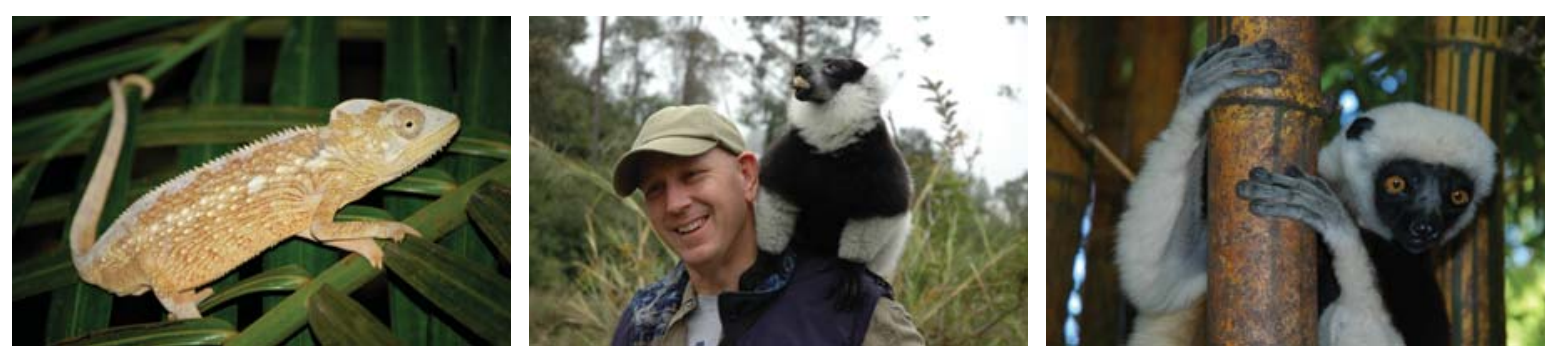


\section{CHALLENGE 9 > \\ INTENSIVELY EXPLOIT REGIONAL OPPORTUNITIES}

Current Reality

Because of its geographical position, Madagascar has joined organizations for cooperation and regional integration like the Indian Ocean Commission (IOC), the Common Market for Eastern and Southern Africa (COMESA), and the Southern African Development Community (SADC). Madagascar has already carried out several adjustments of its customs tariffs and its customs nomenclature for its eventual integration into a regional Customs Union. The benefits of regional into a region for integration for opriate steps to

Goals

The expansion of the market, the development of exchanges, and the promotion of investments will be the core objectives of regional cooperation and economic integration. The integration at the level of sub-regions such as SADC or

COMESA is just the first step to the institution of an African

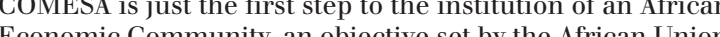

Strategies

1. Ratify regional protocols for improved access to cross border trade and investment opportunities.

2. Promote domestic awareness of regional market opportunities.

3. Promote regionalism through the development of inter and intra regional trade.

4. Boost vertical integration at regional level.

\section{PRIORITY PROJECTS AND ACTIVITIES}

1. Ensure the consistency of regional instruments to national legal texts

2. Examine the socio-economic impact of the various regional instruments

3. Strengthen the capacity of national actors, and operate measures to accompany the implementation of the regional instruments

4. Set up a platform for exchange and information at the national and regional levels about the regional opportunities

5. Encourage the processing and promote the export of processed products instead PROJECT LEADER

Minister responsible for Foreign Affairs Minister responsible for the Economy Minister responsible for Trade

Minister responsible for Trade

\section{CEO of EDBM}

INDICATORS

Market share at regional level (\%)

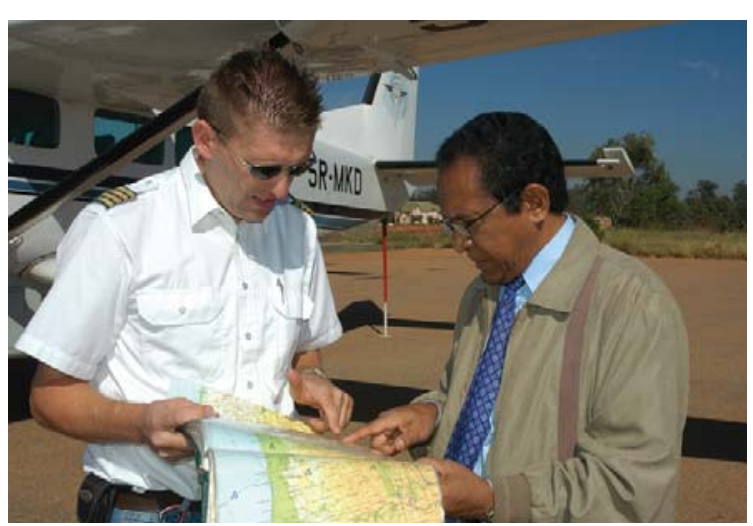




\section{CHALLENGE 10 > \\ THROUGH DIPLOMACY, DEVELOP ECONOMIC SYNERGIES}

\section{Current Realit}

The Government has redirected the main role of overseas representatives; henceforth, diplomacy will be used to promote development. In 2005, more than 15 commercial attachés were working to promote economic ties with partner countries. 23 economic missions came to Madagascar to discuss

investment opportunities; also, 31 forums were organized to promote Madagascar overseas.

Participation in international events has been tremendously intensified. The Economic Development Board of Madagascar (EDBM) has been set up to work with overseas representatives in investment promotion.

Goals

Overseas representatives will act as the key link in the promotion of Malagasy products and will be proactive in international meetings and in the pursuit of economic partnerships. Madagascar will be among the most important destinations for foreign investments.

Strategies

1. Formulate publicity strategy aimed at raising the profile of Madagascar.

2. Establish a coordinating group to promote Madagascar's international branding.

3. Facilitate and intensify international negotiations supporting the promotion of socio-economic activities.
1. Organize regional and international events

2. Set up a permanent « Madagascar Show Case » (Vitrine de Madagascar) within overseas agencies

3. Draw up and spread commercials (films, reports, leaflets, booklets, maps,

4. Carry out advertising campaign in the targeted zones

5. Set up a task force in relation with EDBM in each ministry

6. Increase and optimize the participation in international meetings

7. Improve the participation of the private sector in the different international negotiations

8. Promote inter-country regional cooperation

\section{Minister responsible for Foreign Affairs}

CEO of EDBM

CEO of EDBM

CEO of EDBM

Minister responsible for Foreign Affairs

Minister responsible for Foreign Affairs

Minister responsible for Foreign Affairs 


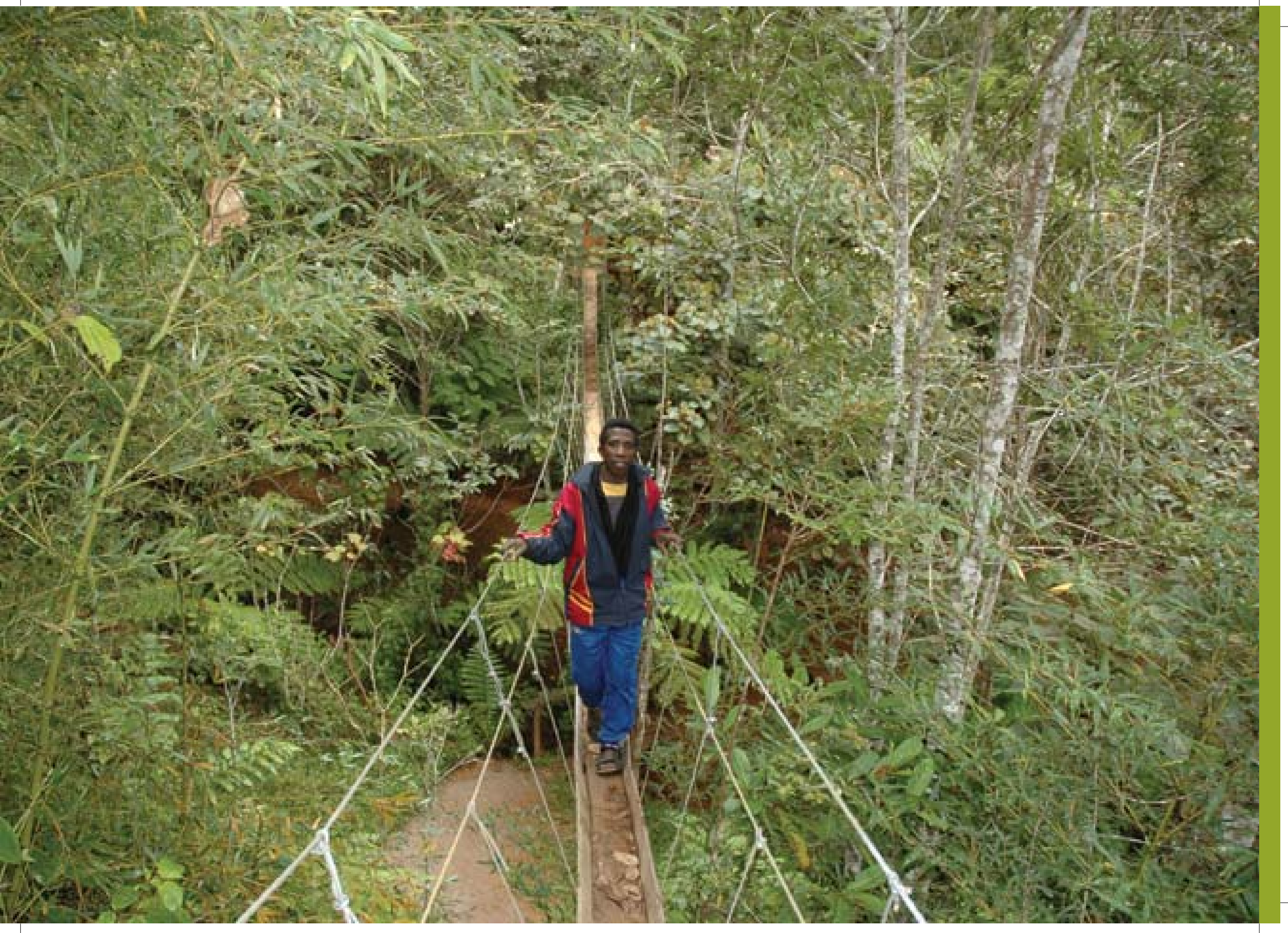




\section{COMMITMENT SEVEN CHERISH THE ENVIRONMENT}

Madagascar will be a world leader in the development and implementation of environmental best-practice. After many decades of exploitation and neglect, we have begun to turn the tide. We will become a "green island" again. Our commitment is to care for, cherish and protect our extraordinary environment. The world looks to us to manage our biodiversity wisely and responsibly and we will. Local communities will be active participants in environmental conservation under the guidance of bold national policies. Given the Government's vision - Madagascar Naturally - we will develop industries around the environment such as eco-tourism, agri-business, sustainable farming practices, and industries based on organic and natural products. These industries and activities will minimize biodiversity damage and maximize benefits for the nation and the people. 


\section{CHALLENGE 1 >}

INCREASE THE PROTECTED AREAS FOR THE CONSERVATION

OF LAND, LAKE, MARINE AND COASTAL BIODIVERSITY

Current Reality

Madagascar has one of the highest rankings of flora and fauna biodiversity richness and endemism in the world. $85 \%$ flora, $39 \%$ birds, $91 \%$ reptiles, $99 \%$ amphibians, an $100 \%$ lemurs are endemic.

Such biodiversity is concentrated in the forest ecosystems which are constantly losing ground to agricultural activity. Losing one hectare of forest in Madagascar has a more seriou effect on the world biodiversity than losing one hectare of forest elsewhere. From a scientific viewpoint, it means the disappearance of several thousands of species, which do not exist anywhere else. Therefore, Madagascar is obliged to preserve endemic biodiversity through responsible governance for protected areas which will be managed either by the State, private entities, or local communities or put under comanagement.

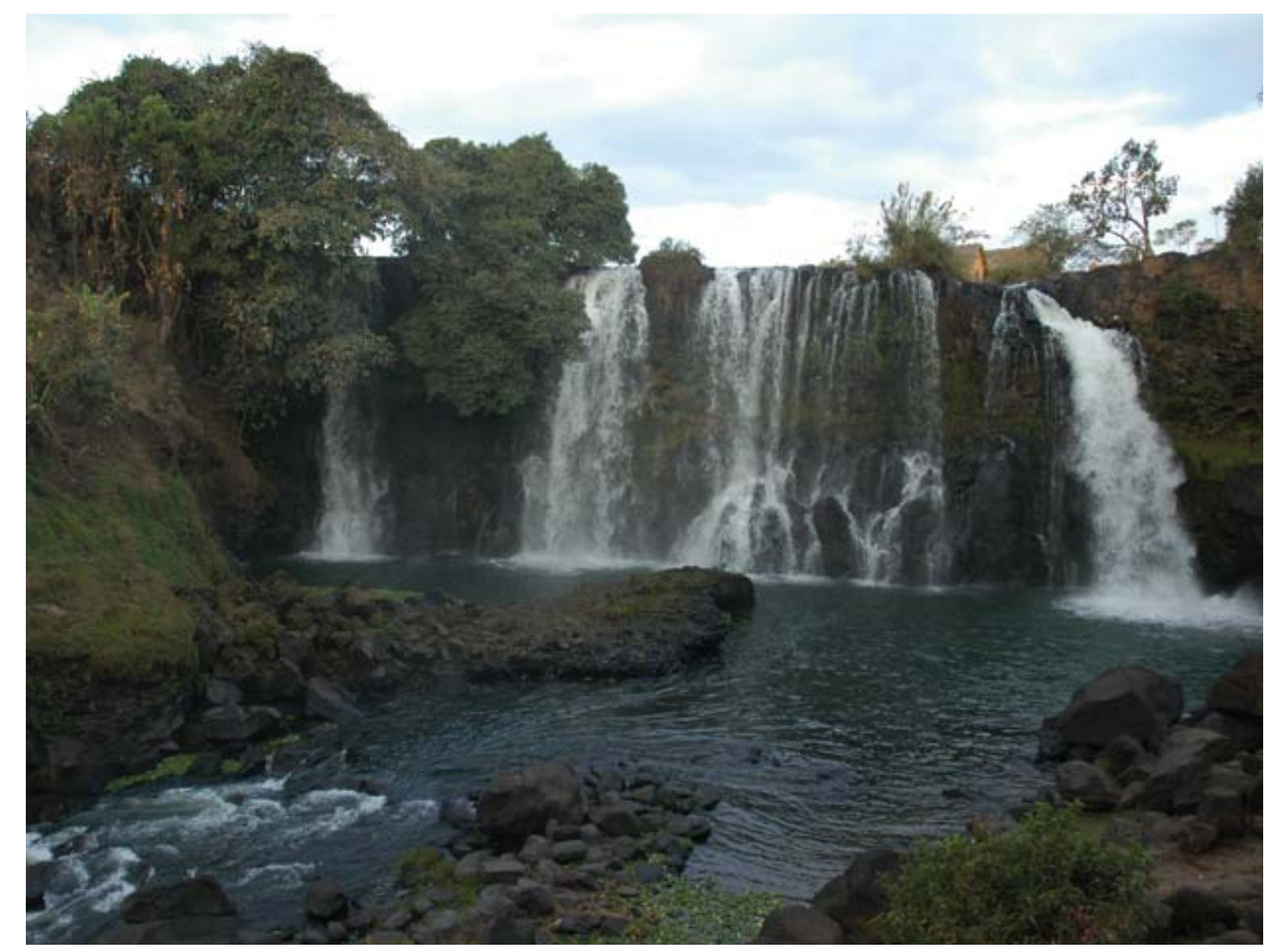


Goals

Madagascar in 2003 committed to increase the volume of protected area from $1.7 \mathrm{~m}$ hectares to $6 \mathrm{~m}$ hectares, and upgrading the protection of the marine economic zone.

The goal is in line with the objective assigned by the International Union for the Conservation of Nature (IUCN) and it accounts for $10 \%$ of the national territory allocated for ecological balance.

Furthermore, Madagascar will abide by the Kyoto Accords and international climate change agreements to ensure that Madagascar is a green country that contributes not just to national well-being but to global well-being.

Strategies

1. Establish new land, lake, marine and coastal protected areas.

2. Ensure financial sustainability for the management of protected areas and the biodiversity

3. Manage the protected areas and the land, lake, marine and coastal biodiversity.

3. Value the biodiversity in a sustainable manner.

4. Establish a national eco-tourism framework and strategy to contribute to the protection and promotion of the environment and to ensure "eco-eco" harmonization (economic - ecological).

\section{PRIORITY PROJECTS AND ACTIVITIES}

1. Inform and raise awareness with all stakeholders

2. Carry out Surveys / Inventories

3. Conduct national, regional and communal consultations

Minister responsible for Environmen

4. Carry out demarcation/ cartography

5. Develop the management scheme and the management mode

6. Mobilize the Funds for the Foundation Minister responsible for Environment

7. Develop other financing instruments Minister responsible for Environment

8. Increase private sector funding Minister responsible for Environment

9. Provide for the ecological monitoring and the implementation of measures for the Minister responsible for Environment conservation of land and watery ecosystems

10. Capitalize the conservation plans per endangered species_Minister responsible for Environment

11. Provide for surveillance and control Minister responsible for Environment

12. Conduct an examination to determine the value of eco-systems services in Minister responsible for Environment Madagascar, including carbon sequestration and it role in financing environmental protection and economic development

\section{INDICATORS}

Representation rate of the habitats in the protected area system

Mobilized capital amoun

Overall efficiency rate or protected areas

Increase rate in number of tourists visiting the protected areas per year
2005

2012

$87 \%$

$87 \%$

US $\$ 18,000,000 \quad$ US $\$ 50,000,000$

$51 \% \quad 70 \%$

$106,600 \quad 149,000$




\section{CHALLENGE 2 > \\ REDUCE THE NATURAL RESOURCE DEGRADATION PROCESS}

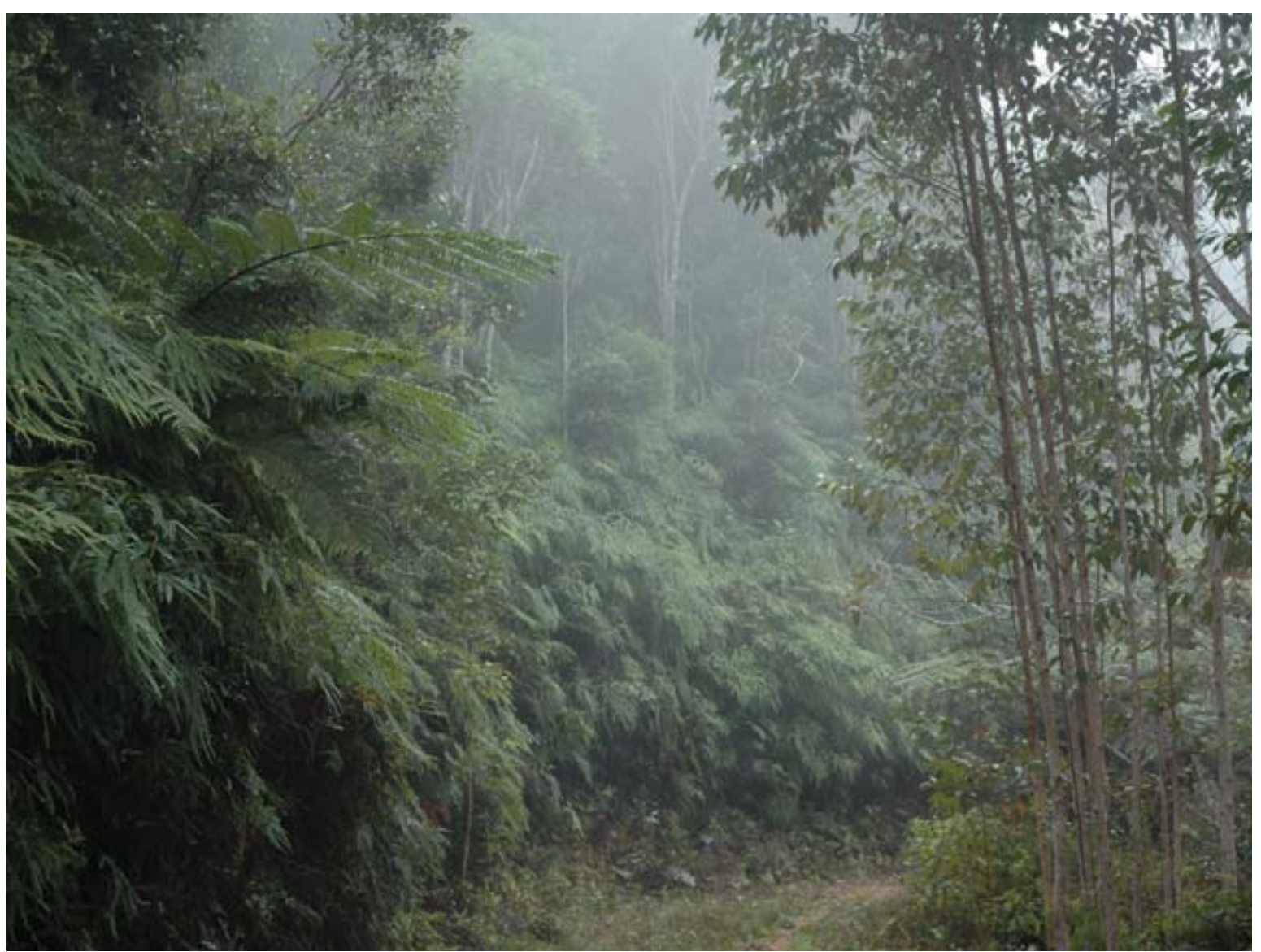

Current Reality

Sadly, Madagascar has not escaped from the increasing degradation of natural resources by irresponsible practices. The abusive and illicit operations by timber and forest producers is one of the major causes of deforestation. This is compounded by the lack of professionalism among fores operators who behave like economic operators who are concerned more about short term profit and interest. In addition, most Malagasy people use wood and its byproduct as an energy source because they do not require preliminary investment in equipment and the product may be purminary in forest and natural resource degradation.

Currently the area of Madagascar forests and wetlands with endemic flora and fauna is $9,000,000 \mathrm{ha}$. But these forests are endangered and must be preserved by setting up sustainable natural resource management sites.

Goals

Madagascar commits to keep its $9 \mathrm{~m}$ hectare forest and wetland area for the conservation of its natural richnes and the sustainable use of its forest, lake, marine and coastal resources.

Strategies

1. Develop and implement sustainable use plans for land, lake, marine, and coastal areas.

2. Promote the development and use of alternative energy resources such as bio-fuels that include palm oil, jatropha, soy and sugar cane.

3. Manage the clearing of vegetation and the damage caused by fires.

4. Promote reforestation and restore degraded habitats.

5. Promote private sector financing to assist in environmental management. 


\section{PRIORITY PROJECTS AND ACTIVITIES}

1. Refine forest zoning

\section{Inventory natural resources}

3. Implement the Sustainable Forest Management Sites [Sites de Gestion Forestièfre Durable [SGFDI] - Koloala

4. Intensify management transfer of natural resources

5. Reorganize the management of traded/tradable species

6. Support the use of improved charcoal making techniques

7. Promote the use of alternative energy

8. Motivate the population on wild fire preventions

9. Strengthen the implementation of anti- fire and clearing laws

10. Implement soil erosion control (by wind and water) by planting windbreaks and cover crops

11. Improve soil fertility with agroforestry systems, cove crops and conservation of ground and surface water
PROJECT LEADER

Minister responsible for Environment

Minister responsible for Environment

Minister responsible for Environment

Minister responsible for Environment

Minister responsible for Environment

Minister responsible for Environment

Minister responsible or Environmen

Minister responsible for Environment

Minister responsible

or Environment

\section{Minister responsible}

for Environment

Minister responsible

for Environment

\begin{tabular}{ll}
$\begin{array}{l}\text { 12. For the better management of freshwater resources, } \\
\text { watersheds and ecosystems develop an integrated } \\
\text { Water Resource Management Plan that includes the } \\
\text { promotion of reforestation to protect catchment areas, } \\
\text { the monitoring of wells and groundwater, and increasing } \\
\text { the efficiency of cropping systems }\end{array}$ & $\begin{array}{l}\text { Minister responsible } \\
\text { for Environment }\end{array}$ \\
$\begin{array}{l}\text { 13. Establish land reserves for reforestation [ réserves } \\
\text { foncięfres pour le reboisement (RFR)] }\end{array}$ & $\begin{array}{l}\text { Minister responsible } \\
\text { for Environment }\end{array}$ \\
$\begin{array}{l}\text { 14. Promote actions for reforestation, bush covering, and } \\
\text { grazing prohibition }\end{array}$ & $\begin{array}{l}\text { Minister responsible } \\
\text { for Environment }\end{array}$ \\
$\begin{array}{l}\text { 15. Manage the pilot sites for carbon sequestration } \\
\text { 16. Promote research and development opportunities } \\
\text { to ensure Madagascar becomes a leader in bio-fuel } \\
\text { production by using palm oil, soy, maze, jatropha, } \\
\text { and sugar cane }\end{array}$ & $\begin{array}{l}\text { Minister responsible } \\
\text { for Environment }\end{array}$ \\
\hline
\end{tabular}

INDICATORS

2005

2012

Number of developed sustainable use plans

\section{8}

Percentage of household using alternative energies

Rate of reduced burnt areas

$10 \%$

Reforested area
$25 \%$

$70 \%$

540,000 ha
360,000 ha 


\section{CHALLENGE 3 > \\ DEVELOP THE ENVIRONMENTAL REFLEX AT ALL LEVELS}

Current Reality

As of 2006, pollution (air, water, soil) is reaching an alarming proportion in Madagascar. Prevention and precaution

mechanisms were initiated in the country through environmental impact and assessment studies, for the protection of sensitive zones (decree MECIE $\mathrm{N}^{\circ}$ 99/954 on 15/12/99 and its riders). The environmental dimension must be mainstreamed into the development actions at all levels and into the sectoral, regione development actions at all levels and int into the business plans and commies. a part on the environment Also, in keeping with land

management, the biggest cities have town master-plans which integrate the environmental dimension. Environmental education and communication hold an important place in these plans.

Goals

We will mainstream the environment into all sectoral plans and develop a strong and effective environmental reflex.

Strategies

1. Explore ways that the government (national, regional and local) with the help of the private sector can assist in global standards are met.

2. Strengthen the framework for preventing environmental damage (including pollution) caused by businesses, miners, farmers, fishermen, and tourism.

3. Contribute to the protection of sensitive zones through comprehensive environmental assessment.

4. Internalize the environmental stake into sectoral, regional, and communal policies.

5. Implement the Education Policy Relative to the Environment [Politique de l'Education Relative à l'Environnement (PERE)].

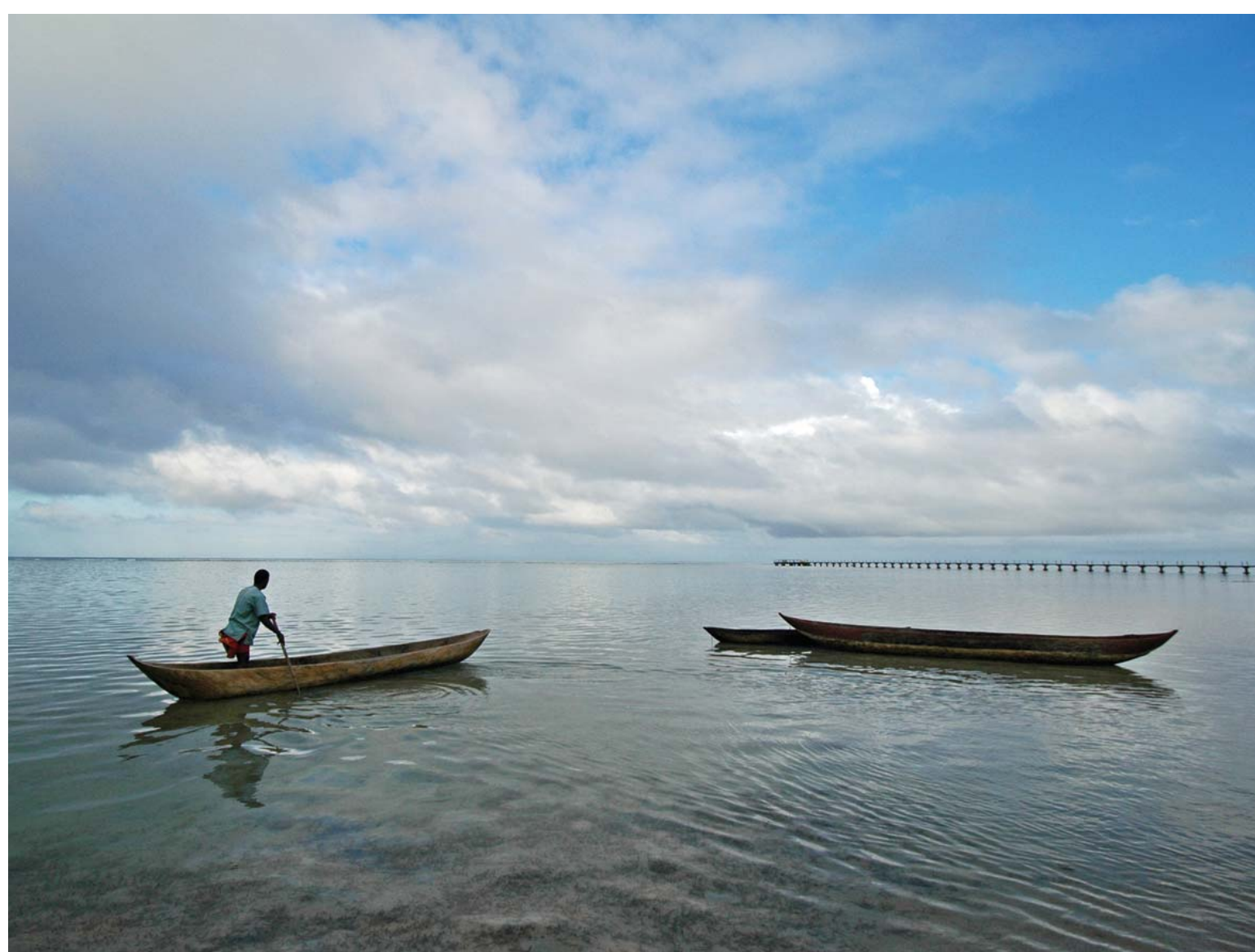




\section{PRIORITY PROJECTS AND ACTIVITIES}

1. Ensure the implementation of international conventions relative to the Environment which are ratified by

Madagascar, such as the Kyoto Accords

2. Develop the Code of the Environment

3. Develop a policy for mining companies and logging ther mechanisms and incentives for environmental protection

4. Reduce pollution in industrial zones located in urban, rural, and port areas 5. Develop the value chains in potential business sectors
to ensure that biodiversity is linked to the economy, and that economic pursuits are done in accord with environmental commitments.

6. Establish an Eco-tourism policy, charter, code that states the vision, the commitment, the values and the tourism throughout the country

7. Establish "wilderness zones" for eco-tourism

8. Promote and create investment standards to maintain quality

9. Develop, coordinate, share and promote important environmental information. This will include on environmental concerns for the diverse stakeholders lpupils, academics, environmental teams farmers associations, communes, regions, mining companies and other businesses)
Minister responsible for Environment

Minister responsible for Environment

Minister responsible for Environment

Minister responsible for Environment

Minister responsible for Environment

Minister responsible for Environment

Minister responsible for Environment

\section{Minister responsible} for Environment

Minister responsible for Environment
10. Promote the compatibility of investment with the environment lcompatibilité des investissements avec ['environnement (MECIE)] and the environmental
Minister responsible management system [ système de management environnemental (SME)] in the sectors of mining transportation, fishery, agriculture, tourism, industry...
11. Promote strategic environmental assessment évaluation environnementale stratégique (EES)]
Minister responsible for Environment

$\begin{array}{ll}\text { 12. Assist communes in developing and controlling PCDs } & \text { Minister responsible } \\ \text { for Environment }\end{array}$
13. Support the formulation and implementation of Urban Development Plans [ plans de développement Minister responsible urbain (PDU)] and Regional Development Plans [Plan Régional de Développement (PRD)] which mainstream the environ
aspects of development

\begin{tabular}{|lll|}
\hline INDICATORS & $\mathbf{2 0 0 5}$ & $\mathbf{2 0 1 2}$ \\
\hline Rate of processed complaint files & $75 \%$ & $95 \%$ \\
\hline Rate of MECIE subject investment: & $30 \%$ & $70 \%$ \\
\hline $\begin{array}{l}\text { Number of regional plans mainstreaming the } \\
\text { environmental prescriptions }\end{array}$ & 9 & 22 \\
\hline $\begin{array}{l}\text { Environmental Curriculum in primary, secondary, } \\
\text { tertiary schools, and vocational schools: adopted }\end{array}$ & $5 \%$ & $90 \%$ \\
\hline
\end{tabular}




\section{CHALLENGE 4 > \\ STRENGTHEN THE EFFECTIVENESS OF FOREST MANAGEMENT}

Current Reality

Over the past decade, the degradation of natural resources has been accentuated through the retreat of the forest and environmental administration which has experienced no significant evolution either in the means they have or in their intervention methods. A consequence is that the forest administration, which has become easy to bypass, has not been able to enact its mission and has watched on the sidelines as the forests have been abused.

Therefore, since 2003 the Government has begun to implement some profound changes within the sector such as the accountability of all stakeholders involved in the management of natural resources, the enforcement of laws, and the strengthening of forest and environment controls. While the Government has articulated a firm and strong vision, the capacity to enforce that vision through coordination and more resources must be further developed.

Goals

1. To strengthen the institutions responsible for environmenta management - the Ministry and environmental protection agencies - to ensure a professional policy making and regulatory framework and to provide technical support to the development and implementation of sector strategies.

2. As a specific goal - As of 2006 the number of forest and environmental offenses are in the order of 440 per year. The target in implementing various changes at the sector level consists in reducing the offense number of 440 to no more than 100 in 2.
Strategies

1. Build human, material, infrastructure capacities in the Ministry to ensure it can effectively pursue its mission.

2. Strengthen forest and environmental regulation, enforcement and control.

3. Implement sustainable forest management techniques and forest plantations in appropriate areas to satisfy the demand for forestry products and tree seedlings and other measures to support forestation.

4. Improve the forest revenue system and reform tax laws to ensure a taxation on negative consequences that contribute to pollution and degradation.

5. Provide for the planning, monitoring, evaluation of all activities of the Ministry, and ensure better coordination, management, dissemination, and use of research, data and best-practices at the national, regional and local levels.

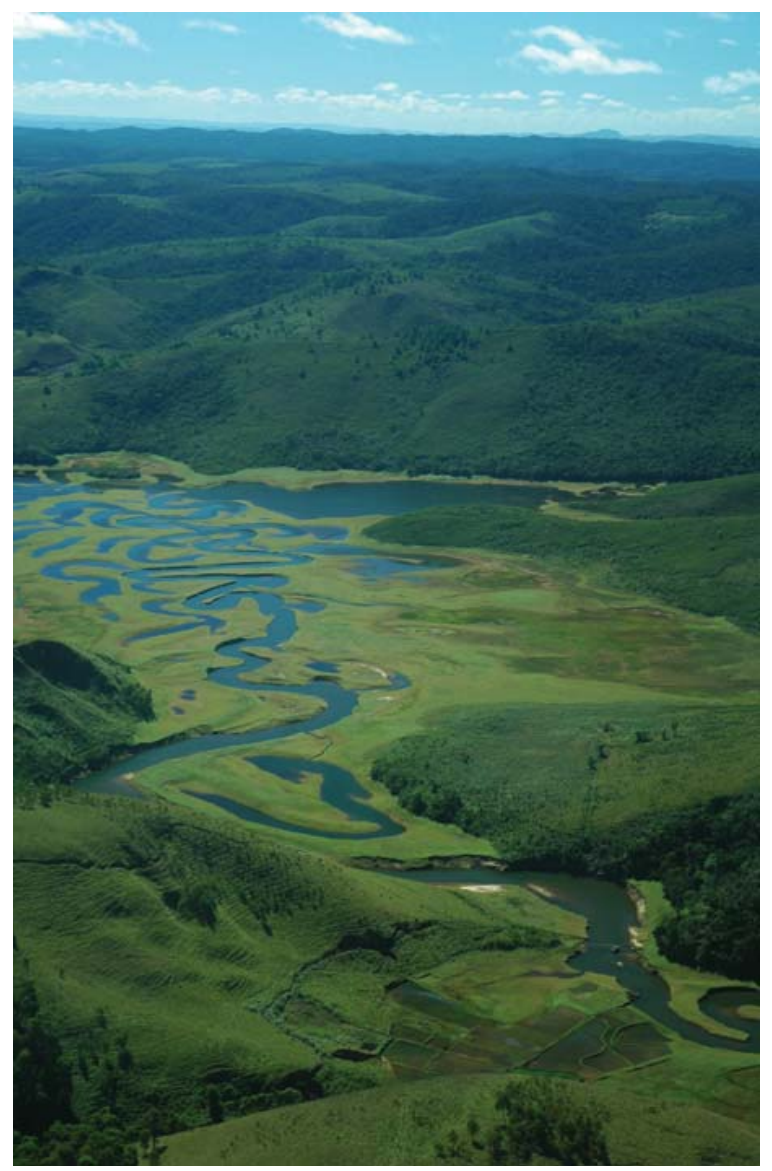




\section{PRIORITY PROJECTS AND ACTIVITIES}

1. Provide for better and more comprehensive environmental regulation and control

2. Strengthen forestry policing, control, and regulatory framework

3. Broaden the watch and information scheme initiated by OSFE

4. Build capacity among stakeholders in forest and environment management

5. Set up an autonomous structure providing for forest and environmental operations

6. Set up and empower forest commissions at the regional level

PROJECT LEADER

Minister responsible for Environment

Minister responsible for Environment

Minister responsible for Environment

Minister responsible or Environment

Minister responsible for Environment

Minister responsible for Environmen

7. Strengthen Environmental units and teams to monitor and assess

Minister responsible or Environment

8. Develop, distribute, and provide for the training on forest and environme

9. Set up framework conditions and tax incentives that promote responsible forest management

Minister responsible for Environment

Minister responsible or Environment

10. Carry out marketing and forest products under concessio

Minister responsible for Environment

11. Provide for the coordination of environment and forest

activities consistent with the policy orientations of

Minister responsible or Environment

\begin{tabular}{|c|c|}
\hline 12. Set up E-Governance of MINENVEF & $\begin{array}{l}\text { Minister responsible } \\
\text { for Environment }\end{array}$ \\
\hline 13. Set up Databases & $\begin{array}{l}\text { Minister responsible } \\
\text { for Environment }\end{array}$ \\
\hline $\begin{array}{l}\text { 14. Carry out the monitoring \& evaluation of projects, } \\
\text { programs and activities }\end{array}$ & $\begin{array}{l}\text { Minister responsible } \\
\text { for Environment }\end{array}$ \\
\hline
\end{tabular}

INDICATORS

2005

2012

Forest control units which are set up

System for tracking forest products : adopted

Rate of forest and environment revenues compared with the operating and capital budget of the Ministry

E-Governance of Ministry

$0 \%$ 


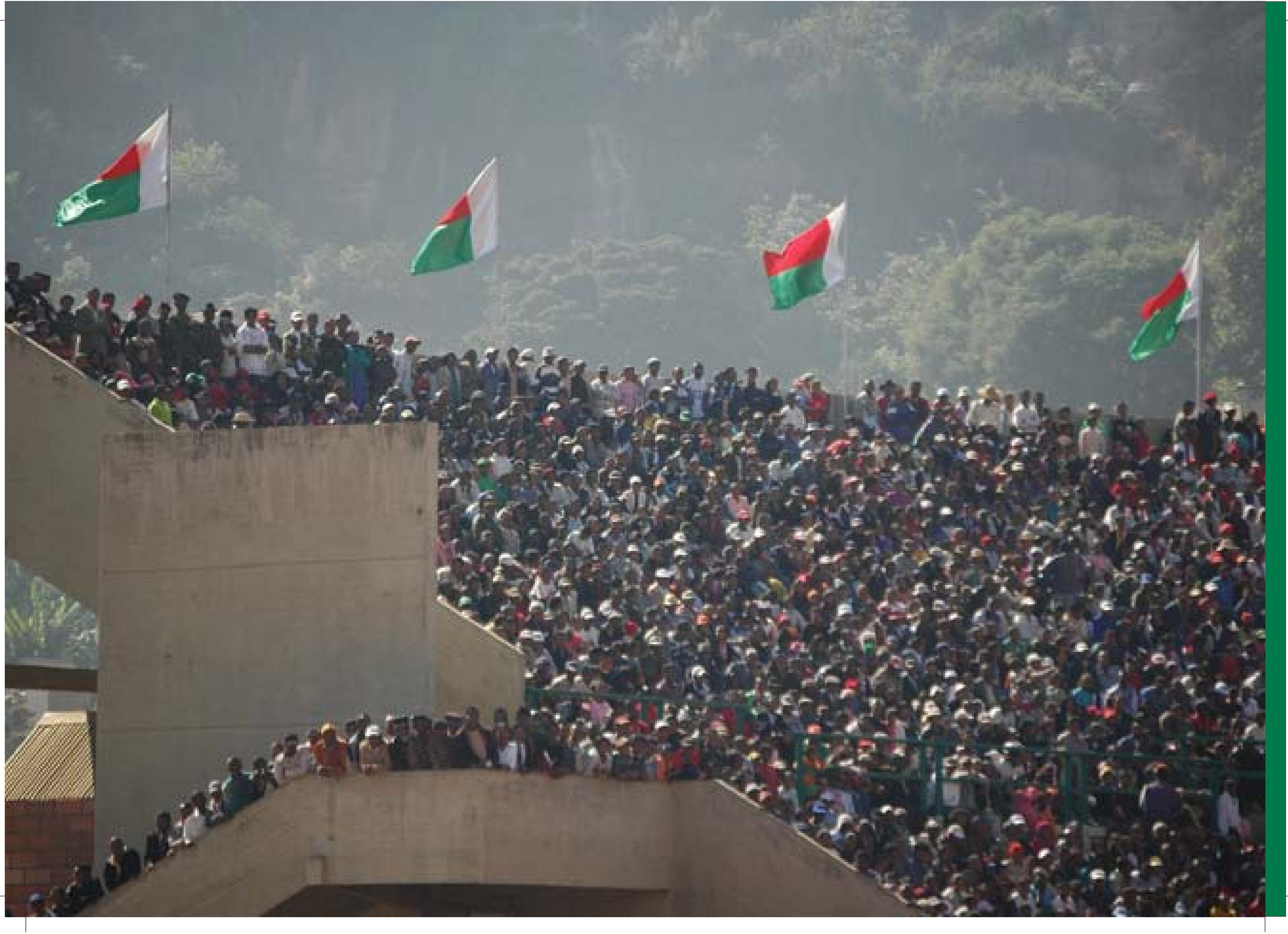




\section{COMMITMENT EIGHT NATIONAL SOLIDARITY}

We will continue to forge a strong, unified national identity that honors the multitude of cultures and traditions of all the people of Madagascar and promotes participation and partnership. Our people must be proud of who they are, stand with their heads held high, display confidence in the face of the many challenges facing us, and take full and shared responsibility for guiding the nation into the future. 


\section{CHALLENGE 1 > \\ CELEBRATE CULTURAL DIVERSITY, UNDERSTANDING AND RESPECT}

\section{Current Reality}

Madagascar is a country with enormous cultural diversity. Due to the multiple origins of its population and the diversity of the climatic zones, the country benefits from a large number of cultural inheritances: traditions, music, dance, literature, architecture, costumes, craft industry, habits. However, many forms of our culture are in danger due to the lack of care and support.

Goals

1. Worthy heritage and cultural traditions will be honored and safeguarded.

2. Cultural practices which contradict national values, hinder development and impede the promotion of national solidarity will be steadily abandoned.

3. The cultural life of the people in all its diverse manifestation will be supported, provided it does not harm others or the environment.

4. The arts and new cultural expressions will be actively encouraged.

Strategies

1. Draw up an inventory of the sites and practices of cultural inheritances, preserve them and develop them;

2. Preserve Malagasy culture, traditions, history and local dialects.

3. Create cultural institutions that promote culture and the arts at national, regional and local levels.

4. Organize multicultural events that encourage dialogue, sharing of culture and build pride.

\begin{tabular}{|c|c|c|}
\hline PRIORITY PROJECTS AND ACTIVITIES & \multicolumn{2}{|c|}{ PROJECT LEADER } \\
\hline 1. Create and improve public cultural centers including reading centers and librarie & & Minister responsible for Culture \\
\hline 2. Identify, collect, preserve, develop and promote cultural inheritance & & Minister responsible for Culture \\
\hline 3. Professionalize artists & & Minister responsible for Culture \\
\hline 4. Create forums for cultural dialogue & & Minister responsible for Culture \\
\hline 5. Create a national award in the field of music, dance, fine arts and literature & & Minister responsible for Culture \\
\hline INDICATORS & 2005 & 2012 \\
\hline National Culture Survey & To be developed & To be developed \\
\hline Number of national cultural inheritances / assets safeguarded & 3 & 20 \\
\hline Number of national artistic award & To be established & To be established \\
\hline
\end{tabular}
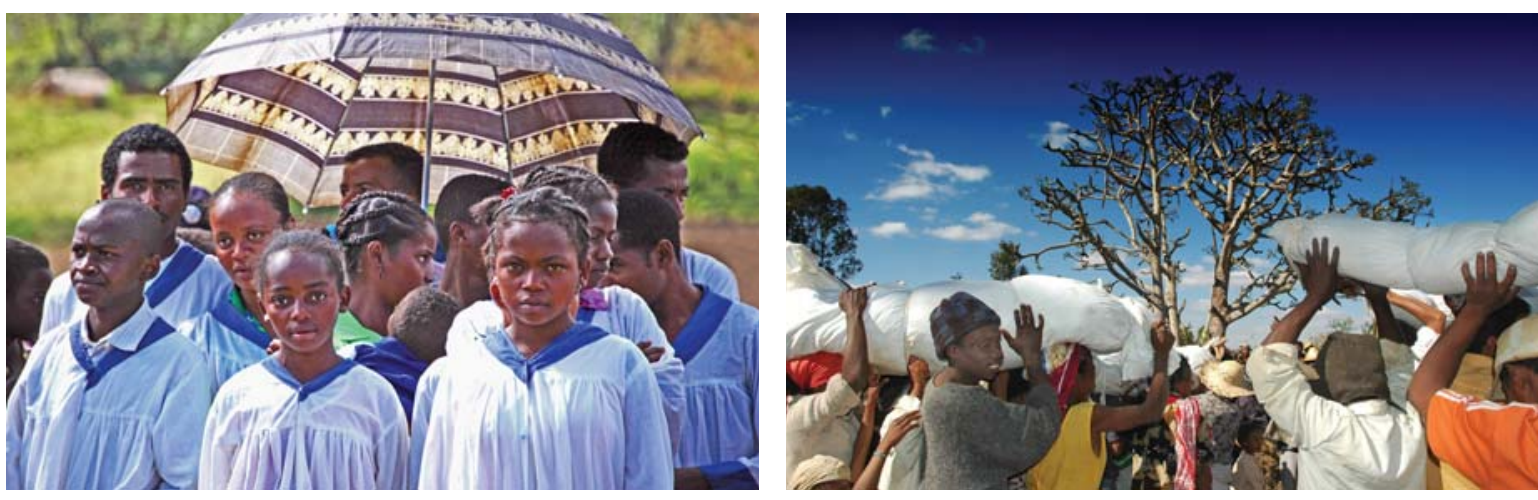


\section{BUILD SOCIAL TRUST AND PROMOTE CIVIC PARTICIPATION}

\section{Current Reality}

Due to many years of colonialism and socialism, Malagasy people were not actively involved in community building, civic participation and public problem solving. Since 2003, that has changed with the creation of 22 regions and the decentralization of government services. There already exists a free and independent media with more than 10 che build the network of social trust and confidence betwe to (1) the people and their authorit

Goals

1. There will be a high level of citizen participation and interest in their community and nation.

2. Civil society will be well coordinated and actively participate in all aspects of social, cultural and political affairs.

3. The media will play a more prominent role in encouraging debate and holding public offices to account.

Strategies

1. Promote citizen participation to ensure a responsive and accountable public service and to reduce abuses.

2. Increase coordination and harmonization of civil society organizations and activities.

3. Regularly survey the needs of people and respond.

4. Mobilize religious organizations to increase their contribution to community development and social cohesion.

5. Further develop a responsible, independent and professional media that constructively contributes to social, economic and political progress.

\section{PRIORITY PROJECTS AND ACTIVITIES}

PROJECT LEADER

1. Develop the civic education of citizens and the Civic Charter

Prime Minister's Office

2. Generate forums for sharing information, engaging in dialogue and contributing to the formulation of public policy

3. Develop a system for civil and community service by high school and Minister responsible for Education university students

4. Develop mechanisms for citizen training and participation National Leadership Institute

5. Provide leadership training for District Chiefs, Mayors and Civil Society to better engage their communities in public problem solving

6. Design and implement media development programs $\begin{array}{r}\text { Minister responsible } \\ \text { for Communications }\end{array}$ National Leadership Institute for Communications

\section{INDICATORS} 2005 2012

National Participation Index To be developed To be developed
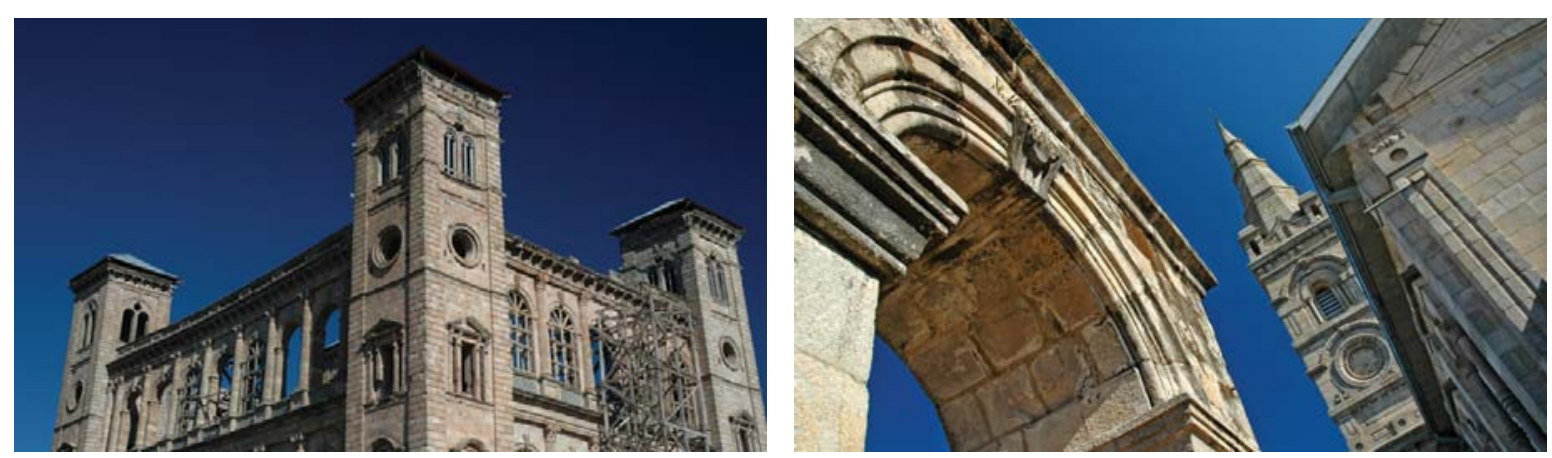


\section{CHALLENGE 3 > \\ PROMOTE SOLIDARITY AND PRIDE}

Current Reality

Malagasy people are united by a common language and an island status. The country has a rich and fascinating history with many periods of great difficulty and suffering but also times of tremendous accomplishment.

Malagasy people are proud of their tribal heritage and also of their nation. However, the diversity of the ethnic groups may sometimes cause misunderstandings and conflict which could impede effective communication and collaboration.

Goals

Malagasy will be even prouder of their country. They will be united and responsible citizens, participating in all aspects of political, economic and social life.

The diversity of groups will be regarded as an asset in the nation's problem solving processes - in government, private sector and the civil society.

Strategies

1. Improve the existing national events to ensure they promote and celebrate national solidarity.

2. Create new events, symbols, and traditions that further enhance the unity of all the peoples of Madagascar.

3. Harness the common values and aspirations that are shared by all Malagasy.

4. Recognise the accomplishments and contributions of those who make Madagascar a better country.

\begin{tabular}{|c|c|}
\hline PRIORITY PROJECTS AND ACTIVITIES & PROJECT LEADER \\
\hline $\begin{array}{l}\text { 1. Celebrate the unique aspects of life, arts, culture as well as the achievements of the } \\
\text { Malagasy people }\end{array}$ & Minister responsible for Culture \\
\hline 2. Promote national and international sports and competition e.g. football, rugby, judo & Minister responsible for Culture \\
\hline 3. Organize and ensure key regional and national events promote national values & Minister responsible for Culture \\
\hline INDICATORS & 2012 \\
\hline National Solidarity Index & To be developed \\
\hline Number of athletes competing at international level & 324 \\
\hline
\end{tabular}

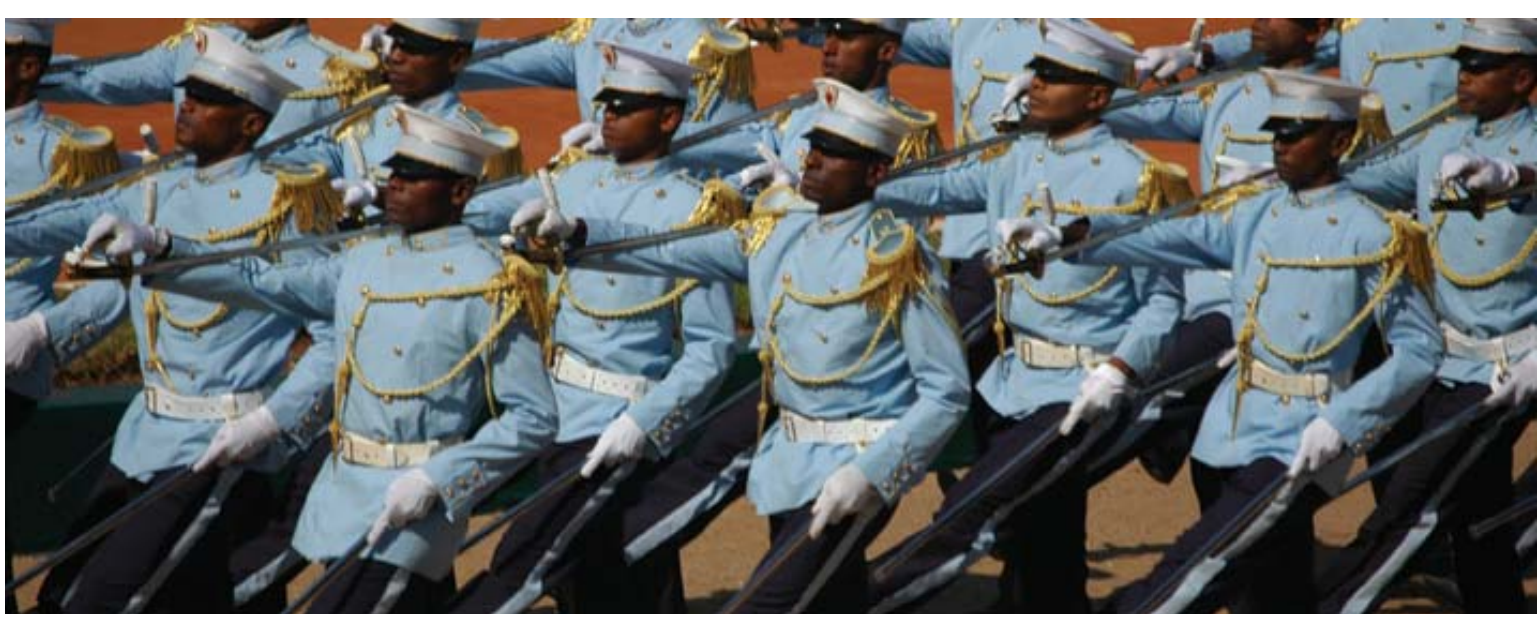




\section{CHALLENGE 4 >}

\section{IMPROVE SUPPORT FOR THE VERY POOR} AND VULNERABLE POPULATIONS

Current Reality

Since 2003, the situation of the poorest and most vulnerable population has improved with the distribution of rice, with the program "Food for Work" and with the improved access of vulnerable to basic social services. Still, some people have no shelter and have no access to basic social services, and people in some parts of the country are not adequately protected against periodic natural disasters like cyclones, rought and floods.

Goals

The minimum level of vital food, shelter and basic needs will be provided for all people.

Strategies

1. Improve Social Protection management and the provision of basic social services to the vulnerable.

2. Improve the targeting and the control of the expenditures in social protection to maximize impact.

3. Ensure the prevention, fast reaction and the lessening of the impact of catastrophes.

4. Guarantee an equitable and adequate legal framework for vulnerable groups.

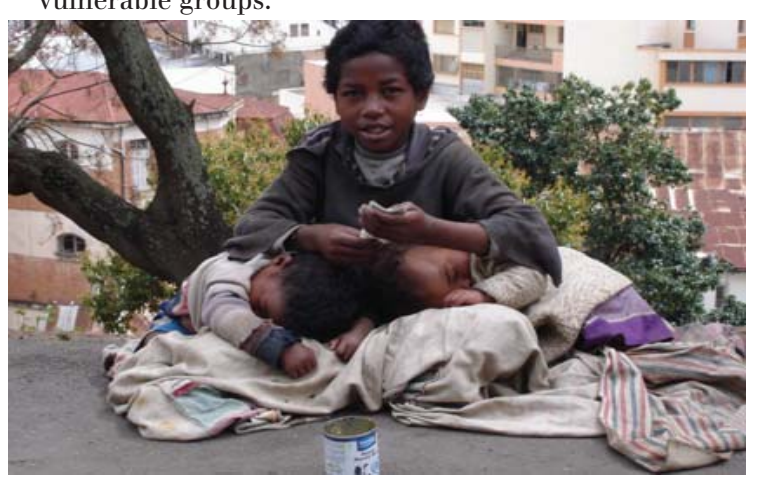

PRIORITY PROJECTS AND ACTIVITIES

1. Adopt and implement an institutional framework for Social Protection

2. Adopt and implement an institutional framework for disaster management

3. Ensure the legal protection of vulnerable groups especially of women and children (fight against human slavery and trafficking, fight against child labor)

4. Provide birth certificate for every citizen

5. Give the vulnerable groups access to basic social services

PROJECT LEADER

Minister responsible for Social Protection

\section{Minister responsible for Interio}

Minister responsible for Social Protection

Minister responsible for Social Protection Minister responsible for Soclal Protection

6. Make the most vulnerable groups integrate economic growth and poverty reduction strengthen the actions of education and ensure revenues to vulnerable groups

\section{INDICATORS} 2005

United Nations hazard related vulnerability index

deaths per million inhabitants)

Percentage of families with more than three poverty indicators

School enrolment rate for the poores

$90 \%$

$61 \%$

Health service access to the poores

$38 \%$

Percentage of youth and children without birth certificates

$33.2 \%$ 


\section{CHALLENGE 5 > \\ PROMOTE GENDER EQUALITY AND EMPOWERMENT OF WOMEN}

\section{Current Reality}

Malagasy women are very active in their family life. Also, outside the family circle they are highly professional and responsible. Yet, women's presence and participation in public life and in the private sector is still limited.

Goals

Participation of women in public problem solving, decision making and management will be substantially increased; and women's rights will be promoted and protected.

Strategies

1. Integrate gender issues in all the policies, plans, and development programs.

2. Support the access of women to economic opportunities. 3. Increase the number of the women occupying higher positions in local, regional and national government levels.

4. Reduce the abuse of women in all its manifestations: physical, sexual and psychological.

5. Eliminate traditional practices that negatively affect women.

6. Honor and cherish women as the bearers of life

7. Establish government institution to promote women's affairs.

\begin{tabular}{lll}
\hline PRIORITY PROJECTS AND ACTIVITIES & PROJECT LEADER \\
\hline $\begin{array}{l}\text { 1. Create an institution within the government to promote the participation and advancing } \\
\text { of women and the protection of women }\end{array}$ & $\begin{array}{l}\text { Minister in charge of } \\
\text { Women's Affairs }\end{array}$ \\
\hline 2. Promote women's participation in economic, social and civic affairs & $\begin{array}{l}\text { Minister in charge of } \\
\text { Women's Affairs }\end{array}$ \\
\hline 3. Intensively recruit more women in the public sector at all levels & $\begin{array}{l}\text { Minister in charge of } \\
\text { Public Service }\end{array}$ & $\mathbf{2 0 1 2}$ \\
\hline & & $30 \%$ \\
\hline INDICATORS & $\mathbf{2 0 0 5}$ & $\mathbf{6}$ \\
\hline Percentage of women in Parliament & $12 \%$ & 300 \\
\hline Number of women in the Cabinet & 1 & $18 \%$ \\
\hline Proportion of women in local, regional and national institutions lindex base 100) & 100 & $36 \%$ \\
\hline Gender salary gap in the private sector & & 300 \\
\hline
\end{tabular}
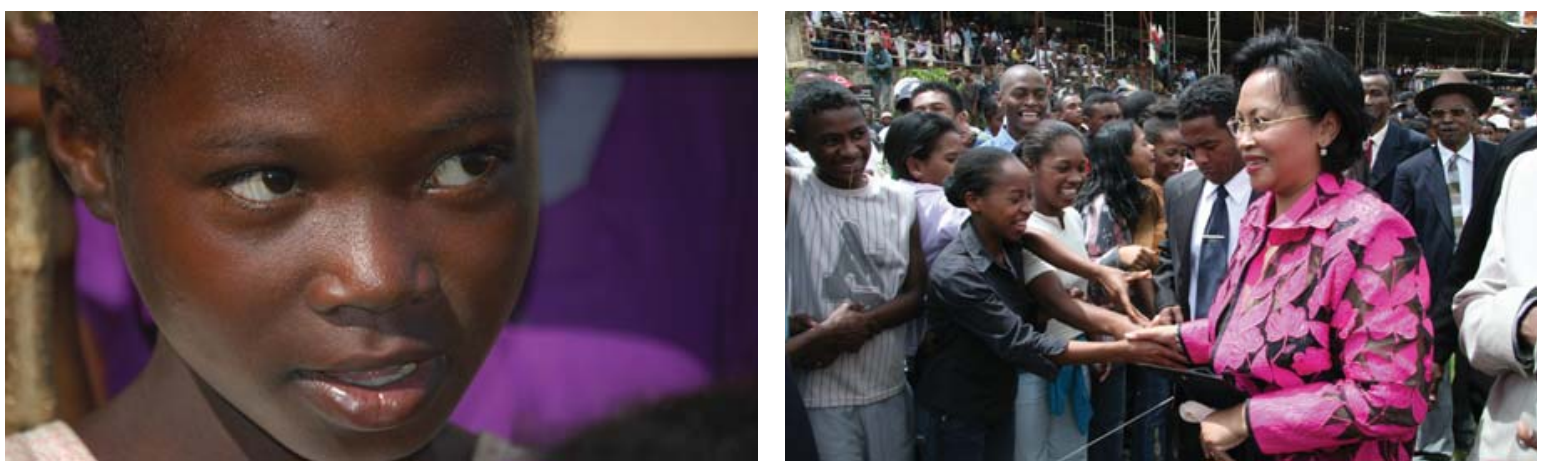